\title{
CATALOGUE
}

KATALOG

Lynx, n. s. (Praha), 52: 155-203 (2021).

ISSN 0024-7774 (print), 1804-6460 (online)

\section{Systematic catalogue of mammals (Mammalia) in the collection of the National Museum Prague. I. Chiroptera: Rhinolophoidea 1}

\section{Petr BENDA}

Department of Zoology, National Museum (Natural History), Václavské nám. 68, CZ-115 79 Praha 1, Czech Republic \& Department of Zoology, Faculty of Science, Charles University in Prague, Viničná 7 , CZ-128 44 Praha 2, Czech Republic; petr.benda@nm.cz

received on 16 November 2021

\begin{abstract}
A list of 1,673 specimens of bats belonging to 36 species, seven genera, and five families of the superfamily Rhinolophoidea, housed in the collection of the National Museum, Prague, Czech Republic, is presented in a systematic review.
\end{abstract}

Key words. National Museum, collection, catalogue, bats, Rhinopomatidae, Rhinolophidae, Hipposideridae, Rhinonycteridae, Megadermatidae.

The collection of mammals housed in the National Museum, Prague (NMP), comprises about forty thousand specimens. With this number of items, it represents the largest and most diversified mammal collection in a public institution of the Czech Republic and ranks among the medium-sized museum collections of mammals in Europe. The collection is composed mostly of small mammals (Eulipotyphla, Rodentia) collected in Central Europe and the Balkans, although it comprises representatives of all mammal groups and most of the families. Majority of the content of the NMP collection of mammals has not yet been presented systematically, several published lists were focused rather randomly on various specialised topics (HERÁŇ 1966, 1988, MazÁK 1974, HerÁŇ \& MaZÁK 1976, AndĚra 1987, HeráŇ et al. 1992, Neumannová 1997, Volf 2010, RoBovskÝ et al. 2015, VolF \& BENDA 2021) or were prepared as guides to permanent exhibitions (HERÁñ 1968a, b, MAZÁK 1976).

Here, the first part of the systematic catalogue of bats housed in the NMP collection is presented. As systematic and complete lists of the NMP collection of mammals, only the catalogues of cetacean and perissodactylian specimens have been presented so far (ROBOVSKÝ \& BENDA 2006, Robovský et al. 2009, 2010, 2014a, b). Various lists of specimens of selected bat taxa housed in the NMP collection are scattered across faunal surveys, reviewing the data on bats of certain geographical scopes, or in the lists of study material used in various morphological, 
Table 1. The Rhinolophoid bats in the collection of the National Museum, Prague, Czech Republic (NMP)

\begin{tabular}{lccr}
\hline family & No. genera & No. species & No. specimens \\
\hline Rhinopomatidae & 1 & 5 & 240 \\
Rhinolophidae & 1 & 17 & 1,109 \\
Hipposideridae & 3 & 10 & 250 \\
Rhinonycteridae & 1 & 3 & 65 \\
Megadermatidae & 1 & 1 & 9 \\
\hline
\end{tabular}

phylogenetical or parasitological studies. Only few times a list of the bat collection items was published, always limited with regard to a certain geographical focus (GAISLER 1956, ANDĚRA 1987, BENDA et al. 2008, 2011, 2019). A provisional review of bats in the museum collections of former Czechoslovakia was given by GAISLER et al. (1978); however, the situation described by the latter authors has changed significantly since then.

The complete number of bats in the NMP collection well exceeds 10,000 specimens, about a quarter of the whole mammal collection. The presented first part of the NMP catalogue of bats consists of representatives of the superfamily Rhinolophoidea; it contains data on 1,673 specimens of five families and 36 species that were formally included in the collection (i.e., an ID was assigned to them) until the end of August 2021 (Table 1). Altogether 38 type specimens of five taxa of this superfamily, including five name-bearing specimens, are parts of the list (some of them were mentioned already by MLíkovskÝ et al. 2011b).

This taxonomic selection is a result of the Covid-19 Chiropteran Knowledge Base project supported by the Synthesys ${ }^{+}$Virtual Access. As a direct consequence of the preparation of this catalogue and a part of the Synthesys ${ }^{+}$project, here presented list of specimens has been submitted paralelly to the Global Biodiversity Information Facility (GBIF).

Since the specimens of Rhinolophoid bats originating from Central Europe are mostly not inventored properly but just several old items (cf. GAISLER 1956), the list of the rhinolophoid specimens (three species) from the Czech Republic and Slovakia will be presented elsewhere, in some of the next volumes of this catalogue series.

The particular species lists of specimens are arranged in a geographic order, according to countries (from west to east and from north to south; from Europe to Asia and to Africa), and within the countries in an alphabetical order (according to the collection locality name) and then, in time order (according to collection date). The lists include, for each item, the following information: (1) indication of sex, (2) collection ID, (3) preparation type (see Abbreviations below), (4) name of the locality (primarily listed by a name of the settlement or notable physical feature; name of the first level administrative division of the respective country where the site lies is added, see Abbreviations below), (5) date of collection, and (6) collector name/s. The currently valid names of localities and the current names of the first level administrative divisions are used in the descriptions of the specimen origin (for geographic coordinates of the localities see Gazetteer below, in alphabetical order). The lists of specimens of particular species are complemented by a list of references reporting the particular specimen/s or the finding/s, i.e. additional data concerning the specimens.

AbBreviations. Preparation type: $\mathrm{A}=$ alcohol specimen; $-\mathrm{B}=$ skin (balg); $\mathrm{K}=$ skin (carpet); $-\mathrm{S}=$ skull; $-\mathrm{Sk}=$ skeleton; $-\mathrm{W}=$ dry wing. - Administrative division: Dep. $=$ Department; - Dist. $=$ District; - Gov. = governorate $;$ - Pref. $=$ prefecture; - Prov. $=$ province $;-$ Reg. $=$ region $;-$ Rep. $=$ Republic. 


\section{LIST OF SPECIMENS}

Rhinopomatida e

\section{Rhinopoma microphyllum (Brünnich, 1782)}

Material (21). Jordan:

1 q (NMP 47965 [S+A]), Tabaqat Fal, Roman Necropolis of Pella (Irbid Prov.), 4 July 1997, leg. P. Benda.

Oman:

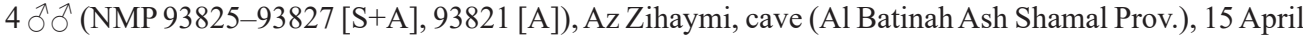
2011, leg. P. Benda, A. Reiter \& M. Uhrin;

6 ふึô, 1 ㅇ (NMP 94080-94085 [S+A], 94079 [A]), Az Zihaymi, cave (Al Batinah Ash Shamal Prov.), 5 April 2012, leg. P. Benda, A. ReITER \& M. Uhrin.

\section{Iran:}

1 (NMP 93877 [S+A]), Bishapur, cave (Fars Prov.), 6 October 2011, leg. M. ANDrEAS, S. Ashrafi, P. BENDA, K. FAizolÂHI, A. REITER \& M. Uhrin;

2 ồ (NMP 93907, 93908 [S+A]), Dehloran Cave (Ilam Prov.), 17 October 2011, leg. M. ANDREAS, P. Benda, K. FaizolÂHi, A. Reiter \& M. Uhrin;

1 ภิ (NMP 93886 [S+A]), Manian, Manian Cave (Fars Prov.), 8 October 2011, leg. M. ANDrEAs, S. AsHrafi, P. Benda, K. FAizolâhi, A. Reiter \& M. Uhrin;

1 ô, 1 ㅇ (NMP 93904, 93905 [S+A]), Mormori, cave (Ilam Prov.), 17 October 2011, leg. M. Andreas, P. BENDA, A. REITER \& M. UHRIN;

2 우우 (NMP 93878, 93879 [S+A]), Tadovan Cave (Fars Prov.), 7 October 2011, leg. M. Andreas, S. Ashrafi, P. Benda, K. Faizolâhi, A. Reiter \& M. Uhrin.

\section{Afghanistan:}

1 Iิ (NMP 95424 [B]), Chak-Naur, caves (Nangarhar Prov.), 7 April 1967, leg. J. GaISLER, D. PovolnÝ, Z. ŠEBEK \& F. TENORA.

References. HŮrka \& Povolný (1968), Baruš \& Tenora (1970), Dusbábek (1970), Gaisler (1970), HŮrka (1970), Groschaft \& Tenora (1973, 1974), Benda \& SÁdlová (1999), Benda et al. (2004a, 2006a, 2009b, 2010b, 2012, 2019a), Hulva et al. (2007), LEVIN et al. (2008), AKMALI et al. (2011), Ž ̌́ÁRSKÁ (2013), BENDA \& GAISLER (2015), SoISOOK et al. (2015), KARMÁČKovÁ (2017), KAFAei et al. (2020).

\section{Rhinopoma muscatellum Thomas, 1903}

MATERIAL (85). Iran:

2 우 (NMP 93898, 93899 [S+A]), Bandar Siraf, cave (Bushehr Prov.), 13 October 2011, leg. M. ANDREAS, P. BENDA, A. ReITER \& M. Uhrin;

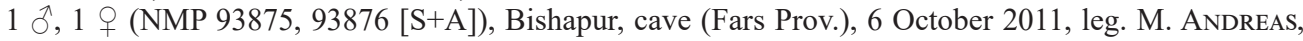
S. Ashrafi, P. Benda, K. Faizolâhi, A. Reiter \& M. Uhrin;

3 ồ $\partial^{2}, 1$ ㅇ (NMP 48443-48446 [S+A]), Hormoz Is., cave (Hormozgan Prov.), 17 April 2000, leg. P. BENDA \& A. REITER;

1 Ĵ, 1 ㅇ (NMP 93888, 93889 [S+A]), Jahrom, Sang Eshkan Mine (Fars Prov.), 8 October 2011, leg. M. Andreas, S. Ashrafi, P. Benda, K. Faizolâhi, A. Reiter \& M. Uhrin;

7 đ̂ํ, 2 우우 (NMP 48387-48395 [S+A]), Mach Gur, cave (Sistan va Baluchestan Prov.), 11 April 2000, P. BENDA, J. OBuCh \& A. ReITER;

1 잉 93887 [S+A]), Manian, Manian Cave (Fars Prov.), 8 October 2011, leg. M. Andreas, S. Ashrafi, P. Benda, K. Faizolâhi, A. Reiter \& M. Uhrin;

1 ô, 1 (NMP 48421, 48422 [S+A]), Pir Sohrab, cave (Sistan va Baluchestan Prov.), 12 April 2000, leg. P. BENDA \& A. REITER;

1 ô, 1 q (NMP 48463, 48464 [S+A]), Pol-e Tang, tomb (Lorestan Prov.), 11 April 1977, leg. B. PražAN; 
8 ふึે, 1 ๆ (NMP 48164-48172 [S+A]), Sarkan near Izeh, cave (Khuzestan Prov.), 12 October 1998, leg. M. ANDREAs, P. Benda, A. ReITER \& M. Uhrin;

1 ( (NMP 93880 [S+A]), Tadovan Cave (Fars Prov.), 7 October 2011, leg. M. ANDreAs, S. Ashrafi, P. Benda, K. Faizolâhi, A. Reiter \& M. Uhrin;

1 (NMP 48423 [S+A]), Tis, cave (Sistan va Baluchestan Prov.), 13 April 2000, leg. J. Овuch.

\section{Oman:}

1 ๙ (NMP 97090 [S+A]), Al Ajal, Wadi Al Ajal, small cave (Al Batinah Al Janub Prov.), 2 November 2019, leg. P. BENDA, J. HáJeK \& A. ReITER;

1 오 (NMP 92625 [A]), Al Aqar, cave (Al Batinah Al Janub Prov.), 17 October 2009, leg. P. Benda, A. REITER \& M. UHRIN;

1 ( NMP 92630 [A]), Al Awabi, fortress (Al Batinah Al Janub Prov.), 18 October 2009, leg. P. BeNDA, A. REITER \& M. UHRIN;

1 ( NMP $92626[\mathrm{~S}+\mathrm{A}]$ ), Al Ghubrah, cave (Al Batinah Al Janub Prov.), 18 October 2009, leg. P. BeNDA, A. REITER \& M. UHRIN;

2 우우 (NMP 93758, 93759 [S+A]), Al Hashah (Wadi Bani Hani), Wadi Hawqain (Al Batinah Al Janub Prov.), 7 April 2011, leg. P. Benda, A. ReITer \& M. Uhrin;

$1 \hat{\jmath}$ (NMP 93756 [S+A]), Al Hawqain, fortress (Al Batinah Al Janub Prov.), 7 April 2011, leg. P. Benda, A. REITER \& M. UHRIN;

$2 \widehat{\jmath} \widehat{o}, 1$ 우 (NMP 93770, 93771 [S+A], 93769 [A]), Al Hoota Cave (Ad Dakhiliyah Prov.), 8 April 2011, leg. P. BENDA, A. ReITER \& M. Uhrin;

1 ô, 1 ㅇ (NMP 93808, 93809 [A]), Al Iraqi, fortress (Adh Dhahirah Prov.), 11 April 2011, leg. P. Benda, A. REITER \& M. UHRIN;

$1 \hat{\jmath}, 1$ ㅇ (NMP 92652 [S+A], 92653 [A]), Al Karbi Ash Sharqiyah, rocks (Al Buraimi Prov.), 20 October 2009, leg. P. BendA, A. ReiTER \& M. Uhrin;

2 ภิ $\widehat{x}$ (NMP 93744, 93745 [S+A]), Al War, Wadi Khabbah (Ash Sharqiyah Ash Shamal Prov.), 5 April 2011, leg. P. Benda, A. ReITER \& M. Uhrin;

1 đ (NMP 93998 [S+A]), Ar Rawdah, small cave (Musandam Prov.), 16 March 2012, leg. P. Benda, A. REITER \& M. UHRIN;

4 우 우 (NMP 92641-92643 [S+A], 92644 [A]), Ar Rustaq, fortress (A1 Batinah Al Janub Prov.), 19 October 2009, leg. P. Benda, A. ReITER \& M. Uhrin;

3 우 (NMP 92635-92637 [S+A]), At Tabaqah, fortress (Al Batinah Al Janub Prov.), 19 October 2009, leg. P. BENDA, A. REITER \& M. Uhrin;

1 ภ , 1 q (NMP 93820, 93824 [S+A]), Az Zihaymi Oasis, cave (Al Batinah Ash Shamal Prov.), 14 \& 15 April 2011, leg. P. Benda, A. Reiter \& M. Uhrin;

1 오 (NMP 93768 [S+A]), Bahla, ruined city (Ad Dakhiliyah Prov.), 8 April 2011, leg. P. Benda, A. REITER \& M. UHRIN;

1 (NMP 93810 [S+A]), Belt, fortress (Adh Dhahirah Prov.), 11 April 2011, leg. P. Benda, A. Reiter \& M. Uhrin;

2 ठึ (NMP 93715, 93716 [A]), Birkat Al Mawz, ruined city (Ad Dakhiliyah Prov.), 27 March 2011, leg. P. BENDA, A. REITER \& M. UHRIN;

1 ㄱ, 2 우우 (NMP 92660-92662 [S+A]), Jabrin, fortress (Ad Dakhiliyah Prov.), 22 October 2009, leg. P. BENDA, A. REITER \& M. Uhrin;

1 (NMP 93757 [S+A]), Jamma, fortress (Al Batinah Al Janub Prov.), 7 April 2011, leg. P. Benda, A. REITER \& M. UHRIN;

1 ( NMP 97089 [S+A]), Jamma, fortress (Al Batinah Al Janub Prov.), 2 November 2019, leg. P. BENDA, J. HÁJEK \& A. REITER;

1 ${ }^{1}, 1$ 우 (NMP 97085 [S+A], 97086 [A]), Khubar, Bait As Saruj Castle (Ad Dakhiliyah Prov.), 31 October 2019, leg. P. Benda, J. HáJeK \& A. ReITER;

1 ㅇ (NMP 93789 [A]), Misfah, abandoned village (Ad Dakhiliyah Prov.), 10 April 2011, leg. P. BendA, A. REITER \& M. UHRIN; 
1 đ̊ (NMP 93792 [A]), Misfah Al Abriyn, Wadi Misfah, cave (Ad Dakhiliyah Prov.), 10 April 2011, leg. P. BENDA, A. REITER \& M. UHRIN;

$1 \hat{\jmath}$ (NMP 92780 [S+A]), Mithqub, Wadi Harabein, Dibab, cave (Masqat Prov.), 3 November 2009, leg. P. BENDA, A. REITER \& M. UHRIN;

1 ( NMP 97082 [S+A]), Mizbar, cave (Ash Sharqiyah Ash Shamal Prov.), 29 October 2019, leg. P. BENDA, J. HÁJEK \& A. REITER;

1 ㅇ (NMP 92769 [S+A]), Muqal, Muqal Cave (Ash Sharqiyah Ash Shamal Prov.), 1 November 2009, leg. P. BENDA, A. ReITER \& M. Uhrin;

1 ( (NMP 92785 [S+A]), Qariah (Mansaft), cave (Masqat Prov.), 4 November 2009, leg. P. Benda, A. REITER \& M. UHRIN;

1 ô, 1 q (NMP 97087 [S+A], 97088 [A]), Samail, castle (Ad Dakhiliyah Prov.), 31 October 2019, leg. P. BENDA, J. HáJeK \& A. ReITER;

$1 \lesssim$ (NMP 93747 [S+A]), Sawt (Al Ghayyan), cave (Ash Sharqiyah Ash Shamal Prov.), 6 April 2011, leg. P. BENDA, A. ReITER \& M. Uhrin;

$1 \delta$ (NMP 94000 [S+A]), Wadi Banah, cave (Musandam Prov.), 16 March 2012, leg. P. Benda, A. ReIter \& M. Uhrin;

3 우 (NMP 92657, 92658 [S+A], 92659 [A]), Yanqul, Bait Al Marah Castle (Adh Dhahirah Prov.), 22 October 2009, leg. P. BENDA, A. ReITER \& M. Uhrin.

References. Benda (2001), Benda et al. (2004a, 2009b, 2012, 2019a), Hulva et al. (2007), Levin et al. (2008), AGNARSSON et al. (2011), ŽĎÁRSKÁ (2013), BENDA \& GAISLER (2015), KARMÁČKOVÁ (2017), Hron et al. (2018), KAFAEI et al. (2020).

\section{Rhinopoma hadramauticum Benda, 2009}

Material (10). Yemen:

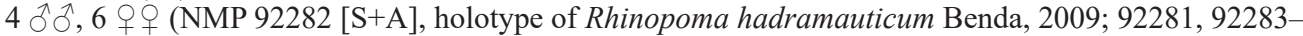
92285, 92287-92289 [S+A], 92280, 92286 [A], paratypes of $R$. hadramauticum Benda, 2009), Ash Sheher, house (Hadramawt Gov.), 6 November 2007, leg. P. Benda, A. K. Nasher \& A. Reiter.

References. Hulva et al. (2007), Benda et al. (2009b, 2012, 2019a), MlíKovskÝ et al. (2011b).

\section{Rhinopoma hardwickii Gray, 1831}

MATERIAL (6). Iran:

1 ind. (NMP 48194 [S+Sk]), Chahak, cave (Bushehr Prov.), 14 October 1998, leg. J. OBuch;

1 ô (NMP 48157 [S+A]), Jelugir, cave (Lorestan Prov.), 11 October 1998, leg. J. OBuch;

1 ô (NMP 93906 [S+A]), Mormori, cave (Ilam Prov.), 17 October 2011, leg. M. ANDrEas, P. Benda, A. REITER \& M. UHRIN;

2 우우 (NMP 48162, 48163 [S+A]), Sarkan near Izeh, cave (Khuzestan Prov.), 12 October 1998, leg. M. AndREAs, P. Benda, A. Reiter \& M. Uhrin.

India:

$1 \widehat{\partial}$ (NMP 94428 [S+A]), Gola Ka Bas (Rajasthan State), 3 April 2008, leg. P. ŠíPEK.

References. Benda (2001), Benda et al. (2004a, 2006a, 2009b, 2012, 2019a), Hulva et al. (2007), KarmÁČKová (2017), Hron et al. (2018), KAFAEI et al. (2020).

\section{Rhinopoma cystops Thomas, 1903}

Material (118). Syria:

2 ふ઼ ฮิ (NMP 48268 [A], 48269 [S+A]), Qala'at Nimrud, ruins (Al Qunaytrah Gov.), 18 July 1999, leg. P. BENDA. 


\section{Jordan:}

2 우 (NMP 92502 [S+A], 92503 [A]), Ash Shunah Al Janubiyya, Wadi Shu'ayb, cave ('Amman Prov.), 22 May 2009, leg. P. BENDA \& A. ReITER;

3 우 (NMP 92463-92465 [S+A]), Aqaba, Ottoman fortress (Aqaba Prov.), 16 May 2009, leg. P. BendA \& A. REITER;

3 우우 (NMP 92444, 92446 [S+A], 92445 [A]), Dhana, Wadi Dhana (Tafila Prov.), 14 May 2009, leg. P. BENDA \& A. REITER;

1 ㄱ, 2 우우 (NMP 92382, 92383 [S+A], 92381 [A]), Ghor As Safi, Lot's Cave (Karak Prov.), 18 October 2008, leg. P. BENDA \& J. OBUCH;

$9 \widehat{\delta} \widehat{\partial}$ (NMP 47966-47974 [S+A]), Tabaqat Fal, Roman Necropolis of Pella (Irbid Prov.), 4 July 1997, leg. P. BENDA;

1 ô (NMP 92363 [S+A]), Wadi As Sir, Iraq Al Amir, cave ('Amman Prov.), 10 October 2008, leg. P. BendA \& J. ОвUсн;

7 ふึ่, 3 우 (NMP 92415-92420, 92422-92424 [S+A], 92421 [A]), Wadi Weida'a, rocky wall (Karak Prov.), 12 May 2009, leg. P. Benda \& A. Reiter.

\section{Yemen:}

$1 \widehat{\partial}$ (NMP 90588 [S+A]), Socotra Is., Desmoiten (Suqutra Gov.), 13 May 2004, leg. P. Benda \& A. Reiter;

1 ( NMP 90594 [S+A]), Socotra Is., Keisu (Suqutra Gov.), 22 May 2004, leg. P. Benda \& A. Reiter;

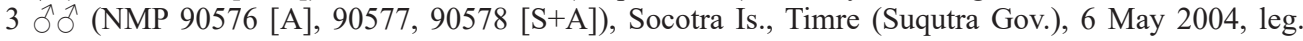
P. BENDA \& A. REITER;

1 đ̊ (NMP 96151 [S+A]), Socotra Is., Wadi Zerig (Suqutra Gov.), 5 March 2000, leg. B. PražAN;

$1 \widehat{\jmath}$ (NMP 92105 [S+A]), Socotra Is., Wadi Zerig (Suqutra Gov.), 2 September 2001, leg. B. PraŽAN;

3 đo ${ }^{\lambda}$ (NMP 90585, 90586 [S+A], 90584 [A]), Socotra Is., Wadi Zerig (Suqutra Gov.), 12 May 2004, leg. P. BENDA \& A. REITER.

\section{Oman:}

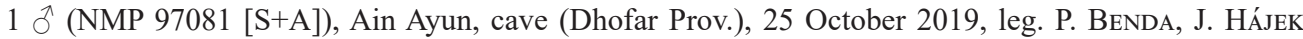
\& A. REITER;

4 우우 (NMP 94049-94051 [S+A], 94052 [A]), Ain Hamran Cave (Dhofar Prov.), 28 March 2012, leg. P. BENDA, A. REITER \& M. Uhrin;

1 o (NMP 97056 [S+A]), Ain Hamran Cave (Dhofar Prov.), 23 October 2019, leg. P. Benda, J. Hásek \& A. REITER;

3 우 (NMP 97078 [A], 97079, 97080 [S+A]), Ain Jarziz, cave (Dhofar Prov.), 24 October 2019, leg. P. BENDA, J. HÁJEK \& A. ReITER;

1 을 (NMP 92696 [S+A]), Rakhyut, wadi (Dhofar Prov.), 25 October 2009, leg. P. BENDA, A. Reiter \& M. UHRIN;

1 ô, 1 우 (NMP 97076, 97077 [S+A]), Raysut, Wadi Shaith, pools (Dhofar Prov.), 23 October 2019, leg. P. BENDA, J. HÁJEK \& A. ReITER;

1 ( NMP 94071 [S+A]), Sadah, cave (Dhofar Prov.), 31 March 2012, leg. P. BendA, A. Reiter \& M. Uhrin.

\section{Egypt:}

3 ते $\delta^{\lambda}, 3$ q $9+$ (NMP 93839-93844 [S+A]), Aswan, west bank of the Nile, Tombs of Nobles (Aswan Gov.), 9 January 2011 , leg. R. LuČAN;

7 ふૈર̂, 3 우우 (NMP 92599, 92600, 92605 [S+A], 92601-92604, 92606-92608 [A]), El Uqsur (Luxor), tombs (El Uqsur Gov.), 27 January 2010, leg. P. BendA, I. HoráčEK \& R. LuČAN;

1 (NMP 90569 [S+A]), Karnak, Eastern Temple of Rameses II (El Uqsur Gov.), 19 April 2002, leg. P. Muclinger \& P. NovÁ;

1 ô (NMP 92000 [B]), Sheikh Jarad, 25 km N of Aswan (Aswan Gov.), 29 April 1984, leg. D. J. OsBorN; 1 ô, 2 inds. (NMP 91982 [S+A], 91991, 91992 [B]), Egypt [undef.], date unlisted, leg. J. GroschaFT.

\section{Libya:}

9 ㅊํㅅ, 5 우 (NMP 49864-49869, 49872-49877 [S+A], 49870, 49871 [A]), Al Jaghbub (Al Butnan Dist.), 13 May 2002, leg. M. Andreas, P. Benda, V. Hanák, A. Reiter \& M. Uhrin. 


\section{Morocco:}

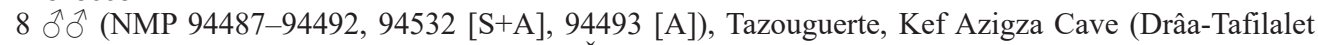
Reg.), 26-27 April 2008, leg. P. Benda, J. ČervenÝ, A. KoneČnÝ \& P. VAllo.

\section{Mauritania:}

5 ふึત, 3 우우 (NMP 93628, 93629, 93633, 93634 [S+A], 93630-93632, 93635 [A]), Ouadâne, old town (Adrar Reg.), 18 October 2010, leg. P. Benda, A. Reiter \& M. Uhrin;

3 우우 (NMP 93636-93638 [S+A]), Tin Labbé, Ghar Alhach Cave (Adrar Reg.), 19 October 2010, leg. P. BENDA, A. ReITER \& M. Uhrin.

\section{Sudan:}

3 추, 2 웅 (NMP 93660-93663 [S+A], 93659 [A]), Dungulah El Ajuz (Old Dongola), tombs (Esh Shimaliya State), 7 December 2010, leg. P. BendA \& J. ŠmíD;

1 ô, 2 우 (NMP 93648-93650 [S+A]), Karima, Jebel Barkal (Esh Shimaliya State), 6 December 2010, leg. P. BENDA \& J. ŠMíD.

References. Benda \& SÁdlová (1999), BejČEK et al. (2001), Benda (2001), ŠŤAstný et al. (2002), BENDA et al. (2004a, 2006a, b, 2008, 2009b, 2010a, b, 2012, 2014a, b, 2017, 2019a), Hulva et al. (2007),

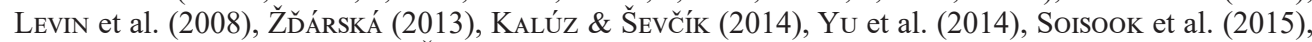
KaRMÁČKoví (2017), Benda \& ŠEvČíK (2020), KAFAEI et al. (2020).

Rhinolophidae

\section{Rhinolophus ferrumequinum (Schreber, 1774)}

Material (389). Croatia:

2 ふึર, 2 q 9 (NMP 96818, 96821, 96822 [S+A], 96823 [A]), Pokrovnik, Škarin Samograd Cave (Šibensko-Kninska County), 5 September 1977, leg. J. ČERVENÝ \& J. KuČERA;

2 우우 (NMP 96853, 96854 [A]), Selce, sea shore cave (Primorsko-Goranska County), 3 March 1856, leg. A. Frič.

\section{Croatia/Montenegro:}

$1 \hat{\jmath}$ (NMP 96852 [A]), Dalmatia [undef.], date unlisted [ 1905], ded. V. FrIČ.

\section{Montenegro:}

1 đิ (NMP 90229 [S+A]), Stari Bar (Bar Dist.), 19 September 2001, leg. J. HÁJEK \& J. Нotový.

\section{Kosovo:}

1 đ̊, 1 ㅇ (NMP 96804 [S+A], 96805 [A]), Mrasor, Mirusha Waterfall, cave (Gjakovë Dist.), 27 October 2001, leg. P. BENDA.

\section{Albania:}

1 đิ (NMP 96487 [S+A]), Juban, Ali Dedës Cave (Shkodër Pref.), 20 October 1960, leg. V. HaNÁK;

1 (NMP 96498 [S+A]), Krongj, Vris stream (Vlorë Pref.), 3 July 2015, leg. P. BendA, F. SPitzenberger, M. UHRIN \& E. WeISS;

2 우 (NMP 58777, 96494 [A]), Kruje (Durrës Pref.), 25 June 1996, leg. M. Vlašín;

3 ठิ่, 6 우 (NMP 96445 [S+B], 96397 [S+A], 96455-96458, 96462,96464 [S+A], 96449 [S]), Mezhgoran, Mezhgorani Cave (Gjirokastër Pref.), 11 October 1960, leg. V. HaNÁK;

1 + (NMP 96592 [S+A]), Ndërlysaj, Thethi River (Shkodër Pref.), 8 July 2016, leg. P. Benda;

3 ๙ิㅅ, 2 우 (NMP 96356, 96357 [S+B], 96358, 96359 [S+A], 96492 [A]), Pishkash, Pishkashi Cave (Elbasan Pref.), 5 October 1960, leg. V. HaNÁK;

1 ô, 1 ㅇ (NMP 96351, 96352 [S+B]), Pogradec, Çervenaka Cave (Korçë Pref.), 4 October 1960, leg. V. HANÁK;

1 đิ (NMP 96530 [S+A]), Prezë, bunker (Tiranë Pref.), 11 July 2015, leg. P. Benda, F. SPitzenberger, M. Uhrin \& E. Weiss; 
1 đิ (NMP 96470 [S]), Vanistër, Vanishta Cave (Gjirokastër Pref.), 12 October 1960, leg. V. HaNÁk;

11 충, 17 우 (NMP 96360-96363, 96365, 96366, 96368-96370, 96373, 96374, 96376-96380, 9638596387 [S+B], 96371, 96372, 96375, 96381, 96383, 96384 [S+A], 96364, 96367, 96382 [S]), Velçë, Velça Cave (Vlorë Pref.), 9 October 1960, leg. V. HANÁK;

1 ㅇ (NMP 96603 [S+A]), Zall-Dardhë, Drini i Zi River (Dibër Pref.), 30 June 2018, leg. P. BendA;

4 inds. (NMP 96488-96491 [S]), Albania [undef.], October 1960, leg. V. HaNÁK.

\section{Bulgaria:}

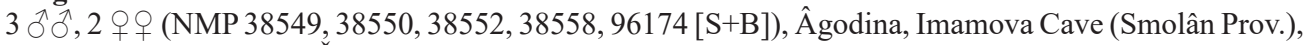
2 August 1971, leg. J. Č́ervenÝ, I. HoráČEK, A. TAušL \& D. VÍteK;

1 ô (NMP 96252 [S]), Âgodina, Sančeva Dupka Cave (Smolân Prov.), 3 August 1971, leg. J. ČERvENÝ, I. HORÁČEK, A. TAUŠL \& D. VÍTEK;

1 đ (NMP 50379 [A]), Brestnica, Săeva Dupka Cave (Loveč Prov.), 8 February 1965, leg. J. Figala, J. GAISLER, V. HANÁK \& K. HŮRKA;

4 우 (NMP 50268-50271 [A]), Devenci, Hajduška Peŝera Cave (Pleven Prov.), 7 July 1975, leg. J. ČERVENÝ;

1 ô (NMP 49808 [S+A]), Dobromir, mine (Burgas Prov.), 30 July 1979, leg. D. HolečKová, P. Donát, I. HorÁČEK, J. JiROUŠ \& V. VOHRALÍK;

1 (NMP 50046 [S+B]), Kamen Brâg, a cave NE of the town (Burgas Prov.), 11 July 1986, leg. V. HanzaL;

$1 \widehat{\jmath}$ (NMP 50051 [S+B]), Kamen Brâg, a cave NE of the town (Burgas Prov.), 12 July 1986, leg. V. HanZaL;

1 ô (NMP 50378 [A]), Karlukovo, Bankovica Cave (Loveč Prov.), 7 February 1965, leg. J. Figala, J. GAISLER, V. HANÁK \& K. HŮRKA;

1 고, 2 우우 (NMP 50236, 50237, 50254 [A]), Karlukovo, Bezimenna 22 Cave (Loveč Prov.), 6 July 1975, leg. J. ČERVENÝ;

1 \ิ (NMP 50257 [A]), Karlukovo, Bezimenna 22 Cave (Loveč Prov.), 7 July 1975, leg. J. Č́ervenÝ;

2 đิ ồ (NMP 50255, 50256 [A]), Karlukovo, Ovnarka Cave (Loveč Prov.), 7 July 1975, leg. J. ČERvenÝ;

1 ภ, 2 우 ㅇ (NMP 50206, 50208, 50209 [S+A]), Karlukovo, rocky amphitheatre (Loveč Prov.), 3 July 1976, leg. M. Braniš, V. HanáK, I. HoráČEK, K. HŮRKa, J. Jirouš, V. Švihla \& V. VohralíK;

3 우 (NMP 49360, 50211, 50213 [S+A]), Karlukovo, rocky amphitheatre (Loveč Prov.), 5 July 1976, leg. M. Braniš, V. HanÁK, I. HoráčEK, K. HŮRKa, J. Jirouš, V. Švihla \& V. VohralíK;

1 § , 2 우 (NMP 49363, 50216, 50217 [S+A]), Karlukovo, rocky amphitheatre (Loveč Prov.), 6 July 1976, leg. M. Braniš, V. HanÁK, I. HoráČEK, K. HŮRKa, J. Jirouš, V. Śvihla \& V. Vohralík;

1 ㅇ (NMP 50225 [S+A]), Karlukovo, rocky amphitheatre (Loveč Prov.), 12 June 1977, leg. V. BEJČEK, J. ŠKOPEK, P. VAŠÁK \& V. VOHRALÍK;

1 † (NMP 50289 [S+A]), Karlukovo, rocky amphitheatre (Loveč Prov.), 6 August 1978, leg. P. Donát, J. FLEGR, J. JANDA \& V. VOHRALÍK;

1 đ (NMP 50424 [S]), Karlukovo, rocky amphitheatre (Loveč Prov.), 8 August 1978, leg. P. DonÁt, J. FLEGR, J. JANDA \& V. VOHRALÍK;

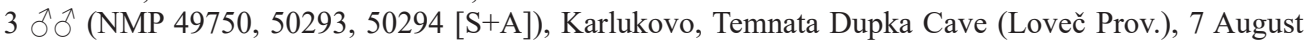
1978, leg. P. Donát, J. Flegr, J. JANDA \& V. Vohralík;

3 우우 (NMP 50321-50323 [S+A]), Komunari, rock labyrinth (Varna Prov.), 12 July 1979, leg. D. HoleČKOvÁ, P. DONÁT, I. HoráČEK, J. JiROUŠ \& V. VOHRALÍK;

1 đ (NMP 40923 [S+B]), Kotel, Nirica Cave (Sliven Prov.), 20 June 1982, leg. D. FrYnTA, D. HoleČKová, I. HoráčEK, H. Prágerová \& V. VohralíK;

2 đ̂̉, 1 오 (NMP 50138-50140 [S+B]), Lakatnik, Golâmata Vraža Dupka Cave (Sofiâ Prov.), 19 March 1956, leg. V. HANÁK;

1 ㅇ (NMP 50423 [S]), Lakatnik, Răžiškata (= Suhata) Peŝera Cave (Sofiâ Prov.), 18 March 1956, leg. V. HANÁK;

1 đ̂, 1 ㅇ (NMP 49144, 49145 [S+B]), Lakatnik, Răžiškata (= Suhata) Peŝera Cave (Sofiâ Prov.), 19 May 1957, leg. V HaNÁK;

1 o (NMP 49812 [S+B]), Lakatnik, Răžiškata (= Suhata) Peŝera Cave (Sofiâ Prov.), 3 January 1962, leg. J. SKLENÁŘ; 
2 $\widehat{\partial}, 1$ q (NMP 50380-50382 [A]), Lakatnik, Răžiškata (= Suhata) Peŝera Cave (Sofiâ Prov.), 10 February 1965, leg. J. Figala, J. Gaisler, V. Hanák \& K. HŮRKa;

2 우, 1 ind. (NMP 49809-49811 [S+B]), Lakatnik, Temnata Dupka Cave (Sofiâ Prov.), 3 January 1962, leg. J. SKLENÁŔ;

1 ind. (NMP 50146 [B]), Lakatnik, Temnata Dupka Cave (Sofiâ Prov.), 28 January 1962, leg. J. SkLENÁŘ;

1 ô (NMP 50334 [S+A]), Orehovo, cave (Smolân Prov.), 25 August 1980, leg. D. HoleČKové, J. Jirouš, H. Prágeroví \& V. VohralíK;

2 ổ (NMP 50369, 50370 [S+A]), Orehovo, cave (Smolân Prov.), 28 June 1984, leg. T. Scholz \& D. KRÁL;

1 ㄱ, 4 우우 (NMP 49841, 49842, 50331-50333 [S+A]), Ploski, cave (Blagoevgrad Prov.), 8 July 1980, leg. D. HolečKová, J. Jirouš, H. Prágerová \& V. Vohralík;

4 ㅊํㅅ, 9 우 (NMP 50345-50357 [S+A]), Ploski, cave (Blagoevgrad Prov.), 18 July 1981, leg. J. FLouseK, R. Fuchs \& V. VOHRALÍK;

1 q (NMP 50358 [S+B]), Ploski, cave (Blagoevgrad Prov.), 17 July 1982, leg. D. FrYnTA, D. HolečKová, I. HORÁČEK, H. PrÁGEROVÁ \& V. VOHRALÍK;

2 우 우 (NMP 50383, 50384 [A]), Ploski, cave (Blagoevgrad Prov.), 30 July 1994, leg. P. BendA, D. FrYNTA \& D. STORCH;

3 ふึํํ, 6 우우 (NMP 50387-50394, 50397 [A]), Ploski, cave (Blagoevgrad Prov.), 31 July 1994, leg. P. BENDA, D. FRYNTA \& D. STORCH;

4 우 (NMP 50374-50377 [S+A]) Ploski, orchard (Blagoevgrad Prov.), 14 August 1987, leg. P. MusIL;

1 ㅇ (NMP 50359 [A]), Primorsko, Arkutino, water station (Burgas Prov.), 13 May 1983, leg. T. Scholz \& D. KRÁL;

3 추, 9 우우 (NMP 38551, 38553, 38554, 38555, 38557, 96195, 96207, 96219, 96232, 96242 [S+B], 96223 [S], 96231 [K]), Primorsko, Maslen Nos Cape, Karaul Taš (Burgas Prov.), 17 August 1971, leg. J. ČERVENÝ, I. HoRÁČEK, A. TAUŠL \& D. VÍTEK;

1 (NMP 49346 [S+B]), Ropotamo River Estuary (Burgas Prov.), 6 June 1957, leg. M. Josifov;

4 inds. (NMP 96194, 96200, 96210, 96247 [S+B]), Bulgaria [undef.], August 1971, leg. J. ČERvenÝ, I. HorÁČEK, A. TAUŠL \& D. VÍTEK.

Greece (mainland):

$1 \widehat{\jmath}$ (NMP 48568 [S+B]), Delfoi (Sterea Ellada Reg.), 23 September 1988, leg. V. HanÁK, I. HoráČEK, Z. ROČEK \& V. VOHRALÍK;

$1 \widehat{o}$ (NMP 48709 [S+B]), Despotiko, stream (Īpeiros Reg.), 3 July 1989, leg. R. ChaloupKa, V. Hanák \& V. VOHRALÍK;

$1 \lesssim$ (NMP 48729 [S+A]), Kompotades, bunker (Sterea Ellada Reg.), 11 September 1996, leg. M. ANDREAS, P. BENDA \& M. UHRIN;

2 우우 (NMP 48644, 48645 [S+B]), Marōneia, stream (Anatolikī Makedonia kai Thrakī Reg.), 19 June 1989, leg. R. Chaloupka, V. Hanák \& V. Vohralík;

3 đิ ô, 1 q (NMP 48638, 48640, 48641 [S+B], 48639 [S]), Marōneia, Kyklōpa Cave (Anatolikī Makedonia kai Thrakī Reg.), 19 June 1989, leg. R. ChaloupKa, V. HanÁK \& V. VohralíK;

$1 \widehat{\partial}$ (NMP 96658 [S+A]), Naoysa, cave (Kentrikī Makedonia Reg.), 16-24 May 1937, leg. J. MAŘAN \& K. TÁBORSKÝ;

1 (NMP 48608 [S]), Petralōna, Petralōna Cave (Kentrikī Makedonia Reg.), 28 September 1988, leg. V. HANÁK, I. HoRÁČEK, Z. RoČEK \& V. VOHRALÍK;

1 ઈิ (NMP 49049 [S+A]), Pylī, Zachariadī Cave (Ditikī Makedonia Reg.), 3 September 2001, leg. P. BeNDA.

Greece (Crete):

1 ô (NMP 91189 [S+A]), Amnisos, Eileithyia Cave (Krīti Reg.), 4 October 2006, leg. P. Benda, V. HANÁK \& P. Hulva;

1 đิ (NMP 91195 [S+A]), Gerani, Geranioy Cave (Krīti Reg.), 6 October 2006, leg. P. Benda, V. Hanák \& P. HuLva;

1 ㅇ (NMP 92293 [S+A]), Gerani, Geranioy Cave (Krīti Reg.), 8 October 2007, leg. P. BendA; 
1 đ̊, 1 (NMP 91119 [S+A], 91120 [A]), Kolymvari, mine (Krīti Reg.), 9 October 2006, leg. P. Benda, V. HANÁK \& P. HuLVA;

1 đ (NMP 91048 [S+A]), Koymares, Arkoydiōtissa Cave (Krīti Reg.), 28 September 2006, leg. P. BendA, V. HANÁK \& P. Hulva;

1 (NMP 92319 [S+A]), Kritsa, Gaidoyrotrypa Cave (Krīti Reg.), 14 October 2007, leg. P. BendA;

2 ô $\partial^{\lambda}$ (NMP 92342, 92343 [S+A]), Kritsa, Gaidoyrotrypa Cave (Krīti Reg.), 31 May 2008, leg. P. BENDA \& V. HANÁK;

1 q (NMP 92332 [S+A]), Leykogeia, Katō Prevelī Monastery, Venetian bridge (Krīti Reg.), 30 May 2008, leg. P. BENDA \& V. HANÁK;

6 숭, 3 우우 (NMP 91101-91103, 91105, 91199, 91200 [S+A], 91104, 91106, 91107 [A]), Milatos, Milatoy Cave (Krīti Reg.), 7 October 2006, leg. P. Benda, V. Hanák \& P. Hulva;

2 ô đ̂̉ (NMP 91177, 91178 [S+A]), Omalos, Tzanī Cave (Krīti Reg.), 1 October 2006, leg. P. Benda, V. HANÁK \& P. HuLVA;

1 ㅇ (NMP 91188 [S+A]), Patsos, Agios Antōnios Cave (Krīti Reg.), 3 October 2006, leg. P. Benda, V. HANÁK \& P. HuLVA;

1 ô (NMP 92291 [S+A]), Ploytī, Mikrī Lavyrinthos Cave (Krīti Reg.), 7 October 2007, leg. P. BendA;

1 Ĵ, 2 우 (NMP 92294, 92296 [S+A], 92295 [A]), Theriso, Sarakinas Cave (Kritti Reg.), 8 October 2007, leg. P. BENDA.

Greece (islands):

3 우 (NMP 48697-48699 [S+B]), Thassos, Arhaggeloy Monastery, spring (Anatolikī Makedonia kai Thrakī Reg.), 26 June 1989, leg. R. Chaloupka, V. HanÁK \& V. VohralíK;

1 ô (NMP 48688 [S+B]), Thassos, Panagia, Drakotrypa Cave (Anatolikī Makedonia kai Thrakī Reg.), 24 June 1989, leg. R. Chaloupka, V. HanáK \& V. Vohralík.

\section{Turkey:}

1 ㄱ, 9 우우 (NMP 47928-47931, 47933, 48089-48093 [S+A]), Çevlik, tomb (Hatay Prov.), 20 May 1995, leg. P. BENDA, J. ČıHÁKová \& J. FlegR;

1 đ̊ (NMP 90490 [S+A]), Muradiye (Van Prov.), 23 June 2003, leg. J. HáseK \& J. HotovÝ.

\section{Cyprus:}

1 (NMP 91235 [S+A]), Afendrika, Panagia Hrysiotissa, ruins (İskele Dist.), 17 October 2005, leg. I. HORÁČEK, P. HULVA \& R. LuČAN;

1 đ (NMP 90425 [S+A]), Çınarlı, Inçirli Cave (Gazimağusa Dist.), 17 April 2005, leg. P. BENDA \& V. HaNÁK;

1 ô (NMP 91234 [S+A]), Çınarlı, Inçirli Cave (Gazimağusa Dist.), 15 October 2005, leg. I. HoRÁČEK, P. Hulva \& R. LuČAN;

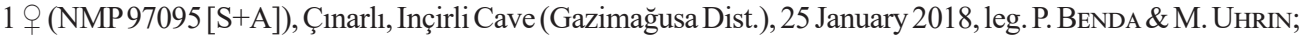

1 đิ (NMP 91225 [S+A]), Kakopetria, Troodos Forest, mine (Leykōsia Dist.), 14 October 2005, leg. I. HORÁČEK, P. Hulva \& R. LuČAN;

1 đ (NMP 97109 [S+A]), Kalkanli, Çoban Cave (Güzelyurt Dist.), 16 May 2018, leg. P. BENDA \& M. Uhrin;

1 q (NMP 90432 [S+A]), Kalavasos, mine (Larnaka Dist.), 19 April 2005, leg. P. BENDA \& V. Hanák;

1 ( NMP 97100 [S+A]), Kumyali, underground quarry (İskele Dist.), 10 May 2018, leg. P. BENDA \& M. Uhrin;

1 (NMP 97119 [S+A]), Kumyali, underground quarry (İskele Dist.), 1 October 2018, leg. P. BENDA \& M. Uhrin;

1 §, 2 우 (NMP 91249, 91250 [S+A], 91248 [A]), Neo Horio, Smigies Trail, Magnesia Mine (Pafos Dist.), 27 March 2005, leg. I. HoRÁČEK, P. Hulva \& R. LuČAN;

3 우 (NMP 91205, 91206 [S+A], 91204 [A]), Neo Horio, Smigies Trail, Magnesia Mine (Pafos Dist.), 12 October 2005, leg. I. HoráČEK, P. Hulva \& R. LuČAN.

\section{Syria:}

1 ô (NMP 48030 [S+A]), As Salihiyyah, Dura Europos (Dayr Az Zawr Gov.), 18 June 1998, leg. M. ANDREAS, P. BENDA \& M. Uhrin;

1 ô (NMP 48804 [S+A]), As Salihiyyah, Dura Europos (Dayr Az Zawr Gov.), 16 May 2001, leg. M. Andreas, P. Benda, A. Reiter \& D. Weinfurtová; 
2 inds. (NMP 90358; skull fragments from owl pellets), As Salihiyyah, Dura Europos (Dayr Az Zawr Gov.), 19 April 2001, leg. J. OBUCH;

2 ふぇ, 3 우 (NMP 48976-48978 [S+A], 48974, 48975 [S+B]), As Salihiyyah, Dura Europos, cave (Dayr Az Zawr Gov.), 20 April 2001, leg. P. MunCLinger \& P. Noví;

1 ภ, 5 우우 (NMP 48854-48858 [S+A], 48859 [A]), Bosra, citadelle (Daraa Gov.), 25 May 2001, leg. M. ANDREAS, P. BENDA \& D. WeINFURTOvÁ;

1 ㄱ, 5 우 (NMP 48759-48764 [S+A]), Qala'at Najm, cellar (Halab Gov.), 10 May 2001, leg. M. ANDrEAS, P. BENDA, A. Reiter \& D. WeinfurTovÁ;

$1 \hat{\jmath}$ (NMP 48270 [S+A]), Qala'at Nimrud, cellar (Al Qunaytrah Gov.), 18 July 1999, leg. P. BendA;

1 ô, 1 ㅇ (NMP 48073, 48074 [S+A]), Qala'at Salah Ad Din, cellar (Al Ladhiqiyah Gov.), 30 June 1998, leg. M. ANDREAS, P. BENDA \& M. Uhrin;

1 ind. (NMP 90342 [S]), Qala' at Salah Ad Din, ruins (Al Ladhiqiyah Gov.), 13 October 2004, leg. R. LuČAN;

4 우 (N (NMP 48935, 48936 [S+A], 48937 [S+B], 48938 [A]), Qala' at Samaan, cellar (Halab Gov.), 3 June 2001, leg. M. ANDREAS, A. ReITER \& D. WeINFURTová;

7 우우 (NMP 48077-48082 [S+A], 48083 [A]), Qala'at Sheisar, cellar (Hama Gov.), 1 July 1998, leg. M. ANDREAS, P. BENDA \& M. UHRIN;

1 ㅇ (NMP 48892 [S+A]), Qala'at Sheisar, ruins (Hama Gov.), 31 May 2001, leg. M. ANDrEAs, P. BendA, A. REITER \& D. WeINFURTOví;

2 우 우 (NMP 48927, 48928 [S+A]), Qatura, ruins (Halab Gov.), 2 June 2001, leg. M. ANDREAS, P. BendA, A. ReITER \& D. Weinfurtoví.

\section{Lebanon:}

1 ภิ (NMP 93683 [S+A]), Aamchit, Saleh Cave (Jebel Lubnan Gov.), 14 March 2009, leg. T. BARTONIČKA, P. BENDA, I. HORÁČEK \& R. LUČAN;

1 đ (NMP 91791 [S+A]), Aanjar, Aanjar Cave (El Beqaa Gov.), 24 January 2007, leg. P. BendA, R. ČERnÝ, I. HORÁČEK \& R. LUČAN;

1 đ̊, 1 ㅇ (NMP 93550, 93551 [S+A]), Aanjar, Aanjar Cave (El Beqaa Gov.), 5 June 2010, leg. P. BENDA \& M. UHRIN;

1 đิ (NMP 95831 [S+A]), Afqa, Afqa Cave (Jebel Lubnan Gov.), 26 June 2006, leg. I. HoráčEK, P. Hulva, R. LUČAN \& P. NĚMEC;

3 ภิ ภૈ (NMP 90895, 90896 [S+A], 90897 [A]), Afqa, Afqa Cave (Jebel Lubnan Gov.), 15 July 2006, leg. P. BENDA;

1 đ (NMP 91781 [S+A]), Afqa, Afqa Cave (Jebel Lubnan Gov.), 22 January 2007, leg. P. BendA, R. ČERnÝ, I. HORÁČEK \& R. LUČAN;

1 ㅇ (NMP 91892 [S+A]), Afqa, Afqa Cave (Jebel Lubnan Gov.), 17 January 2008, leg. P. Benda, I. HORÁČEK, R. LUČAN \& M. UHRIN;

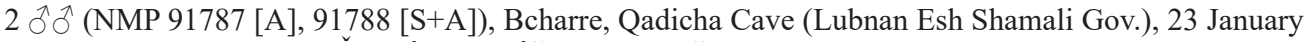
2007, leg. P. BENDA, R. ČERnÝ, I. HorÁČEK \& R. LuČAN;

1 ô (NMP 91800 [S+A]), Faraya, El Qana Cave (Jebel Lubnan Gov.), 27 January 2007, leg. P. BendA, R. ČERNÝ, I. HORÁČEK \& R. LUČAN;

1 (NMP 91768 [S+A]), Haqel El Azime, Achou Cave (Lubnan Esh Shamali Gov.), 21 January 2007, leg. P. BENDA, R. ČERnÝ, I. HORÁČEK \& R. LuČAN;

$1 \lesssim$ (NMP 93573 [S+A]), Khirbet Qanafar, El Jaouz Cave (El Beqaa Gov.), 9 June 2010, leg. P. BendA \& M. Uhrin;

3 우우 (NMP 91750, 91751 [S+A], 91752 [A]), Marjaba, mine (Jebel Lubnan Gov.), 19 January 2007, leg. P. BENDA, R. ČERNÝ, I. HORÁČEK \& R. LUČAN;

1 ô (NMP 93705 [S+A]), Ouadi Jilo, cave (Lubnan El Janubi Gov.), 22 March 2009, leg. T. BARTONIČKA, P. BENDA, I. HORÁČEK \& R. LUČAN;

1 đ̊ (NMP 91796 [S+A]), Ras Al Assi, cave (Baalbek-El Hermel Gov.), 25 January 2007, leg. P. BENDA, R. ČERNÝ, I. HORÁČEK \& R. LUČAN;

1 ㄱ, 4 우우 (NMP 95834, 95837-95839, 95849 [S+A]), Ras El Assi, Deir Mar Maroun Monastery (Baalbek-El Hermel Gov.), 29 June 2006, leg. I. HorÁČEK, P. Hulva, R. LuČAN \& P. NĚMEC; 
1 o (NMP 91785 [A]), Tourzaiya, Mebaaj Cave (Jebel Lubnan Gov.), 23 January 2007, leg. P. BeNDA, R. ČERNÝ, I. HORÁČEK \& R. LUČAN;

$1 \hat{\jmath}$ (NMP 91767 [S+A]), Trablous, Matal El Azraq Cave (Lubnan Esh Shamali Gov.), 21 January 2007, leg. P. Benda, R. ČERnÝ, I. HoráČEK \& R. LuČAn.

\section{Jordan:}

1 ô (NMP 92408 [S+A]), Dibbin, Dibbin Forest, underground corridor (Irbid Prov.), 27 October 2008, leg. P. BENDA;

1 ( (NMP 92562 [S+A]), Malka, artificial cave (Irbid Prov.), 28 May 2009, leg. Z. AmR, P. BENDA \& A. ReITER;

1 o, 1 ind. (NMP 92504 [S+A], 92505 [A]), Tabaqat Fahl, Roman Necropolis of Pella (Irbid Prov.), 24 May 2009, leg. P. BENDA \& A. ReITER;

1 ภิ, 2 우 (NMP 92403, 92404 [S+A], 92405 [A]), Zubiya, Zubiya Cave (Irbid Prov.), 25 October 2008, leg. P. BENDA \& J. OBUCH;

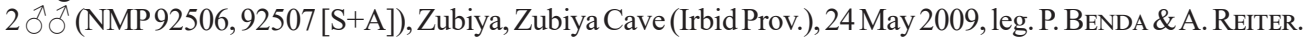

\section{Russia:}

2 + +, 2 inds. (NMP 91485, 91486 [S+B], 91487, 91488 [S+K]), Staraâ Macesta (Krasnodarskij Prov.), 24 June 1960 , leg. V. HANÁK.

\section{Georgia:}

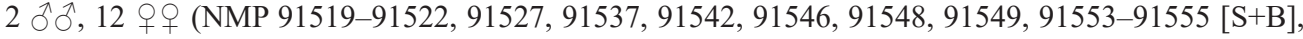
93853 [S]), Džal, tunnel (Aphazeti Rep.), 14 July 1964, leg. V. HANÁK.

\section{Azerbaijan:}

1 ภ, 1 ㅇ (NMP 91453, 91454 [S+B]), Acinohur, steppe (Şəki Dist.), 27 June 1986, leg. D. FrYnTA, J. NovÁK, J. PleSNÍK \& I. REHÁK;

1 ㄱ, 6 우, 1 ind. (NMP 91405-91409, 91411,91412 [S+A], 91410 [S+B]), Mingəçevir, cave (Mingəçevir Dist.), 25 June 1984, leg. M. ČernÝ, D. Frynta, J. Moravec, Z. Švecová \& P. VolF;

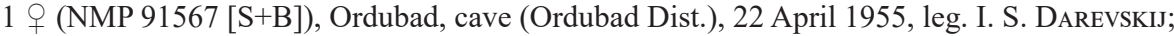

1 ô (NMP 91275 [S+A]), Qobustan, rocky town (Bak1 Dist.), 20 June 1979, leg. V. HanÁK;

1 ô (NMP 91441 [S+B]), Qobustan, rocky town (Bak1 Dist.), 22 June 1987, leg. J. Buchar \& M. ŠvátorA;

2 ふૈર, 1 ㅇ (NMP 91299, 91305 [S+A], 91300 [S+B]), Şamaxı, canyon (Şamaxı Dist.), 26 June 1979, leg. V. HANÁK.

\section{Iran:}

1 + (NMP 48148 [S+A]), Bisotun, cave (Kermanshah Prov.), 8 October 1998, leg. M. AndreAs, P. BendA, A. REITER \& M. Uhrin;

1 đ (NMP 48122 [S+A]), Chuplu, cave (Azarbaijan-e Gharbi Prov.), 3 October 1998, M. Andreas, P. BENDA, A. REITER \& M. Uhrin;

2 우 (NMP 93861, 94107 [S+A]), Dashkasan, Dashkasan Cave (Ardabil Prov.), 29 September 2011, leg. M. Andreas, P. Benda, A. Reiter \& M. Uhrin;

1 (NMP 48352 [S+A]), Deh Bakri, small cave (Kerman Prov.), 7 April 2000, leg. A. ReITER \& J. OBuch;

1 ô (NMP 93911 [S+A]), Karaftu Cave (Kordestan Prov.), 18 October 2011, leg. M. ANDreAs, P. Benda, A. ReITER \& M. Uhrin.

Turkmenistan:

2 đ̂̉, 1 우 (NMP 91605, 91606, 91645 [S+B]), Bäherden, Bäherden Cave (Ahal Reg.), 29 July 1964, leg. V. HANÁK.

\section{Uzbekistan:}

1 ふै, 1 우 (NMP 94093, 94094 [S+A]), Aman-Kutan, mine (Samarqand Reg.), 1 October 1985, leg. J. MORAVEC;

1 ô, 1 ㅇ (NMP 91467, 91468 [S+B]), Toshkent, cave (Toshkent Reg.), 30 September 1963, leg. V. HANÁK.

\section{Kirghizstan:}

4 วิ $\widehat{x}$ (NMP 91706-91708 [S+A], 91705 [S+B]), Kadamžaj, cave (Batken Reg.), 22 May 1980, leg. J. GAISLER \& V. HANÁK; 
1 ठ (NMP 58329 [S+A]), Kara-Kokty, mine (Oš Reg.), 13 July 1988, leg. J. ČERvENÝ \& J. OBuCh;

$2 \widehat{o} \hat{o}$ (NMP 58778/1, 58778/2 [S+A]), Oš Dist. [undef.] (Oš Reg.), 1988, leg. J. ČervenÝ \& J. Obuch;

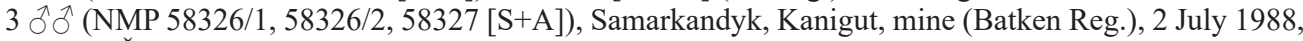
leg. J. ČERVENÝ \& J. OBUCH;

4 ऊ̂̉ స̂, 2 우 (NMP 58325/1 [A], 58325/2-6 [S+A]), Toâ-Moûn, Kolodec Fersmana mine (Oš Reg.), 12 July 1988, leg. J. Č́nVENÝ \& J. ОвuCh.

Tajikistan:

1 I (NMP 58328 [S+A]), Čorku, mine (Suġd Reg.), 3 July 1988, leg. J. Č́ervenÝ \& J. Obuch;

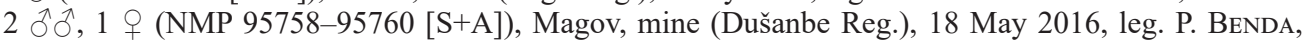
A. REITER \& M. UHRIN;

1 (NMP 95744 [S+A]), Qaraġoč, loess cave (Hatlon Reg.), 15 May 2016, leg. P. Benda, A. Reiter \& M. Uhrin;

1 đิ (NMP 95743 [S+A]), Širg, mine (Muhtori Kūhistoni Badahšon Reg.), 13 May 2016, leg. P. BENDA, A. ReITER \& M. UHRIN.

\section{Libya:}

$1 \delta^{\lambda}$ (NMP 49856 [S+A]), Ain Az Zarqa, oasis (Jabal Al Gharbi Dist.), 9 May 2002, leg. M. AndreAS, P. Benda, V. HANÁK, A. ReITER \& M. Uhrin;

1 을 (NMP 49967 [S+A]), Nanatalah, oasis (Jabal Al Gharbi Dist.), 27 May 2002, leg. M. ANDrEAS, P. Benda, V. HanÁK, A. Reiter \& M. Uhrin.

\section{Morocco:}

1 ㅇ (NMP 90035 [S+A]), Talkount, Oued Tessaoud, mine (Béni Mellal-Khénifra Reg.), 30 August 2003, leg. P. BENDA.

ReFERENCES. Frič (1864), HANÁK \& Josifov (1959), HANAK et al. (1961), HŮRKa (1962, 1963a, b, 1969, 1970, 1984a, b, 1997), DusBábeK (1964), HANÁK (1964, 1969), HorÁČEK et al. (1971, 1974, 2008, 2009), KuČERA (1979), HorÁČEK (1984), HoŠEK (1985), Č́ERVENÝ \& KRYŠTUFEK (1988), HoŠEK \& HorÁČEK (1989), Zima et al. (1991, 1992), KRYŠTuFEK (1993), BENDA \& HorÁČEK (1998), BENDA (2001), HANÁK et al. (2001), Rahmatulina \& Gasanov (2002), Benda et al. (2003, 2004b, 2006a, 2007, 2009a, 2010b, 2011a, 2012, 2014b, 2016a, 2017, 2018, 2019b), RAHMATUlina (2005), KŮs (2007), Rossiter et al. (2007), Flanders et al. (2009, 2011), Benda \& VAllo (2012), JŮn (2013), PATRICK et al. (2013), ŠEvČíK et al. (2013), Ž̌̌ÁrsKÁ (2013), KoH et al. (2014), PresetniK et al. (2014), KarmáčKová (2017), Hron et al. (2018), Demos et al. (2019), JiAng et al. (2019), NAJAFi et al. (2019), Mehdizadeh et al. (2020).

\section{Rhinolophus nippon Temminck, 1835}

Material (3). China:

1 ô, 1 \& (NMP 90551, 90552 [S+A]), Foping, 7 km N, cave (Shaanxi Prov.), 13 September 2004, leg. P. BENDA \& P. KAŇUCH;

1 ภ (NMP 90557 [S+A]), Daguping, cave (Shaanxi Prov.), 18 September 2004, leg. P. Benda \& P. KaŇUch.

References. Rossiter et al. (2007), Flanders et al. (2009, 2011), Benda \& Vallo (2012), Demos et al. (2019).

\section{Rhinolophus clivosus Cretzschmar, 1828}

MATERIAL (22). Jordan:

1 ઈิ (NMP 92425 [S+A]), Al Qurayqira, Wadi Ghuweir, Khirbet Feynan (Aqaba Prov.), 13 May 2009, leg. P. BENDA \& A. REITER;

1 ` (NMP 92447 [S+A]), Ar Rajif, Jebel Masuda, Ain Amshit (Ma'an Prov.), 15 May 2009, leg. P. BENDA \& A. REITER; 
2 우 (NMP 92495 [S+A], 92496 [A]), Jabal Al Bayda, cave (Ma’an Prov.), 19 May 2009, leg. P. BendA \& A. REITER;

$1 \delta$ (NMP 92843 [S+B]), Petra [= Al Batra], cave (Ma'an Prov.), 4 May 1983, leg. P. Boye;

1 J, 1 q (NMP 92810, 92811 [A]), Wadi Dharih, small cave (Tafila Prov.), 8 July 2010, leg. P. BeNDA \& A. REITER.

\section{Yemen:}

1 ind. (NMP 92108 [S+A]), Al Mahabishah (Hajjah Gov.), 26 June 2002, leg. A. K. NAsHeR;

1 q (NMP 90589 [S+A]), Socotra Is., Desmoiten, house (Suqutra Gov.), 14 May 2004, leg. P. BENDA \& A. REITER;

1 (NMP 90580 [S+A], paratype of Rhinolophus clivosus socotranus Benda, Reiter et Vallo, 2017), Socotra Is., Diksam Plateau, Hofur Cave (Suqutra Gov.), 8 May 2004, leg. P. BendA \& A. Reiter;

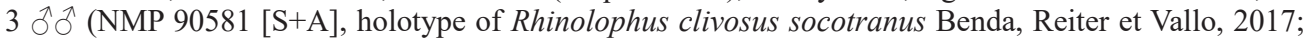
90582 [S+A], 90583 [A], paratypes of R. c. socotranus Benda, Reiter et Vallo, 2017), Socotra Is., Diksam Plateau, Marshim Cave (Suqutra Gov.), 8 May 2004, leg. P. BENDA \& A. ReITER;

1 ㅇ (NMP 90593 [S+A], paratype of Rhinolophus clivosus socotranus Benda, Reiter et Vallo, 2017), Socotra Is., Keisu (Suqutra Gov.), 21 May 2004, leg. P. Benda \& A. Reiter.

\section{Oman:}

1 đ (NMP 92736 [A]), Ain Tabruq, cave (Dhofar Prov.), 28 October 2009, leg. P. BendA, A. Reiter \& M. Uhrin;

1 ( (NMP 92755 [S+A]), Mirbat, house (Dhofar Prov.), 30 October 2009, leg. P. Benda, A. Reiter \& M. Uhrin;

1 ( (NMP 92695 [S+A]), Mudhai, cave (Dhofar Prov.), 25 October 2009, leg. P. Benda, A. Reiter \& M. Uhrin.

\section{Egypt:}

1 ( NMP 91994 [S]), Abu Rawash (El Jizeh Gov.), 15 April 1959, leg. H. RoER;

1 đิ (NMP 91987 [S+B]), Abu Rihal, 90 km E of Idfu (El Bahr El Ahmar Gov.), date unlisted, leg. D. J. OSBORN;

1 (ึ (NMP 92584 [S+A]), Aswan, orchard (Aswan Gov.), 24 January 2010, leg. P. Benda, I. HoráčEK \& R. LUČAN;

1 q (NMP 92596 [S+A]), El A'aqab (Aswan Gov.), 25 January 2010, leg. P. BeNDA, I. HorÁČEK \& R. LuČAN;

1 을 (NMP 90498 [S+A]), Feiran (Janub Sina' Gov.), 10 September 2005, leg. M. Andreas, P. Benda, J. НотоvÝ \& R. LuČAN.

References. Hanák (1969), Boye (1983), Disi \& Hatough-Bouran (1999), Benda et al. (2006b, 2008, 2010b, 2014a, 2017), Benda \& VAllo (2012), Ž ̌̌Árská (2013), KarmáČKová (2017), Hermida et al. (2018), Demos et al. (2019), Benda \& ŠEvČí́ (2020), Mehdizadeh et al. (2020).

\section{Rhinolophus bocharicus Kaŝenko et Akimov, 1918}

MATERIAL (27). Uzbekistan:

4 우 (NMP 91458-91461 [S+B]), Samarqand, cave (Samarqand Reg.), 28 September 1963, leg. V. HanÁK; 1 ô, 7 우 (NMP 91489-91496 [S+B]), Samarqand, cave (Samarqand Reg.), 14 October 1963, leg. A. K. Sagitov.

\section{Kirghizstan:}

1 ơ (NMP 58445 [S+A]), Oš Dist. [undef.] (Oš Reg.), 1987, leg. J. Овuch;

4 ô $\widehat{~}$ (NMP 58336/1 [A], 58336/2-4 [S+A]), Samarkandyk, Kanigut, mine (Batken Reg.), 2 July 1988, leg. J. ČERVENÝ \& J. OBUCH.

\section{Tajikistan:}

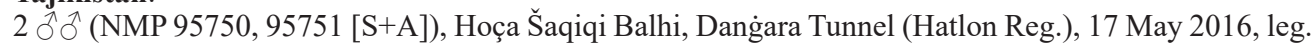
P. BENDA, A. ReITER \& M. Uhrin; 
1 đ̊, 6 우우 (NMP 95707-95711, 95713 [S+A], 95712 [A]), Levap, old farm (Hatlon Reg.), 5 May 2016, leg. P. BENDA, A. Reiter \& M. Uhrin;

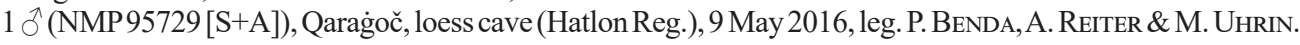

References. HANÁK (1969), Zima et al. (1991, 1992), HŮRKa (1970, 1997), Benda et al. (2011a, 2012), BENDA \& GAISLER (2015)

\section{Rhinolophus acrotis von Heuglin, 1861}

MATERIAL (7). Ethiopia:

1 đ̊ (NMP 95891 [S+A]), Aksum, King Basen's Tomb (Tigray Reg.), 1 November 2012, leg. P. BendA;

$1 \hat{\delta}$ (NMP $95962[\mathrm{~S}+\mathrm{A}]$ ), Bonga, Chara (Southern Nations, Nationalities and Peoples Reg.), 26 November 2012, leg. P. BENDA;

3 우우 (NMP 95937-95939 [S+A]), Kesa, Dangola Washa Caves (Amhara Reg.), 12 November 2012, leg. P. BENDA;

1 o (NMP 95913 [S+A]), Simien National Park, Aman Amba Area (Amhara Reg.), 5 November 2012, leg. P. BENDA;

1 ऽ (NMP 92118 [S+A]), Sof Omar Caves (Oromiya Reg.), 2 May 2003, leg. P. Benda \& J. Obuch.

References. Benda \& Vallo (2012), Benda et al. (2017), Demos et al. (2019).

\section{Rhinolophus horaceki Benda et Vallo, 2012}

MATERIAL (5). Libya:

$1 \widehat{\partial}$ (NMP 49861 [S+A], paratype of Rhinolophus horaceki Benda et Vallo, 2012), Al Bardiyah (Al Butnan Dist.), 12 May 2002, leg. M. Andreas, P. Benda, V. Hanák, A. Reiter \& M. Uhrin;

1 ( NMP 49915 [S+A], paratype of Rhinolophus horaceki Benda et Vallo, 2012), Wadi Al Kuf (Al Jabal Al Akhdar Dist.), 20 May 2002, leg. M. Andreas, P. Benda, V. Hanák, A. Reiter \& M. Uhrin;

2 ภ̄ô (NMP 49880 [S+A], holotype of Rhinolophus horaceki Benda et Vallo, 2012; NMP 49879 [S+A], paratype of $R$. horaceki Benda et Vallo, 2012), Wadi Darnah, mine (Darnah Dist.), 15 May 2002, leg. M. Andreas, P. Benda, V. Hanák, A. Reiter \& M. Uhrin;

1 (NMP 49882 [S+A], paratype of Rhinolophus horaceki Benda et Vallo, 2012), Wadi Darnah, $10 \mathrm{~km}$ S of Darnah, cave (Darnah Dist.), 16 May 2002, leg. M. Andreas, P. Benda, V. Hanák, A. Reiter \& M. UHRIN.

References. Benda \& Vallo (2012), Benda et al. (2014b, 2017), KarmáčKová (2017), Demos et al. (2019).

\section{Rhinolophus fumigatus Rüppell, 1842}

MATERIAL (9). Ethiopia:

$1 \widehat{\jmath}$ (NMP 95877 [S+A]), Desea Forest, 2 km E of Atsbi (Tigray Reg.), 30 October 2012, leg. P. BeNDA;

1 ô (NMP 96885 [S+A]), Edaga Arbi (Tigray Reg.), 2 April 2017, leg. BrhanE.

1 ô, 1 ind. (NMP 95917 [S+A], 95918 [S+Sk]), Gondar, Royal Enclosure (Amhara Reg.), 6 November 2012, leg. P. BENDA;

Benin:

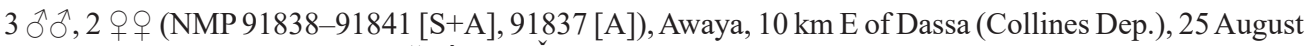
2007, leg. P. Benda, A. KoneČnÝ \& R. ŠumberA.

References. Benda \& Vallo (2012), Kassahun Aysheshm et al. (2015), Demos et al. (2019). 


\section{Rhinolophus eloquens Andersen, 1905}

MATERIAL (6). Ethiopia:

$1 \delta$ (NMP 92112 [S+A]), cave 20 km NE of Harbona (Oromiya Reg.), 29 April 2003, leg. P. Benda \& J. OBUCH;

1 đิ (NMP 92154 [S+A]), Sof Omar Caves (Oromiya Reg.), 2 May 2003, leg. P. Benda \& J. Obuch.

4 우 (NMP 92157-92159 [S+A], 92156 [A]), Sof Omar Caves (Oromiya Reg.), 3 May 2003, leg. P. BENDA \& J. ОвUCH.

\section{Rhinolophus darlingi Andersen, 1905}

MATERIAl (1). South Africa:

1 o (NMP 95680 [S+A]), Musina, Limpopo Safaris Farm, pool (Limpopo Prov.), 10 March 2004, leg. J. NovÁK.

\section{Rhinolophus denti Thomas, 1904}

MATERIAl (1). South Africa:

1 ind. (NMP 60353 [A]), Cradock, cave (Eastern Cape Prov.), date unlisted, leg. E. Holub.

REFERENCES. MLíKOvSKÝ et al. (2011a).

\section{Rhinolophus euryale Blasius, 1853}

MATERIAL (251). Italy:

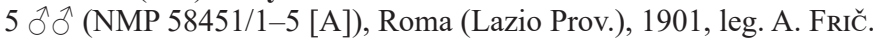

\section{North Macedonia:}

1 đิ (NMP 96855 [S]), Leskoec, cave (Resen Dist.), 18 September 1964, leg. H. Felten \& G. Storch.

Albania:

6 ふึ่̂, 1 우 (NMP 96442 [S+A], 96444, 96450, 96451, 96460, 96461 [S+B], 96443 [B]), Mezhgoran, Mezhgorani Cave (Gjirokastër Pref.), 11 October 1960, leg. V. HaNák;

1 q (NMP 96355 [B]), Pishkash, Pishkashi Cave (Elbasan Pref.), 5 October 1960, leg. V. Hanák;

1 §ิ (NMP 96493 [S+A]), Albania [undef.], 1960, leg. V. HanÁk.

\section{Bulgaria:}

1 O (NMP 49804 [S+A]), Bilka, Golâm Kamăk, cave (Burgas Prov.), 13 July 1979, leg. D. HolečKová, I. HORÁČEK \& V. VOHRALÍK;

4 ภ̊̉, 1 q (NMP 50263-50267 [A]), Devenci, Hajduška Peŝera Cave (Pleven Prov.), 7 July 1975, leg. J. ČERVENÝ;

1 ô (NMP 49650 [S+A]), Devenci, Hajduška Peŝera Cave (Pleven Prov.), 14 June 1977, leg. V. BeJČEK, J. ŠKOPEK, P. VAŠÁK \& V. VOHRALÍK;

1 추, 3 우 (NMP 49756, 49757, 49762, 49763 [S+A]), Karlukovo, cave (Loveč Prov.), 8 August 1978, leg. P. Donát, J. Flegr, J. Janda \& V. Vohralík;

1 đ (NMP 49778 [S+A]), Karlukovo, cave (Loveč Prov.), 9 August 1978, leg. P. Donát, J. Flegr, J. JANDA \& V. VOHRALÍK;

1 J, 6 우 (NMP 50247-50253 [A]), Karlukovo, Čerdženica Cave (Loveč Prov.), 6 July 1975, leg. J. ČERvENÝ;

1 O (NMP 49352 [S+A]), Karlukovo, rocky amphitheatre (Loveč Prov.), 3 July 1976, leg. M. Braniš, V. HaNÁK, I. HoráČEK, K. HŮRKa, J. Jirouš, V. Švihla \& V. VOHRALíK;

1 ภ , 3 우 (NMP 49353, 49355, 49358, 49359 [S+A]), Karlukovo, rocky amphitheatre (Loveč Prov.), 5 July 1976, leg. M. Braniš, V. Hanák, I. HoráčEK, K. HŮrka, J. Jirouš, V. Švihla \& V. Vohralík; 
6 우우 (NMP 49437-49441, 49638 [S+A]), Karlukovo, rocky amphitheatre (Loveč Prov.), 12 June 1977, leg. V. BejČEK, J. ŠKoPEK, P. VAŠÁK \& V. VOHRALÍK;

2 우 (NMP 49652, 49656 [S+A]), Karlukovo, rocky amphitheatre (Loveč Prov.), 15 June 1977, leg. V. BEJČEK, J. ŠKOPEK, P. VAŠÁK \& V. VOHRALÍK;

1 † (NMP 49707 [S+A]), Karlukovo, rocky amphitheatre (Loveč Prov.), 6 August 1978, leg. P. Donát, J. Flegr, J. JANDA \& V. VohraLíK;

1 q (NMP 49749 [S+A]), Karlukovo, Temnata Dupka Cave (Loveč Prov.), 7 August 1978, leg. P. Donát, J. Flegr, J. JANDA \& V. VOHRALíK;

1 ind. (NMP 50142 [S+B]), Lakatnik, Răžiškata (= Suhata) Peŝera Cave (Sofiâ Prov.), 21 December 1956, leg. V. BEŠKOv;

1 đ̃, 1 ㅇ (NMP 49994, 49995 [S+A]), Orehovo, cave (Smolân Prov.), 24 August 1980, leg. D. HolečKová, J. Jirouš, H. Prágerová \& V. Vohralík;

1 (NMP 50041 [S+A]), Orehovo, cave (Smolân Prov.), 28 June 1984, leg. T. Scholz \& D. KRÁL;

1 đ̃ (NMP 50044 [S+A]), Orehovo, cave (Smolân Prov.), 30 June 1984, leg. T. Scholz \& D. KRÁL;

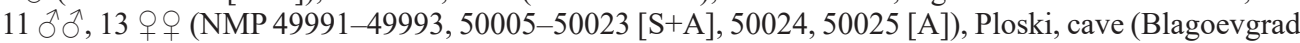
Prov.), 18 July 1981, leg. J. Flousek, R. Fuchs \& V. Vohralík;

1 ( NMP 50033 [S+B]), Ploski, cave (Blagoevgrad Prov.), 16 July 1982, leg. D. Frynta, D. HoleČKová, I. HORÁČEK, H. PrÁGEROVÁ \& V. VOHRALíK;

1 §, 1 ㅇ (NMP 50064, 50065 [S+A]), Ploski, cave (Blagoevgrad Prov.), 14 August 1987, leg. P. MusiL;

2 우 (NMP 50385, 50386 [A]), Ploski, cave (Blagoevgrad Prov.), 30 July 1994, leg. P. BENDA, D. FrYNTA \& D. STORCH;

1 đo (NMP 50395 [A]), Ploski, cave (Blagoevgrad Prov.), 31 July 1994, leg. P. BendA;

1 ㄱ, 7 우 우 (NMP 49183, 49195, 49201 [S+A], 49194, 49196, 49199, 49200, 49343 [S+B]), Primorsko, Maslen Nos Cape, cave (Burgas Prov.), 5 June 1957, leg. V. HaNák;

8 웅, 10 inds. (NMP 38564, 38791, 38793, 38795, 96173, 96193, 96196, 96201, 96204, 96227, 96237, 96248 [S+B], 96190, 96202, 96203, 96206, 96220, 96246 [S]), Primorsko, Maslen Nos Cape, Karaul Taš, rocks (Burgas Prov.), 17 August 1971, leg. J. ČERvenÝ, I. HoráčEK, A. TAušL \& D. VíteK;

$6 \hat{\jmath} \widehat{\jmath}, 40$ 오 (NMP 96170-96172, 96175, 96176, 96178-96182, 96189, 96192, 96197, 96198, 96205, 96208, 96209, 96211-96214, 96216, 96217, 96221, 96222, 96224-96226, 96228-96230, 96234-96236, 96238-96241, 96244, 96245, 96251 [S+B], 96199, 96215, 96218, 96233, 96243 [S]), Primorsko, Maslen Nos Cape, Karaul Taš, rocks (Burgas Prov.), 18 August 1971, leg. J. ČERveNÝ, I. HoráČEK, A. TAUŠL \& D. VÍTEK;

6 ふ઼่, 4 우우 (NMP 49170, 49175, 49182 [S+A], 49167-49169, 49171-49174 [S+B]), Sliven, Zmeevi Dupki Cave (Sliven Prov.), 25 May 1957, leg. V. Hanák;

5 궁ㅅ, 10 우우 (NMP 49675-49681, 49684, 49685 [S+B], 50274-50277, 50282, 50284 [S+A]), Sliven, Zmeevi Dupki Cave (Sliven Prov.), 15 July 1975, leg. J. ČervenÝ;

$1 \widehat{\jmath}$ (NMP 50055 [S+B]), Spahievo, Aida Hill, mine (Haskovo Prov.), 16 July 1986, leg. V. HanZaL.

Greece (mainland):

1 ô (NMP 96657 [S+A]), Naoysa, cave (Kentrikī Makedonia Reg.), 16-24 May 1937, leg. J. MAŘAN \& K. TÁBORSKÝ;

8 ふึิึ, 1 ㅇ (NMP 48595-48597, 48604, 48612-48615 [S+B], 48598 [S]), Petralōna, Petralōna Cave (Kentrikī Makedonia Reg.), 28 September 1988, leg. V. Hanák, I. HoráčEK, Z. RočEK \& V. VOHRALÍK;

1 ㅇ (NMP 49046 [S+A]), Pylī, Zachariadī Cave (Ditikī Makedonia Reg.), 3 September 2001, leg. P. Benda.

Turkey:

1 ふै, 1 q (NMP 47951, 47953 [S+A]), Sergen, Safe Suyu Spring Cave (Kırklareli Prov.), 1 September 1996, leg. M. ANDREAS, P. Benda \& M. Uhrin.

\section{Cyprus:}

1 ind. (NMP 97096 [S]), Lapta, water gallery (Girne Dist.), 24 January 2018, leg. P. BENDA, S. GüCEL \& M. Uhrin; 
3 우우 (NMP 97103, 97104 [S+A], 97105 [A]), Lapta, water gallery (Girne Dist.), 12 May 2018, leg. P. BENDA \& M. UHRIN.

\section{Syria:}

1 ㅇ (NMP 49985 [S+A]), Qala'at Al Hosn, 5 km west (Homs Gov.), 13 May 2001, leg. R. LuČAN; 1 ind. (NMP 90343 [S]), Qala'at Salah Ad Din, ruins (Al Ladhiqiyah Gov.), 13 October 2004, leg. R. LuČAN.

\section{Lebanon:}

2 ठิ ठૈ, 1 q (NMP 91803 [A], 91804, 91805 [S+A]), Aamchit, Saleh Cave (Jebel Lubnan Gov.), 28 January 2007, leg. P. BENDA, R. ČERNÝ, I. HORÁČEK \& R. LuČAN;

5 ô ô (NMP 93684-93687 [S+A], 93688 [A]), Aamchit, Saleh Cave (Jebel Lubnan Gov.), 14 March 2009, leg. T. BARTONIČKA, P. BENDA, I. HORÁČEK \& R. LuČAN;

1 đิ (NMP 95813 [S+A]), El Aaqoura, Er Rouais Cave (Jebel Lubnan Gov.), 26 June 2006, leg. I. HorÁČEK, P. HuLVA, R. LUČAN \& P. NĚMEC;

2 우우 (NMP 91771, 91772 [S+A]), Haqel El Azime, Achou Cave (Lubnan Esh Shamali Gov.), 21 January 2007, leg. P. BENDA, R. ĆERNÝ, I. HorÁČEK \& R. LuČAN;

2 우 (NMP 95841, 95842 [S+A]), Ras El Assi, Deir Mar Maroun Monastery (Baalbek-El Hermel Gov.), 29 June 2006, leg. I. HoráČEK, P. Hulva, R. LuČAn \& P. NĚMEC.

\section{Jordan:}

1 (NMP 92834 [S+A]), Dibbin, Dibbin Forest, underground corridor (Irbid Prov.), 14 July 2010, leg. P. BENDA \& A. REITER;

1 ₹, 1 ㅇ (NMP 92524, 92525 [S+A]), Khashibah, Al Wardeh Mine (Irbid Prov.), 26 May 2009, leg. P. BENDA \& A. REITER;

1 ô (NMP 92835 [S+A]), Khashibah, Al Wardeh Mine (Irbid Prov.), 14 July 2010, leg. P. Benda \& A. ReITER;

$3 \widehat{o} \widehat{\partial}, 4$ 우 (NMP 92534-92539 [S+A], 92540 [A]), Kufranja, Iraq Al Wahaj Cave (Irbid Prov.), 26 May 2009, leg. P. BENDA \& A. ReITER;

1 ô, 1 o (NMP 92406, 92407 [S+A]), Zubiya, Zubiya Cave (Irbid Prov.), 25 October 2008, leg. P. BendA \& J. OвUCH;

2 ๙ิ઼, 3 우우 (NMP 92511-92514 [S+A], 92515 [A]), Zubiya, Zubiya Cave (Irbid Prov.), 24 May 2009, leg. P. BENDA \& A. REITER.

\section{Armenia:}

1 ind. (NMP 91581 [S+B]), Armenia [undef.], date and collector unlisted.

Georgia:

4 ふึ่̂, 13 우우 (NMP 91518, 91523-91526, 91529-91534, 91538, 91539, 91543, 91544, 91556 [S+B], 91545 [B]), Džal, tunnel (Aphazeti Rep.), 14 July 1964, leg. V. HANÁK.

\section{Algeria:}

1 đิ (NMP 58452 [A]), Tébessa (Tébessa Prov.), 1930, leg. J. V. STANĚK.

REFERENCES. HŮRKA (1958, 1962, 1963a, 1969, 1984b), HANÁK \& Josifov (1959), HANAK et al. (1961), DusbábeK (1964), HANÁK (1964), HoráČeK et al. (1974, 2008), Felten et al. (1977), KuČERA (1979), HorÁČEK (1984), ZiMA et al. (1991, 1992), KRYŠTUFEK et al. (1992), BENDA \& HoRÁČEK (1998), BENDA (2001), HANÁK et al. (2001), BENDA et al. (2003, 2006a, 2010b, 2011a, 2016a, 2018, 2019b), KŮs (2007), JŮN (2013), ŽĎÁRSKÁ (2013), KARMÁČKOVÁ (2017).

\section{Rhinolophus mehelyi Matschie, 1901}

MATERIAL (66). Romania:

8 đิ $\widehat{x}, 15$ 우 (NMP 90256-90278 [S+B]), Limanu, Peştera de la Limanu Cave (Constanţa County), 21 July 1974, leg. J. ČERVENÝ.

\section{Bulgaria:}

1 ऊ̂̉ (NMP 49176 [S+B]), Sliven, Zmeevi Dupki Cave (Sliven Prov.), 27 May 1957, leg. V. Hanák; 


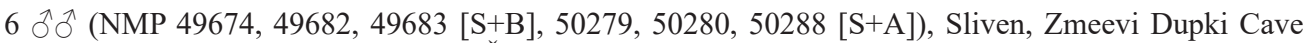
(Sliven Prov.), 15 July 1975, leg. J. ČERVENÝ.

Greece (mainland):

3 우우 (NMP 48668-48670 [S+B]), Didymoteiho, Cave (Anatolikī Makedonia kai Thrakī Reg.), 22 June 1989, leg. R. Chaloupka, V. Hanák \& V. Vohralík;

1 오 (NMP 48672 [S+B]), Kimmeria, mine (Anatolikī Makedonia kai Thrakī Reg.), 23 June 1989, leg. R. ChaloupKa, V. Hanák \& V. Vohralík;

1 q (NMP 48637 [S+B]), Marōneia, Kyklōpa Cave (Anatolikī Makedonia kai Thrakī Reg.), 18 June 1989, leg. R. Chaloupka, V. HanÁK \& V. VohralíK;

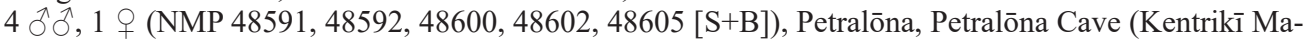
kedonia Reg.), 28 September 1988, leg. V. HANÁK, I. HoráčEK, Z. RočEK \& V. VohraLíK.

Turkey:

1 o (NMP 47961 [S+A]), Sergen, Safe Suyu Spring Cave (Kırklareli Prov.), 1 September 1996, leg. M. ANDREAs, P. Benda \& M. Uhrin.

Syria:

1 ind. (NMP 90359; skull fragments from owl pellet), Halabiyyeh, ruins (Dayr Az Zawr Gov.), 15 April 2001, leg. Ј. Овисн.

Armenia:

3 inds. (NMP 91578-91580 [S+B]), Armenia [undef.], date and collector unlisted.

Azerbaijan:

1 đิ (NMP 91303 [S+A]), Şamaxı, canyon (Şamaxı Dist.), 26 June 1979, leg. V. HaNÁK.

Libya:

16 ふึ่, 4 웅 (NMP 90240-90242 [S+B], 90237, 90245-90247, 90249, 90250, 90254, 90255 [S+W], 90236, 90238, 90239, 90243, 90244, 90248, 90251-90253 [S]), Wadi Al Kuf, cave (Al Jabal Al Akhdar Dist.), 23 April 1980, leg. V. HANÁK \& K. HŮRKA.

REFERENCES. HŮRKa (1958, 1982), HANÁK \& Josifov (1959), KuČERA (1979), ČERVENÝ (1982), HANÁK \& Elgadi (1984), HošEK (1985), HošEK \& HorÁČEK (1989), BENDA \& HorÁČEK (1998), BeNDA (2001), HANÁK et al. (2001), BENDA et al. (2003, 2006a, 2011a, 2014b, 2019b), RAHMATULina (2005), KARMÁČKOví (2017).

\section{Rhinolophus blasii Peters, 1866}

Material (126). Croatia:

1 đิ (NMP 96808 [S+W]), Mokošica, cave (Dubrovačko-Neretvanska County), 26 August 1977, leg. J. ČERVENÝ \& J. KUČERA;

1 đ̂, 1 ㅇ (NMP 96819, 96820 [S+W]), Pokrovnik, Škarin Samograd Cave (Šibensko-Kninska County), 5 September 1977, leg. J. ČERVENÝ \& J. KuČERA.

\section{Kosovo:}

1 오 (NMP 96802 [S+A]), Bubël, cave (Gjakovë Dist.), 27 October 2001, leg. P. BendA.

\section{Albania:}

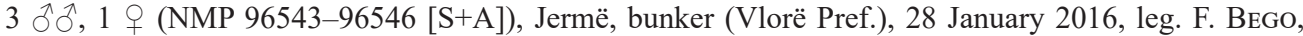
P. BENDA \& M. Uhrin;

3 ふึ่⿵ 5 우우 (NMP 96447, 96452, 96454, 96459 [S+B], 96463 [S], 96446, 96448 [A], 96453 [B]), Mezhgoran, Mezhgorani Cave (Gjirokastër Pref.), 11 October 1960, leg. V. HanáK;

1 ô (NMP 96537 [S+A]), Mezhgoran, Mezhgorani Cave (Gjirokastër Pref.), 26 January 2016, leg. F. Bego, P. BENDA \& M. Uhrin;

1 ô, 1 q (NMP 96353, 96354 [B]), Pishkash, Pishkashi Cave (Elbasan Pref.), 5 October 1960, leg. V. HaNák; 
1 o (NMP 96535 [S+A]), Tren, Treni II Cave (Korçë Pref.), 25 January 2016, leg. F. Bego, P. BendA \& M. Uhrin.

\section{Bulgaria:}

1 q (NMP 50101 [S+B]), Lakatnik, Temnata Dupka Cave (Sofiâ Prov.), 10 February 1965, leg. J. GaisLer, V. HANÁK \& K. HŮRKA.

\section{Greece (mainland):}

1 \& (NMP 48590 [S+B]), Aidonohōri, Aōos River (Īpeiros Reg.), 28 September 1988, leg. V. HanÁk, Z. ROČEK \& V. VOHRALÍK;

3 q + (NMP 48634-48636 [B]), Marōneia, Kyklōpa Cave (Anatolikī Makedonia kai Thrakī Reg.), 18 June 1989, leg. R. Chaloupka, V. HanÁK \& V. Vohralík;

4 ふึ่, 3 우 (NMP 48593, 48594, 48599, 48601, 48603, 48606, 48607 [B]), Petralōna, Petralōna Cave (Kentrikī Makedonia Reg.), 28 September 1988, leg. V. HanÁk, I. HoráČEK, Z. RočEK \& V. VOHRALÍK;

2 ふึ, 2 우 (NMP 51479-51482 [S+A]), Stoypa near Kardamylī, cave (Peloponnīsos Reg.), 8 July 1991, leg. M. ANDĚra \& P. ZBYTOvsKÝ.

\section{Greece (Crete):}

$1 \lesssim$ (NMP 91190 [S+A]), Amnisos, Eileithyia Cave (Krīti Reg.), 4 October 2006, leg. P. Benda, V. Hanák \& P. HuLVA;

3 ภิ 27 May 2008, leg. P. BENDA;

1 o (NMP 91179 [S+A]), Omalos, Tzanī Cave (Krīti Reg.), 1 October 2006, leg. P. Benda, V. Hanák \& P. Hulva;

1 옹 (NMP 92312 [S+A]), Peykoi, Vreiko Cave (Krīti Reg.), 12 October 2007, leg. P. Benda;

2 đิ ô (NMP 92348 [S+A], 92347 [A]), Royva Forest, Agios Iōannis Royva (Krīti Reg.), 4 June 2008, leg. P. BENDA, P. GEORGIAKAKIS \& V. HANÁK;

1 \& (NMP 92301 [S+A]), Theriso, Sarakinas Cave (Krīti Reg.), 8 October 2007, leg. P. BendA.

Greece (islands):

1 ô (NMP 96651 [S+A]), Kalymnos, Skalia Cave (Notio Aigaio Reg.), 3 October 2017, leg. P. BendA \& M. UHRIN;

$3 \widehat{\partial}$ (NMP 92358, 92359 [S+A], 92357 [A]), Karpathos, Aperi, bridge (Notio Aigaio Reg.), 30 September 2008, leg. P. BENDA;

1 ( NMP 96727 [B]), Petala, cave (DitikīEllada Reg.), 17 July 1956, leg. F. Baschieri SALVAdORI \& S. Patrizi.

\section{Turkey:}

3 ổ $\widehat{o}$ (NMP 90297-90299 [S+B]), Narlıkuyu, Cehennem Cave (Mersin Prov.), 2 May 1991, leg. V. HANZAL \& P. HoráK;

6 ô ${ }^{\lambda}$ (NMP 47917-47922 [S+A]), Narlıkuyu, Cehennem Cave (Mersin Prov.), 3 August 1992, leg. P. BENDA, J. Čináková \& J. FlegR;

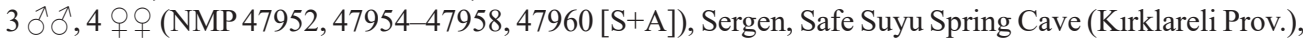
1 September 1996, leg. M. Andreas, P. Benda \& M. Uhrin.

\section{Cyprus:}

2 우 (NMP 90929, 90930 [S+A]), Kakopetria, Troodos Forest, mine (Leykōsia Dist.), 27 July 2006, leg. P. BENDA;

1 ก (NMP 90433 [S+A]), Kalavasos, mine (Larnaka Dist.), 19 April 2005, leg. P. Benda \& V. Hanák;

1 o (NMP 97120 [S+A]), Kumyali, underground quarry (İskele Dist.), 1 October 2018, leg. P. BENDA \& M. UHRIN;

1 ind. (NMP 97097 [S+Sk]), Lapta, water gallery (Girne Dist.), 24 January 2018, leg. P. BendA, S. GÜCEL \& M. Uhrin;

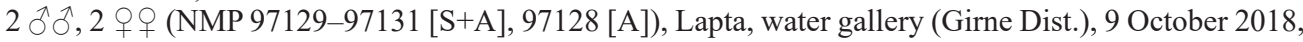
leg. P. BENDA \& M. UHRIN. 


\section{Lebanon:}

1 ㅇ (NMP 91908 [S+A]), Aamchit, Saleh Cave (Jebel Lubnan Gov.), 22 January 2008, leg. P. BendA, I. HORÁČEK, R. LUČAN \& M. UHRIN;

1 ( NMP 91900 [S+A]), Haqel El Azime, Achou Cave (Lubnan Esh Shamali Gov.), 18 January 2008, leg. P. BENDA, I. HORÁČEK, R. LuČAN \& M. UHRIN;

2 ㅊํㄱ, 2 우우 (NMP 91793-91795 [S+A], 91792 [A]), Kfar Zabad, cave (E1 Beqaa Gov.), 24 January 2007, leg. P. BENDA, R. ČERnÝ, I. HoRÁČEK \& R. LuČAN;

1 (NMP 91897 [S+A]), Ras Nhach, Musailha Fort, mine (Lubnan Esh Shamali Gov.), 18 January 2008, leg. P. BENDA, I. HORÁČEK, R. LUČAN \& M. UHRIN;

1 ภ (NMP 91898 [S+A]), Trablous, Mtal El Azraq Cave (Lubnan Esh Shamali Gov.), 18 January 2008, leg. P. Benda, I. HoráČEK, R. LuČAn \& M. UHRIN.

\section{Jordan:}

1 ind. (NMP 92429 [S+Sk]), Al Qurayqira, Wadi Ghuweir (Aqaba Prov.), 14 May 2009, leg. P. BendA \& A. REITER;

2 ㅅํㅅ, 3 우우 (NMP 92387-92390 [S+A], 92391 [A]), Ash Shawbak, Ash Shawbak Castle (Ma'an Prov.), 20 October 2008, leg. P. BENDA \& J. OBUCH;

2 우우 (NMP 92526, 92527 [S+A]), Khashibah, Al Wardeh Mine (Irbid Prov.), 26 May 2009, leg. P. BendA \& A. REITER;

3 ถึ ช̂̉ (NMP 92541-92543 [S+A]), Kufranja, Iraq Al Wahaj Cave (Irbid Prov.), 26 May 2009, leg. P. BendA \& A. REITER;

1 ภ (NMP 92412 [S+A]), Wadi As Sir, Iraq Al Amir, cave ('Amman Prov.), 10 May 2009, leg. P. BendA \& A. REITER;

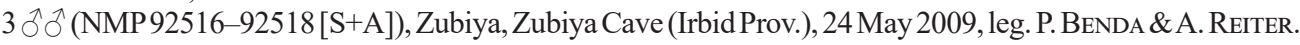

Turkmenistan:

1 đ̃, 3 우 (NMP 91598-91600, 91644 [S+B]), Bäherden, Bäherden Cave (Ahal Reg.), 29 July 1964, leg. V. HANÁK.

\section{Iran:}

11 ふึર, 2 우 우 (NMP 48098-48110 [S+A]), Emamzadeh, water gallery (Esfahan Prov.), 1 May 1997, leg. P. BENDA, J. ČıHÁKoví \& J. Flegr;

1 오 (NMP 93864 [S+A]), Meymand, valley (Kohgiluye va Boyer Ahmad Prov.), 4 October 2011, leg. M. Andreas, P. Benda, A. Reiter \& M. Uhrin.

\section{Morocco:}

1 o (NMP 94521 [S+A]), Takoumit, small cave (Drâa-Tafilalet Reg.), 26 April 2008, leg. P. Benda, J. Č́eRVEnÝ, A. KoneČNÝ \& P. VALlo;

5 ठิ ô, 4 우 (NMP 94494-94496, 94500, 94501, 94533 [S+A], 94497-94499 [A]), Tazouguerte, Kef Azigza Cave (Drâa-Tafilalet Reg.), 26-27 April 2008, leg. P. BendA, J. ČERVEnÝ, A. KoneČnÝ \& P. VAllo.

References. Lanza (1957), HanaK et al. (1961), Hůrka (1962, 1963a), HanÁK (1964), ČervienÝ \& KRYŠTUFEK (1988), BENDA \& HorÁČEK (1998), HANÁK et al. (2001), KRYŠTUFEK \& Đulić (2001), BENDA et al. (2003, 2006a, 2007, 2009a, 2010a, b, 2011a, 2012, 2016a, 2018, 2019b), KŮs (2007), HoRÁČEK et al. (2008, 2009), ŠEvČík et al. (2013), Ž̄̌ÁRSKÁ (2013), Benda \& GAisLer (2015), Benda \& Uhrin (2017), KARMÁČKOVÁ (2017), Hron et al. (2018).

\section{Rhinolophus landeri Martin, 1937}

\section{MATERIAL (2). Ethiopia:}

1 o (NMP 95919 [S+A]), Alatish National Park, Megbiya Ber Scout Post (Amhara Reg.), 7 November 2012, leg. P. BENDA.

1 ô (NMP 92119 [S+A]), Sof Omar Caves (Oromiya Reg.), 2 May 2003, leg. P. Benda \& J. Obuch;

REFERENCES. KRUSKOP et al. (2016). 


\section{Rhinolophus hipposideros (Borkhausen, 1797)}

Material (168). Croatia:

1 đ̂, 1 ㅇ (NMP 96815 [S+A], 96816 [A]), Pokrovnik, Škarin Samograd Cave (Šibensko-Kninska County), 5 September 1977, leg. J. ČERVENÝ \& J. KuČERA.

\section{Serbia:}

1 đ̊ (NMP 38955 [S+B]), Petnica (Kolubarski Dist.), 23 May 1969, leg. J. HanZÁk;

1 ind. (NMP 96856 [S+B]), Serbia [undef.], May 1969, leg. J. HanZÁK.

\section{Kosovo:}

$1 \widehat{\delta}$ (NMP 96803 [S+A]), Bubël, cave (Gjakovë Dist.), 27 October 2001, leg. P. BendA.

North Macedonia:

1 (NMP 96847 [S+A]), north-eastern bank of the Ohrid Lake (Ohrid Dist.), 10 July 1977, leg. V. TAUBER.

Albania:

$1 \widehat{\partial}$ (NMP 96541 [S+A]), Gjirokastër, castle (Gjirokastër Pref.), 27 January 2016, leg. F. BEGO, P. BENDA \& M. Uhrin;

1 (NMP 96536 [S+A]), Gollomboç, Hermit Cave (Korçë Pref.), 25 January 2016, leg. F. Bego, P. BendA \& M. Uhrin;

1 ( (NMP 96531 [S+A]), Tren, Treni Cave (Korçë Pref.), 25 January 2016, leg. F. Bego, P. BendA \& M. Uhrin; 1 ô (NMP 96551 [A]), Vithkuq, chapel crypt (Korçë Pref.), 27 June 2016, leg. P. BendA \& M. Uhrin.

\section{Bulgaria:}

1 ồ (NMP 49789 [S+A]), Âgodina, Dolna Karanska Dupka Cave (Smolân Prov.), 16 August 1978, leg. P. DONÁT, J. Flegr, J. JANDA \& V. VOHRALÍK;

1 ơ (NMP 49788 [S+A]), Âgodina, Gorna Karanska Dupka Cave (Smolân Prov.), 16 August 1978, leg. P. Donát, J. Flegr, J. Janda \& V. VOHRALÍK;

5 đ̂̉, 1 ㅇ (NMP 49780-49784, 49786 [S+A]), Âgodina, Imamova Dupka Cave (Smolân Prov.), 15 August 1978, leg. P. Donát, J. Flegr, J. JANDA \& V. VohralíK;

2 ô ô (NMP 49434, 49435 [S+A]), Bačkovo, Bačkovski Monastery (Plovdiv Prov.), 14 July 1976, leg. M. Braniš, V. Hanák, I. HoráČeK, K. HŮRKa, J. Jirouš, V. Švihla \& V. Vohralík;

1 o (NMP 49807 [S+A]), Bačkovo, cave (Plovdiv Prov.), 30 July 1979, leg. D. HolečKová, P. Donát, I. HORÁČEK, J. JiROUŠ \& V. VOHRALíK;

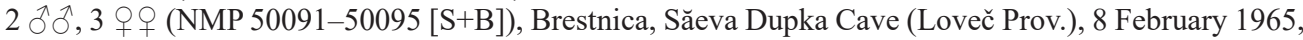
leg. J. Figala, J. Gaisler, V. HanÁK \& K. HŮRKa;

1 đิ (NMP 49433 [S+A]), Č́epelare, church (Smolân Prov.), 13 July 1976, leg. M. Braniš, V. HanÁK, I. HORÁČEK, K. HŮRKA, J. JiROUŠ, V. ŠVIHLA \& V. VOHRALíK;

3 우우 (NMP 50027-50029 [S+A]), Gorna Breznica, cottage (Blagoevgrad Prov.), 21 July 1981, leg. J. FLOUSEK, R. FuChS \& V. VOHRALÍK;

2 우오 (NMP 50030, 50031 [S+A]), Gorna Breznica, drainage tube (Blagoevgrad Prov.), 24 July 1981, leg. J. FlouseK, R. FuChS \& V. VOHRALÍK;

1 đิ (NMP 50080 [S+B]), Karlukovo, Bankovica Cave (Loveč Prov.), 7 February 1965, leg. J. Figala, J. GAISLER, V. HANÁK \& K. HŮRKA;

1 (NMP 49758 [S+A]), Karlukovo, cave behind monastery (Loveč Prov.), 8 August 1978, leg. P. Donát, J. Flegr, J. JANDA \& V. VOHRALÍK;

1 (NMP 49777 [S+A]), Karlukovo, cave behind monastery (Loveč Prov.), 9 August 1978, leg. P. Donát, J. Flegr, J. JANDA \& V. VOHRALÍK;

1 옹 (NMP 49354 [S+A]), Karlukovo, rocky amphitheatre (Loveč Prov.), 5 July 1976, leg. M. Braniš, V. HANÁK, I. HoráČEK, K. HŮRKA, J. JiROUŠ, V. Švihla \& V. VOHRALÍK;

$1 \widehat{\jmath}$ (NMP 49753 [S+A]), Karlukovo, Temnata Dupka Cave (Loveč Prov.), 7 August 1978, leg. P. DonÁt, J. FLEGR, J. JANDA \& V. VOHRALÍK;

5 đ̂̉ (NMP 49793-49797 [S+A]), Kotel, cottage (Sliven Prov.), 15 July 1979, leg. D. HolečKová, P. DONÁT, I. HoráČeK, J. Jirouš \& V. VOHRALÍK; 
2 đิ ổ (NMP 50136, 50137 [S+B]), Lakatnik, Svinskata Dupka Cave (Sofiâ Prov.), 19 March 1956, leg. V. HANÁK;

1 ind. (NMP 49813 [S+B]), Lakatnik, Temnata Dupka Cave (Sofiâ Prov.), 3 January 1962, leg. J. SkLENáŘ;

1 Ĵ, 4 우 (NMP 49368-49372 [S+A]), Lilânovo (Blagoevgrad Prov.), 9 July 1976, leg. M. Braniš,

V. HANÁK, I. HoráČEK, K. HŮRKA, J. Jirouš, V. Švihla \& V. Vohralík;

1 ㅇ (NMP 58543 [A]), Lûtibrod, Čerepiški Monastery (Vraca Prov.), 12 October 1952, leg. Z. VogeL;

1 ô (NMP 50072 [S+B]), Peŝera, Novata Peŝera Cave (Pazardžik Prov.), 4 February 1965, leg. J. Figala, J. GAISLER, V. HANÁK \& K. HŮRKA;

1 ô (NMP 50076 [S+B]), Peŝera, Snežanka Cave (Pazardžik Prov.), 5 February 1965, leg. J. Figala, J. GAISLER, V. HANÁK \& K. HŮRKA;

5 ふึ่, 2 우우 (NMP 49997-50003 [S+A]), Razlog, Meča Dupka Cave (Blagoevgrad Prov.), 30 August 1980, leg. D. HolečKová, J. Jirouš, H. Prágerová \& V. Vohralík;

1 \& (NMP 49347 [S+B]), Ropotamo River Estuary (Burgas Prov.), 6 June 1957, leg. M. Josifov.

\section{Greece (mainland):}

1 ㄱ, 5 우우 (NMP 48710-48715 [S+A]), Kompotades, bunker (Sterea Ellada Reg.), 9 September 1996, leg. M. ANDREAS, P. BENDA \& M. UHRIN;

1 q (NMP 49028 [S+A]), Kompotades, bunker (Sterea Ellada Reg.), 31 August 2001, leg. P. BendA;

1 q (NMP 48643 [S+B]), Marōneia, Kyklōpa Cave (Anatolikī Makedonia kai Thrakī Reg.), 19 June 1989, leg. R. ChaloupKa, V. HanáK \& V. VohralíK.

\section{Greece (Crete):}

1 đ (NMP 92303 [A]), Avdoy, Agios Fōteinīs Cave (Krīti Reg.), 10 October 2007, leg. P. Benda;

1 ô, 1 q (NMP 91193, 91194 [S+A]), Gerani, Geranioy Cave (Krīti Reg.), 6 October 2006, leg. P. Benda, V. HANÁK \& P. Hulva;

1 ô (NMP 92292 [A]), Gerani, Geranioy Cave (Krīti Reg.), 8 October 2007, leg. P. BendA;

1 ô (NMP 92320 [S+A]), Kritsa, Gaidoyrotrypa Cave (Krīti Reg.), 14 October 2007, leg. P. BendA;

1 ô, 1 ㅇ (NMP 91197, 91198 [S+A]), Milatos, Milatoy Cave (Krīti Reg.), 7 October 2006, leg. P. Benda, V. HANÁK \& P. HuLVA;

1 đิ (NMP 92290 [A]), Ploytī, Mikrī Lavyrinthos Cave (Krīti Reg.), 7 October 2007, leg. P. BendA;

1 ô (NMP 92317 [S+A]), Sitanos, Exō Latsidi Cave (Krīti Reg.), 13 October 2007, leg. P. BendA;

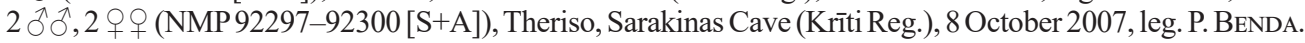

Greece (islands):

1 đิ (NMP 96614 [S+A]), Rhodes, Agios Paylos (Notio Aigaio Reg.), 16 August 2012, leg. P. BendA;

3 우우 (NMP 96615, 96616 [S+A], 96617 [A]), Rhodes, Gadoyra Dam, hut (Notio Aigaio Reg.), 17 August 2012, leg. P. BENDA.

\section{Turkey:}

1 ภิ (NMP 51475 [A]), Konac1k (Hatay Prov.), 21 October 1991, leg. J. Č́ervenÝ;

2 우 (NMP 90488, 90489 [S+A]), Posyagbasan (Adana Prov.), 15 June 2003, leg. J. HÁJEK \& J. Hotový.

Cyprus:

1 o (NMP 97092 [S+A]), Afendrika, Panagia Hrysiotissa, cave (İskele Dist.), 21 January 2018, leg. P. BENDA \& M. UHRIN;

1 ô (NMP 97121 [S+A]), Alevkaya, Küpö Cave (Lefkoşa Dist.), 2 October 2018, leg. P. BendA \& M. Uhrin;

2 ổ (NMP 91269 [S+A], 91270 [A]), Çınarlı, Inçirli Cave (Gazimağusa Dist.), 6 April 2005, leg. I. HORÁČEK, P. Hulva \& R. LuČAN;

1 ồ (NMP 90424 [S+A]), Çınarlı, Inçirli Cave (Gazimağusa Dist.), 17 April 2005, leg. P. BENDA \& V. HanÁK;

1 O (NMP 91830 [A]), Çınarlı, Inçirli Cave (Gazimağusa Dist.), 15 October 2005, leg. I. HoRÁČEK, P. Hulva \& R. LUČAN;

1 o (NMP 91263 [A]), Kakopetria, Troodos Forest, mine (Leykōsia Dist.), 29 March 2005, leg. I. HoRÁČEK, P. Hulva \& R. LuČAN;

1 ô (NMP 91229 [A]), Kakopetria, Troodos Forest, mine (Leykōsia Dist.), 14 October 2005, leg. I. HORÁČEK, P. Hulva \& R. LuČAN; 
4 ふึ ô, 2 q ㅇ (NMP 90924-90928 [S+A], 90923 [A]), Kakopetria, Troodos Forest, mine (Leykōsia Dist.), 27 July 2006, leg. P. BENDA;

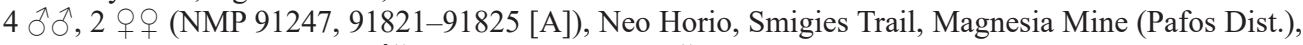
27 March 2005, leg. I. HoRÁČEK, P. Hulva \& R. LuČAN;

3 ڤึ ชิ (NMP 91261, 91262, 91827 [A]), Troodos, Troodos Forest, mine (Lemesos Dist.), 29 March 2005, leg. I. HoráČeK, P. Hulva \& R. LuČAn.

\section{Syria:}

3 우우 (NMP 48054 [S+A], 48055, 48056 [A]), Qala'at Salah Ad Din, ruins (Al Ladhiqiyah Gov.), 30 June 1998, leg. M. ANDREAS \& M. Uhrin;

1 일 48979 [S+A]), Qanawat, house (As Suwayda' Gov.), 27 April 2001, leg. P. Munclinger \& P. Nová.

\section{Lebanon:}

2 ภิ $\widehat{~}$ (NMP 91806 [S+A], 91807 [A]), Aamchit, Saleh Cave (Jebel Lubnan Gov.), 28 January 2007, leg. P. BENDA, R. ČERNÝ, I. HORÁČEK \& R. LUČAN;

$1 \lesssim$ (NMP 93709 [S+A]), Aamchit, Saleh Cave (Jebel Lubnan Gov.), 25 March 2009, leg. T. BARTONIČKA, P. BENDA, I. HORÁČEK \& R. LUČAN;

1 ภ, 1 우 (NMP 93552 [S+A], 93553 [A]), Aanjar, Aanjar Cave (El Beqaa Gov.), 5 June 2010, leg. P. BENDA \& M. Uhrin;

1 (N (NMP 91782 [S+A]), Afqa, Afqa Cave (Jebel Lubnan Gov.), 17 January 2008, leg. P. Benda, I. HORÁČEK, R. LUČAN \& M. UHRIN;

1 đ (NMP 91798 [S+A]), Antelias, Kenaan Cave (Jebel Lubnan Gov.), 25 January 2007, leg. P. BENDA, R. ČERNÝ, I. HORÁČEK \& R. LUČAN;

1 đ̃, 1 q (NMP 91789, 91790 [S+A]), Bcharre, Qadicha Cave (Jebel Lubnan Gov.), 23 January 2007, P. BENDA, R. ČERnÝ, I. HORÁČEK \& R. LuČAN;

1 ㅇ (NMP 93711 [A]), Dahr El Mghara, Aaonamie Cave (Jebel Lubnan Gov.), 28 March 2009, leg. T. BARTONIČKA, P. BENDA, I. HORÁČEK \& R. LUČAN;

$1 \lesssim$ (NMP 91775 [S+A]), El Aaqoura, Er Rouais Cave (Jebel Lubnan Gov.), 22 January 2007, leg. P. BeNDA, R. ČERNÝ, I. HORÁČEK \& R. LUČAN;

1 ภ (NMP 91801 [A]), Faraya, El Qana Cave (Jebel Lubnan Gov.), 27 January 2007, leg. P. Benda, R. ČERNÝ, I. HORÁČEK \& R. LUČAN;

2 ठิ่ (NMP 93537, 93538 [S+A]), Faraya, Raymond Cave (Jebel Lubnan Gov.), 2 July 2010, leg. P. BENDA \& M. UHRIN;

1 đ̊, 1 ( NMP 91770 [S+A], 91769 [A]), Haqel El Aazime, Achou Cave (Lubnan Esh Shamali Gov.), 21 January 2007, leg. P. BENDA, R. ČERnÝ, I. HORÁČEK \& R. LuČAN;

1 ô (NMP 91802 [A]), Hrajel, Seraaya Cave (Jebel Lubnan Gov.), 27 January 2007, leg. P. Benda, R. ČERNÝ, I. HORÁČEK, R. LUČAN \& M. UHRIN;

1 o (NMP 91906 [S+A]), Hrajel, Seraaya Cave (Jebel Lubnan Gov.), 20 January 2008, leg. P. BENDA, I. HORÁČEK, R. LUČAN \& M. UHRIN;

1 ㅇ (NMP 95792 [S+A]), Jezzine, Pont El Khalass (Lubnan El Janubi Gov.), 23 June 2006, leg. I. HorÁČEK, P. Hulva, R. LuČAN \& P. NĚMEC;

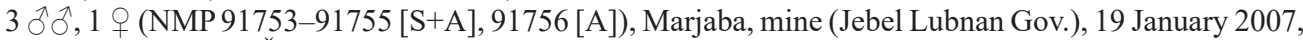
leg. P. BENDA, R. ČERnÝ, I. HORÁČEK \& R. LuČAN;

1 ô (NMP 91809 [S+A]), Nabaa Es Safa, mine (Jebel Lubnan Gov.), 29 January 2007, leg. P. BENDA, R. ČERNÝ, I. HORÁČEK \& R. LUČAN;

1 ㅇ (NMP 93706 [S+A]), Ouadi Jilo, cave (Lubnan El Janubi Gov.), 22 March 2009, leg. T. BARTONIČKA, P. BENDA, I. HORÁČEK \& R. LUČAN;

1 ㅇ (NMP 93577 [S+A]), Seraal, Qadicha Valley, cave (Lubnan Esh Shamali Gov.), 10 June 2010, leg. P. BENDA \& M. UHRIN;

$1 \widehat{\partial}$ (NMP 91786 [S+A]), Tourzaiya, Maba'aj Cave (Jebel Lubnan Gov.), 23 January 2007, leg. P. BeNDA, R. ČERNÝ, I. HORÁČEK \& R. LUČAN. 


\section{Jordan:}

1 ind. (NMP 92842 [S+Sk]), Bait Idis, Jesus' Cave (Irbid Prov.), 15 July 2010, leg. P. BendA \& A. REITER;

2 우 (NMP 92409, 92410 [S+A]), Dibbin, Dibbin Forest, underground corridor (Irbid Prov.), 27 October 2008, leg. P. BENDA \& J. OBUCH;

1 ภ, 2 우 (NMP 92508-92510 [S+A]), Zubiya, Zubiya Cave (Irbid Prov.), 24 May 2009, leg. P. BendA \& A. REITER.

\section{Azerbaijan:}

1 ㅇ (NMP 91697 [S+B]), Suçma (Şəki Dist.), 25 April 1976, leg. I. K. Rahmatulina.

\section{Iran:}

1 ઈิ (NMP 94427 [A]), Assalem (Gilan Prov.), 3 October 2002, leg. P. Hulva;

2 ô $\partial^{2}$ (NMP 48096, 48097 [S+A]), Emamzadeh, water gallery (Esfahan Prov.), 1 May 1997, leg. P. BeNDA, J. Č̈HÁKovÁ \& J. FLEGR;

1 ô (NMP 48439 [S+A]), Emamzadeh, water gallery (Esfahan Prov.), 6 April 2000, leg. P. BENDA \& A. REITER;

1 ô (NMP 39588 [A]), Karaj River Valley (Alborz Prov.), 1934, leg. KaRGL;

1 ind. (NMP 93858 [S+Sk]), Moghan, Moghan Cave (Khorasan-e Razawi Prov.), October 1999, leg. K. FAIZOLÂHI \& M. TARAHOMI;

1 ㅇ (NMP 48117 [S+A]), Nosrat Abad, small house (Sistan va Baluchestan Prov.), 7 May 1997, leg. P. BENDA.

\section{Oman:}

2 우 (NMP 93717 [S+A], 93718 [A]), Bani Habib, house (Ad Dakhiliyah Prov.), 28 March 2011, leg. P. BENDA, A. ReITER \& M. Uhrin;

$1 \widehat{\delta}$ (NMP 93782 [S+A]), Misfah, mosque (Ad Dakhiliyah Prov.), 9 April 2011, leg. P. BendA, A. Reiter \& M. Uhrin;

1 (NMP 93994 [S+A]), Sal Alah, Birkat Khaldiyah, cistern (Musandam Prov.), 13 March 2012, leg. P. BENDA, A. REITER \& M. Uhrin.

\section{Kirghizstan:}

1 f (NMP 58323 [S+A]), Kyzyl-Kiâk, cave (Batken Reg.), 30 June 1988, leg. J. ČErvenÝ \& J. ОвUCH;

1 옹 (NMP 58324/2 [S+A]), Toâ-Moûn, Kolodec Fersmana mine (Oš Reg.), 12 July 1988, leg. J. ČERVENÝ \& J. OвUCH.

\section{Tajikistan:}

1 o (NMP 95742 [S+A]), Zingrog், small cave (Muhtori Kūhistoni Badahšon Reg.), 12 May 2016, leg. P. Benda, A. ReITER \& M. Uhrin.

\section{Morocco:}

1 ㅇ (NMP 93602 [S+A]), Gorges du Dadès, Aït-Ali (Drâa-Tafilalet Reg.), 7 October 2010, leg. P. BeNDA, A. REITER, M. ŠEVČ́́K \& M. Uhrin;

2 우우 (NMP 94519, 94520 [S+A]), Takoumit, small cave (Drâa-Tafilalet Reg.), 26 April 2008, leg. P. BENDA, J. ČervenÝ, A. KoneČnÝ \& P. VAllo.

\section{Ethiopia:}

1 옹 (NMP $95890[\mathrm{~S}+\mathrm{A}]$ ), Degum, Yohannis Maikudi Church (Tigray Reg.), 31 October 2012, leg. P. BENDA.

References. Gaisler (1956), HanÁk \& Josifov (1959), HoŠEK (1985), HoŠEK \& HoráČeK (1989), ČervenÝ \& KryštufeK (1988), HŮrka (1997), Benda \& HoráČé (1998), Benda (2001), HanÁk et al. (2001), BENDA et al. (2003, 2006a, 2007, 2009a, 2010a, b, 2011a, 2012, 2016a, b, 2018, 2019b), RAHMAtUlina (2005), KŮs (2007), HoráČEK et al. (2008, 2009), Benda \& VAllo (2012), Dool et al. (2013), ŽĎÁrská (2013), BENDA \& GAisler (2015), KARMáČKová (2017), Hron et al. (2018), Wu et al. (2018). 


\section{Rhinolophus affinis Horsfield, 1823}

Material (11). China:

1 đ̊ (NMP 90548 [S+A]), Bangfangzi, Chang Pin Valley, stream (Shaanxi Prov.), 10 September 2004, leg. P. BENDA \& P. KAŇUCH;

3 취ํ, 5 우우 (NMP 90558, 90560, 90562-90565 [S+A], 90559, 90561 [A]), Daguping, cave (Shaanxi Prov.), 18 September 2004, leg. P. BendA \& P. KAŇUCH;

1 ㅇ (NMP 90549 [S+A]), Houzhenzi, stream (Shaanxi Prov.), 11 September 2004, leg. P. BendA \& P. KAŇUCH;

1 đ (NMP 90543 [S+A]), Taibaishan National Park, Sworded Peak, cave (Shaanxi Prov.), 8 September 2004, leg. P. BENDA \& P. KAŇUCH.

REFERENCES. Hron et al. (2018).

\section{Rhinolophus lepidus Blyth, 1844}

MATERIAL (15). Uzbekistan:

2 우우 (NMP 94095, 94096 [S+A]), Aman-Kutan, mine (Samarqand Reg.), 1 October 1985, leg. J. Moravec.

\section{Kirghizstan:}

3 ठิ $\widehat{\partial}, 2$ 우 (NMP 58896/1, 58896/3, 60517, 60518 [S+A], 58896/2 [A]), Kara-Kokty, mine (Oš Reg.), 28 May 1990, leg. J. ČERVENÝ \& J. OBuCH;

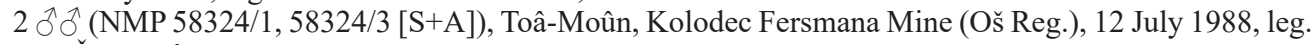
J. ČERVENÝ \& J. OBuCH.

\section{Tajikistan:}

3 ડึ่ 3 , 3 우 (NMP 95762-95766 [S+A], 95761 [A]), Magov, mine (Dušanbe Reg.), 18 May 2016, leg. P. Benda, A. ReITER \& M. Uhrin.

References. Zima et al. (1991, 1992), HoráčeK \& Zima (1996), HŮRKa (1997), Zima (2004), Benda et al. (2011a, 2016b), Hron et al. (2018).

Hip posiderida e

\section{Hipposideros caffer (Sundevall, 1846)}

Material (4). South Africa:

3 우 (NMP 95682-95684 [S+A]), Ka-Sunduza, house (Limpopo Prov.), 13 March 2004, leg. J. NovÁk.

Zimbabwe/Zambia:

$1 \widehat{\jmath}$ (NMP 37303 [B, incl. S]), Zambezi [undef.], August 1875, leg. E. Holub.

\section{Hipposideros tephrus Cabrera, 1906}

Material (13). Morocco:

$4 \partial^{\lambda}, 3$ 9 + (NMP 94432-94437 [S+A], 94438 [A]), Sidi Binzarne, canalisation tube (Souss-Massa Reg.), 12 April 2008, leg. P. Benda, J. ČervenÝ, A. KoneČnÝ \& P. VAllo;

1 đิ (NMP 94439 [S+A]), Massa, rocky overhang (Souss-Massa Reg.), 12 April 2008, leg. P. Benda, J. ČervienÝ, A. KoneČnÝ \& P. VAllo.

\section{Mauritania:}

$1 \widehat{\partial}$ (NMP 93646 [S+A]), Terjit, oasis (Adrar Reg.), 21 October 2010, leg. P. BendA, A. Reiter \& M. UHRIN. 


\section{Ethiopia:}

2 ฮิ วิ (NMP 96882, 96883 [A]), Abune Aregawi Zeya Cave (Tigray Reg.), 24 February 2017, leg. BRHANE;

1 ô, 1 ㅇ (NMP 96892, 96893 [S+A]), Abune Aregawi Zeya Cave (Tigray Reg.), 18 September 2019, leg. P. Benda.

References. Vallo (2008), Vallo et al. (2008), Benda et al. (2010a), Grandjon \& Birnbaum (2010), BALdwin et al. (2014), KARMáčKová (2017), PATTERSON et al. (2020).

\section{Hipposideros ruber (Noack, 1893)}

Material (10). Ethiopia:

$1 \widehat{\jmath}$ (NMP 95948 [S+A]), Bolo, 18 km NW of Nekemte, Geda Gilinde Cave (Oromiya Reg.), 16 November 2012, leg. P. BENDA;

4 ふ̊̂, 2 우 (NMP 95893-95897 [S+A], 95892 [A]), Mai Temen, 47 km SW of Sheraro (Tigray Reg.), 2 November 2012, leg. P. BENDA.

\section{Benin:}

1 J , 1 q (NMP 91848, 91849 [S+A]), Awaya, $10 \mathrm{~km}$ E of Dassa (Collines Dep.), 25 August 2007, leg. P. BENDA, A. KoneČNÝ \& R. ŠUMBERA;

1 o (NMP 91879 [S+A]), Tagayé, stream (Atakora Dep.), 30 August 2007, leg. P. BendA, B. Duossa, A. KONEČNÝ \& R. ŠUMBERA.

References. Vallo (2008), Vallo et al. (2008, 2011), Grandjon \& Birnbaum (2010), Monadjem et al. (2013), BAldwin et al. (2014, 2021), OpoKu (2016), PATterson et al. (2020), Mamba et al. (2021)

\section{Hipposideros abae Allen, 1917}

Material (2). Benin:

$2 \widehat{\jmath}$ (NMP 91850, 91851 [S+A]), Awaya, $10 \mathrm{~km}$ E of Dassa (Collines Dep.), 25 August 2007, leg. P. Benda, A. KoneČnÝ \& R. Šumbera.

References. Vallo (2008), Vallo et al. (2008), Grandjon \& Birnbaum (2010), Monadjem et al. (2013), Baldwin et al. (2014), Patterson et al. (2020), Liang et al. (2021), Rossoni et al. (2021).

\section{Hipposideros jonesi Hayman, 1947}

Material (6). Benin:

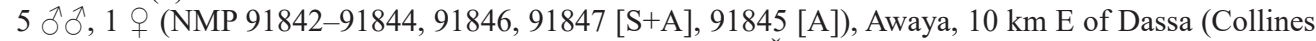
Dep.), 25 August 2007, leg. P. Benda, A. KoneČnÝ \& R. Šumbera.

References. Vallo (2008), Vallo et al. (2008), Grandjon \& Birnbaum (2010), Monadjem et al. (2013), Baldwin et al. (2021), PATterson et al. (2020).

\section{Hipposideros megalotis (von Heuglin, 1862)}

\section{Material (3). Ethiopia:}

1 ind. (NMP 96881 [A]), Abune Aregawi Zeya Cave (Tigray Reg.), 24 February 2017, leg. Brhane;

2 ô ${ }^{\lambda}$ (NMP 96894, 96895 [S+A]), Abune Aregawi Zeya Cave (Tigray Reg.), 18 September 2019, leg. P. BENDA. 


\section{Aselliscus tricuspidatus (Temminck, 1835)}

\section{Material (1). Papua New Guinea:}

1 ô (NMP 39587 [A]), New Guinea [undef.], 1896, leg. E. S. VRÁz.

\section{Asellia tridens (Geoffroy, 1813)}

MATERIAL (178). Syria:

6 inds. (NMP 90360; skull fragments from owl pellets), As Salihiyyah, Dura Europos (Dayr Az Zawr Gov.), 19 April 2001, leg. J. ОвUсн;

1 ind. (NMP 90361; skull fragments from owl pellet), As Salihiyyah, Dura Europos (Dayr Az Zawr Gov.), 19 April 2001, leg. J. Овuсн;

9 우우 (NMP 48019-48021, 48024-48027 [S+A], 48022, 48023 [S+B]), Halabiyyeh, ruins (Dayr Az Zawr Gov.), 17 June 1998, leg. M. Andreas, P. Benda \& M. Uhrin;

3 inds. (NMP 90362; skull fragments from owl pellets), Halabiyyeh, ruins (Dayr Az Zawr Gov.), 17 June 1998, leg. Ј. ОвUсн;

17 inds. (NMP 90363; skull fragments from owl pellets), Halabiyyeh, ruins (Dayr Az Zawr Gov.), 15 April 2001, leg. J. ОвuCH;

1 ô (NMP 48813 [S+A]), Qala'at Ar Rahba (Dayr Az Zawr Gov.), 17 May 2001, leg. M. Andreas, P. Benda, A. Reiter \& D. Weinfurtová;

11 ổ (NMP 48037, 48038, 48040-48047 [S+A], 48039 [S+B]), Tadmor, Afqa Cave (Homs Gov.), 23 June 1998, leg. M. Andreas, P. Benda \& M. Uhrin;

3 ổ (9 (92090-92092 [A]), Tadmor, Afqa Cave (Homs Gov.), 3 October 2004, leg. R. LuČAN;

1 ind. (NMP 90364; skull fragment from owl pellet), Tadmor, desert (Homs Gov.), 23 June 1998, leg. J. OBuch; 1 ind. (NMP 90366; skull fragments from owl pellet), Tadmor, ruins (Homs Gov.), 23 June 1998, leg. J. OBUCH; 1 ô (NMP 47926 [A]), Tadmor, ruins (Homs Gov.), 30 April 1995, leg. M. KafTAN;

5 inds. (NMP 90365; skull fragments from owl pellets), Tadmor, ruins (Homs Gov.), 23 April 2001, leg. J. OBUCH;

3 inds. (NMP 90367; skull fragments from owl pellets), Zalabiyyeh, ruins (Dayr Az Zawr Gov.), 15 April 2001, leg. Ј. Овисн.

\section{Iran:}

5 ふふર, 10 우 (NMP 48173-48177, 48180-48187 [S+A], 48178, 48179 [A]), Choqazanbil, ruins (Khuzestan Prov.), 15 October 1998, leg. M. Andreas, P. BendA, A. Reiter \& M. Uhrin;

1 ㅇ (NMP 93901 [S+A]), Choqazanbil, ruins (Khuzestan Prov.), 16 October 2011, leg. M. Andreas, P. BENDA, A. ReITER \& M. Uhrin;

2 ổ (NMP 93909, 93910 [S+A]), Dehloran Cave (Ilam Prov.), 17 October 2011, leg. M. AndreAs, P. Benda, K. Faizolâhi, A. Reiter \& M. Uhrin;

3 inds. (NMP 48202-48204 [S+Sk]), Hormoz Is., Daneshyu Salt Cave (Hormozgan Prov.), 25 January 1999, leg. J. BRUTHANS;

1 ô, 1 q (NMP 93894, 93895 [S+A]), Jahrom, Sang Eshkan Mine (Fars Prov.), 8 October 2011, leg. M. Andreas, S. Ashrafi, P. Benda, K. Faizolâhi, A. Reiter \& M. Uhrin;

1 ㅇ (NMP 93900 [S+A]), Shanbeh, ruins (Bushehr Prov.), 14 October 2011, leg. M. Andreas, P. Benda, A. REITER \& M. Uhrin.

\section{Oman:}

1 đ̃, 2 우 (NMP 92627, 92628 [S+A], 92629 [A]), Al Ghubrah, cave (Al Batinah Al Janub Prov.), 18 October 2009, leg. P. Benda, A. Reiter \& M. Uhrin;

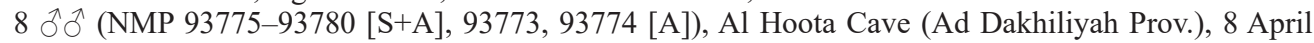
2011, leg. P. Benda, A. ReITER \& M. Uhrin;

2 우 (NMP 92761, 92762 [S+A]), Al Mintirib, fortress (Ash Sharqiyah Ash Shamal Prov.), 1 November 2009, leg. P. Benda, A. Reiter \& M. Uhrin; 
1 ठิ (NMP 94007 [S+A]), Mudhai, small oasis (Dhofar Prov.), 25 March 2012, leg. P. Benda, A. Reiter \& M. Uhrin;

4 ภิ $\widehat{~(N M P ~ 92770-92772 ~[S+A], ~} 92773$ [A]), Muqal, Muqal Cave (Ash Sharqiyah Ash Shamal Prov.), 1 November 2009, leg. P. Benda, A. Reiter \& M. Uhrin;

1 ㅇ (NMP 93995 [S+A]), Sal Alah, Birkat Khaldiyah, cistern (Musandam Prov.), 13 March 2012, leg. P. BENDA, A. REITER \& M. Uhrin;

1 ㅇ (NMP 94004 [S+A]), Sal Alah, Birkat Khaldiyah, cistern (Musandam Prov.), 18 March 2012, leg. P. BENDA, A. REITER \& M. UHRIN;

5 ๙ิ่ (NMP 93748-93751 [S+A], 93752 [A]), Sawt, cave (Ash Sharqiyah Ash Shamal Prov.), 6 April 2011, leg. P. BENDA, A. ReITER \& M. UHRIN;

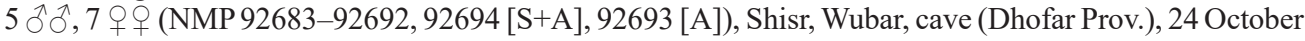
2009, leg. P. Benda, A. ReITER \& M. Uhrin;

1 ô, 1 ㅇ (NMP 93796, 93797 [S+A]), Tanuf, Ain Ghubrat Cave (Ad Dakhiliyah Prov.), 10 April 2011, leg. P. BENDA, A. Reiter \& M. Uhrin.

\section{Egypt:}

8 속, 2 우 오 (NMP 92585-92591 [S+A], 92592-92594 [A]), Aswan, tunnel under railway (Aswan Gov.), 24 January 2010, leg. P. BENDA, I. HORÁČEK \& R. LUČAN;

2 §o (NMP 94987, 94990 [S+A]), Aswan, tunnel under railway (Aswan Gov.), 10 January 2011, leg. R. LUČAN;

1 우 (NMP 94983 [S+A]), Dakhla Oasis, El Qasr (E1 Wadi El Jadid Gov.), 31 March 2011, leg. R. LUČAN;

1 ô, 1 ㅇ (NMP 94978, 94979 [S+A]), Dakhla Oasis, Er Rashda (El Wadi El Jadid Gov.), 10 October 2011, leg. R. LUČAN;

4 우 (NMP 90351, 90352, 90354 [S+A], 90353 [A]), Siwa Oasis, Old Shaly (Matruh Gov.), 12 April 2002, leg. P. Munclinger \& P. Nová.

\section{Libya:}

1 o (NMP 48317 [S+A]), Ghat (Ghat Prov.), 3 October 1999, leg. P. Benda.

\section{Morocco:}

3 우 우 (NMP 94441-94443 [S+A]), Tassetift, palm grove (Drâa-Tafilalet Reg.), 22 April 2008, leg. P. BENDA, J. ČervenÝ, A. KoneČnÝ \& P. VAllo.

\section{Mauritania:}

1 ऽิ (NMP 93647 [S+A]), Terjit, oasis (Adrar Reg.), 21 October 2010, leg. P. BendA, A. ReITER \& M. Uhrin;

7 우 우 (NMP 93639-93641, 93643-93645 [S+A], 93642 [A]), Tin Labbé, Akhnik Akhmoudi Cave (Adrar Reg.), 19 October 2010, leg. P. BEndA, A. Reiter \& M. Uhrin.

\section{Sudan:}

1 o (NMP 93680 [S+A]), Bayudah Desert (Wadi Barkol), $8 \mathrm{~km} \mathrm{~W}$ of Masoud (Nahr En Nil State), 13 December 2010, leg. P. BENDA \& J. ŠmíD;

4 ภิ ô (NMP 93664-93666 [S+A], 93667 [A]), Dungulah El Ajuz (Old Dongola), tombs (Esh Shimaliya State), 7 December 2010, leg. P. Benda \& J. ŠmíD;

7 우 (우 (NMP 90344-90350 [S+A]), Jebel El Azraq, cave (Khartoum State), 18 February 1966, leg. P. ŠTYS;

3 ふึત, 4 우 (NMP 93651-93653, 93655-93657 [S+A], 93654 [A]), Karima, Jebel Barkal, cave (Esh Shimaliya State), 6 December 2010, leg. P. BENDA \& J. ŠmíD;

1 ภิ, 2 우 (NMP 93670, 93671 [S+A], 93672 [A]), Kuikkah, tomb (Esh Shimaliya State), 9 December 2010, leg. P. BENDA \& J. ŠMÍD.

ReFERENCES. BENDA (2001), Benda et al. (2006a, 2008, 2010a, 2011b, 2012, 2014a, b, 2017, 2019a), Benda \& VAllo (2009), Agnarsson et al. (2011), VAllo et al. (2011), ŽĎÁrsKá (2013), Yu et al. (2014), BraY \& Benda (2016), KarmáčKová (2017), Benda \& Ševčí́ (2020), MehdizadeH et al. (2020), PatTerson et al. (2020), BAGHERFARD et al. (2021). 


\section{Asellia italosomalica De Beaux, 1931}

MATERIAL (10). Yemen:

3 đึ đૈ (NMP 90590, 90592 [S+A], 90591 [A]), Socotra Is., Mazaaba, Wadi Darho (Suqutra Gov.), 14 May 2004, leg. P. BENDA \& A. REITER;

6 우 (NMP 90571-90575 [S+A], 90570 [A]), Socotra Is., Kam (Suqutra Gov.), 5 May 2004, leg. P. BENDA \& A. REITER;

$1 \lesssim$ (NMP 90579 [S+A]), Socotra Is., Suq (Suqutra Gov.), 7 May 2004, leg. P. Benda \& A. Reiter.

References. Benda et al. (2006b, 2011b, 2017), Bray \& Benda (2016), Amador et al. (2018), Patterson et al. (2020).

\section{Asellia arabica Benda, Vallo et Reiter, 2011}

MATERIAL (23). Oman:

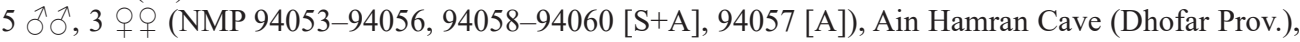
28 March 2012, leg. P. Benda, A. Reiter \& M. Uhrin;

2 ㅊํ, 2 우우 (NMP 92721-92724 [S+A]), Ain Jarziz, cave (Dhofar Prov.), 27 October 2009, leg. P. BENDA, A. REITER \& M. UHRIN;

1 o (NMP 92753 [A]), Ain Tabruq, cave (Dhofar Prov.), 29 October 2009, leg. P. Benda, A. Reiter \& M. UHRIN.

\section{Yemen:}

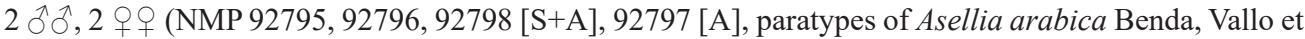
Reiter, 2011), Damqawt, cave (Al Mahra Gov.), 16 October 2005, leg. P. BENDA;

4 ふึ่, 2 우 (NMP 92790 [S+A], holotype of Asellia arabica Benda, Vallo et Reiter, 2011; NMP 9279192794 [S+A], 92789 [A], paratypes of A. arabica Benda, Vallo et Reiter, 2011), Hawf, gardens, pool (Al Mahra Gov.), 14-15 October 2005, leg. P. BendA.

References. Benda et al. (2011b, 2017), ŽĎÁRská (2013), Baldwin (2015), Bray \& Benda (2016), KARMÁČKOVÁ (2017), PATtERSON et al. (2020).

Rhinonycterida e

\section{Triaenops persicus Dobson, 1871}

Material (37). Oman:

1 ภ, 3 웅 (NMP 92717-92719 [S+A], 92720 [A]), Ain Jarziz, cave (Dhofar Prov.), 27 October 2009, leg. P. BENDA, A. ReITER \& M. Uhrin;

1 ภ, 1 ㅇ (NMP 92703 [S+A], 92704 [A]), Hagarir, haunt (Dhofar Prov.), 25 October 2009, leg. P. BENDA, A. REITER \& M. UHRIN;

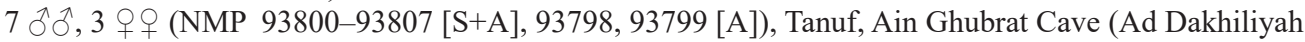
Prov.), 10 April 2011, leg. P. Benda, A. Reiter \& M. Uhrin;

$4 \widehat{\partial} \widehat{\jmath}$ (NMP 92758-92760 [S+A], 92757 [A]), Taiq Cave (Dhofar Prov.), 30 October 2009, leg. P. BeNDA, A. REITER \& M. UHRIN;

1 đ (NMP 94065 [S+A]), Wadi Hannah, pool (Dhofar Prov.), 30 March 2012, leg. P. BendA, A. Reiter \& M. Uhrin.

\section{Yemen:}

1 ઈิ (NMP 92279 [S+A]), Al Mawqir, Wadi Zabid, stream (Al Hudaydah Prov.), 30 October 2007, leg. P. BENDA \& A. REITER; 
1 ô, 1 (NMP 92271, 92273 [S+A]), Damqawt, cave (Al Mahra Gov.), 16 October 2005, leg. P. BENDA;

3 ổ (NMP 92253, 92254 [S+A], 92255 [A]), Hawf, at border check-point, pool (Al Mahra Gov.), 12 October 2005, leg. P. BENDA;

5 ふ઼๊, 1 q (NMP 92257, 92258, 92260-92262 [S+A], 92263 [A]), Hawf, gardens, pool (Al Mahra Gov.), 14 October 2005, leg. P. BeNDA;

1 오 (NMP 92277 [A]), Kadamat Al 'Abdali, Wadi Tuban (Lahj Gov.), 24 October 2007, leg. P. Benda \& A. REITER;

1 ㅇ (NMP 92278 [A]), Qaryat Al Hasib, Wadi Zabid, channel (Al Hudaydah Gov.), 29 October 2007, leg. P. BENDA \& A. ReITER;

1 ô, 1 우 (NMP 92275, 92276 [S+A]), Riqab, Jebel Bura Mts., pool (Al Hudaydah Gov.), 30 October 2005, leg. P. BENDA.

References. Vallo (2008), Benda \& Vallo (2009), Agnarsson et al. (2011), Monadjem et al. (2013), ŽĎÁRSKÁ (2013), Yu et al. (2014), BOLDWIN (2015), KARMÁČKOvá (2017), RosSONI et al. (2021).

\section{Triaenops parvus Benda et Vallo, 2009}

MATERial (13). Oman:

1 ภ (NMP 92705 [S+A]), Hagarir, haunt (Dhofar Prov.), 25 October 2009, leg. P. Benda, A. Reiter \& M. UHRIN;

1 (NMP 97064 [S+A]), Raysut, Wadi Shaith, pools (Dhofar Prov.), 23 October 2019, leg. P. Benda, J. HÁJEK \& A. REITER.

\section{Yemen:}

1 ภิ (NMP 92272 [S+A]), Damqawt, cave (Al Mahra Gov.), 16 October 2005, leg. P. BendA;

1 o (NMP 92256 [S+A]), Hawf, at border check-point, pool (Al Mahra Gov.), 12 October 2005, leg. P. BENDA;

3 đิ ô, 4 우 (NMP 92259, 92264-92267, 92269 [S+A], 92268 [A], paratypes of Triaenops parvus Benda et Vallo, 2009), Hawf, gardens, pool (Al Mahra Gov.), 14 October 2005, leg. P. BendA;

1 (NMP 92270 [S+A], holotype of Triaenops parvus Benda et Vallo, 2009), Hawf, gardens, pool (Al Mahra Gov.), 15 October 2005, leg. P. BENDA;

$1 \hat{\sigma}$ (NMP 92274 [S+A]), 25 km WSW of Sayhut, well (Al Mahra Gov.), 17 October 2005, leg. P. BENDA.

References. Vallo (2008), Benda \& Vallo (2009), Agnarsson et al. (2011), MlíkovskÝ et al. (2011b), ŽĎÁRSKÁ (2013), KARMÁČKOVÁ (2017), RosSONI et al. (2021).

\section{Triaenops afer Peters, 1876}

MATERIAL (15). Ethiopia:

1 ô (NMP 95925 [S+A]), Alatish National Park, Megenagna (Amhara Reg.), 8 November 2012, leg. P. BENDA;

1 ภ, 3 우우 (NMP 92150-92152 [S+A], 92153 [A]), Sof Omar Caves (Oromiya Reg.), 2 May 2003, leg. P. BENDA \& J. OBUCH.

6 ふึ่̂, 2 우우 (NMP 92161, 92163-92167 [S+A], 92160, 92162 [A]), Sof Omar Caves (Oromiya Reg.), 3 May 2003, leg. P. Benda \& J. ОвUCh.

References. Vallo (2008), Benda \& Vallo (2009), Agnarsson et al. (2011), Kassahun Aysheshm et al. (2015), KrusKop et al. (2016), AmAdor et al. (2018), JofFrin (2019), LiANG et al. (2021), Rossoni et al. (2021). 
Me ga dermatid a e

\section{Cardioderma cor (Peters, 1872)}

MATERIAl (9). Ethiopia:

1 (NMP 92110 [S+A]), Awash National Park, Gotu Area (Afar Reg.), 28 April 2003, leg. P. BendA \& J. ОвUсн;

$2 \widehat{\partial} \widehat{\partial}, 3$ 우 (NMP 95008-95012 [S+A]), Mago National Park, headquarters (Southern Nations, Nationalities and Peoples Reg.), 14 November 2012, leg. J. Bryja, P. KaŇUCh, R. Šumbera \& Yonas Meheretu;

1 ô, 2 우 (NMP 96896, 96897 [S+A], 96898 [A]), Mille, 10 km south-west, bridge (Afar Reg.), 28 September 2019, leg. P. BENDA \& J. BRYJA.

References. Kalúz \& ŠEvČík (2015), KaňUch et al. (2015), Kassahun Aysheshm et al. (2015).

Acknow ledgements

The preparation of this cataloue was supported by the project by Synthesys ${ }^{+}$Virtual Access (\# Covid-19 Chiropteran Knowledge Base). The author as a curator of the NMP collection of mammals is obliged to all collectors who provided the specimens or helped in the collection of specimens that enriched the collection and are presented here.

\section{REFERENCES}

Agnarsson I., Zambrana-Torrelio C. M., Flores-Saldana N. P. \& May-Collado L. J., 2011: A time-calibrated species-level phylogeny of bats (Chiroptera, Mammalia). Public Library of Science Currents, 2011(3: 1212): 1-27.

Akmali V., Farazmand A., Darvish J. \& Sharifi M., 2011: Phylogeography and taxonomic status of the greater mouse-tailed bat Rhinopoma microphyllum (Chiroptera: Rhinopomatidae) in Iran. Acta Chiropterologica, 13: 279-290.

Amador L. I., Moyers Arévalo R. L., Almeida F. C., Catalano S. A. \& Giannini N. P., 2018: Bat systematics in the light of unconstrained analyses of a comprehensive molecular supermatrix. Journal of Mammalian Evolution, 25: 37-70.

ANDĚRA M., 1987: Materiály z mammaliologického referátu zoologického oddělení Národního muzea v Praze. - III. Savci z území Prahy a okolí [Materials of the mammalogical section of the Department of Zoology of the National Museum in Prague. - III. Mammals of the territory of Prague and surroundings]. Lynx, n. s., 23: 113-119 (in Czech, with a summary in English).

Bagherfard S., Najafi N., Gharzi A. \& Akmali V., 2021: Lack of intraspecific variations of the mitochondrial cytochrome $\mathrm{b}$ gene in the greater mouse-tailed bat Rhinopoma microphyllum (Chiroptera: Rhinopomatidae) in Iran. Genetica, 149: 37-45.

Baldwin H. J., 2015: Epidemiology and Ecology of Virus and Host: Bats and Coronaviruses in Ghana, West Africa. Unpubl. PhD Thesis. Macquarie Univeristy \& Ulm University, Sydney \& Ulm, xiv+191 pp.

Baldwin H., Vallo P., Gardner M., Drosten C., TschapKa M. \& Stow A., 2014: Isolation and characterization of 11 novel microsatellite loci in a West African leaf-nosed bat, Hipposideros aff. ruber. BioMedCentral Research Notes, 7(1): 607-610.

Baldwin H. J., Vallo P., Ruiz A. T., Anti P., Nkrumah E. E., Badu E. K., Oppong S. K., Kalko E. K. V., Tschapka M. \& Stow A. J., 2021: Concordant patterns of genetic, acoustic, and morphological divergence in the West African Old World leaf-nosed bats of the Hipposideros caffer complex. Journal of Zoological Systematics and Evolutionary Research, 59: 1390-1407.

BARUš V. \& TENORA F., 1970: Further discoveries of nematodes in the bats of Afghanistan. Sbornik Vysoké Školy Zemédělské v Brně (̌̌ada A), Spisy Fakulty Agronomické, 18: 133-141. 
BEJČEK V., PrAŽAN B. \& ŠŤASTnÝ K., 2001: Socotra 2000. Tvorba ekologické sitě a agrolesnická výchovná a kulturní východiska trvale udržitelného rozvoje ostrova Socotra. II. Tvorba ekologické sitè-faunistické zmapováni biotopů. III. Kulturní a výchovná východiska. Přiloha k závěrečné zprávě [Socotra 2000. II. Creation of an Ecological Network and Agroforestry Educational and Cultural Resources of a Sustainable Development of the Island of Socotra. III. Cultural and Educational Resources. Annex to the Final Report]. Unpubl. Report. FOA - Foundation for Ecological Agriculture, Praha, $141 \mathrm{pp}$.

Benda P., 2001: Poznámky k biogeografii a systematice eurasijských netopýru (Chiroptera) [Notes on Biogeography and Systematics of the Euro-Asian Bats (Chiroptera)]. Unpubl. PhD Thesis. Katedra zoologie, Př́rodovědecká fakulta University Karlovy, Praha, 354 pp (in Czech).

Benda P. \& Gaisler J., 2015: Bats (Mammalia: Chiroptera) of the Eastern Mediterranean and Middle East. Part 12. Bat fauna of Afghanistan: revision of distribution and taxonomy. Acta Societatis Zoologicae Bohemicae, 79: 267-458.

BENDA P. \& HoRÁČEK I., 1998: Bats (Mammalia: Chiroptera) of the Eastern Mediterranean. Part 1. Review of distribution and taxonomy of bats in Turkey. Acta Societatis Zoologicae Bohemicae, 62: 255-313.

BENDA P. \& SÁDloví J., 1999: New records of small mammals (Insectivora, Chiroptera, Rodentia, Hyracoidea) from Jordan. Časopis Národního Muzea, Řada Přirodovědná, 168: 25-36.

Benda P. \& ŠEvČíK M., 2020: Bats (Mammalia: Chiroptera) of the Eastern Mediterranean and Middle East. Part 16. Review of the distribution and taxonomy of bats in Egypt. Acta Societatis Zoologicae Bohemicae, 84: 115-279.

Benda P. \& Uhrin M., 2017: First records of bats from four Dodecanese islands, Greece (Chiroptera). Lynx, n. s., 48: 15-38.

Benda P. \& Vallo P., 2009: Taxonomic revision of the genus Triaenops (Chiroptera: Hipposideridae) with description of a new species from southern Arabia and definitions of a new genus and tribe. Folia Zoologica, 53 (Monograph 1): 1-45.

Benda P. \& VAllo P., 2012: New look on the geographical variation in Rhinolophus clivosus with description of a new horseshoe bat species from Cyrenaica, Libya. Vespertilio, 16: 69-96.

Benda P., Ivanova T., Horáček I., Hanák V., Červený J., Gaisler J., Gueorguieva A., Petrov B. \& Vohralík V., 2003: Bats (Mammalia: Chiroptera) of the Eastern Mediterranean. Part 3. Review of bat distribution in Bulgaria. Acta Societatis Zoologicae Bohemicae, 67: 245-357.

Benda P., Hanák V., Andreas M., Reiter A. \& Uhrin M., 2004a: Two new species of bats (Chiroptera) for the fauna of Libya: Rhinopoma hardwickii and Pipistrellus rueppellii. Myotis, 41-42: 109-124.

Benda P., Ruedi M. \& Aulagnier S., 2004b: New data on the distribution of bats (Chiroptera) in Morocco. Vespertilio, 8: 13-44.

Benda P., Andreas M., Kock D., LuČan R., Munclinger P., Nová P., Obuch J., Ochman K., Reiter A., Uhrin M. \& Weinfurtoví D., 2006a: Bats (Mammalia: Chiroptera) of the Eastern Mediterranean. Part 4. Bat fauna of Syria: distribution, systematics, ecology. Acta Societatis Zoologicae Bohemicae, 70: 1-329.

Benda P., Reiter A. \& Al-Jumaily M. M., 2006b: Bats of Socotra. P.: 139. In: Cheung C., DeVantier L. \& Van Damme K. (eds.): Socotra. A Natural History of the Islands and their People. Odyssey Books \& Guides, Hong Kong, [xiv]+393 pp.

Benda P., Hanák V., Horáček I., Hulva P., LuČan R. \& Ruedi M., 2007: Bats (Mammalia: Chiroptera) of the Eastern Mediterranean. Part 5. Bat fauna of Cyprus: review of records with confirmation of six species new for the island and description of a new subspecies. Acta Societatis Zoologicae Bohemicae, 71: 71-130.

Benda P., Dietz C., Andreas M., Hotový J., LuČan R. K., Maltby A., Meakin K., Truscott J. \& Vallo P., 2008: Bats (Mammalia: Chiroptera) of the Eastern Mediterranean and Middle East. Part 6. Bats of Sinai (Egypt) with some taxonomic, ecological and echolocation data on that fauna. Acta Societatis Zoologicae Bohemicae, 72: 1-103.

Benda P., Georgiakakis P., Dietz C., Hanák V., Galanaki K., Markantonatou V., Chudárková A., Hulva P. \& HorÁČEK I., 2009a: Bats (Mammalia: Chiroptera) of the Eastern Mediterranean and Middle East. Part 7. The bat fauna of Crete, Greece. Acta Societatis Zoologicae Bohemicae, 72: 105-190. 
Benda P., Reiter A., Al-Jumaily M., Nasher A. K. \& Hulva P., 2009b: A new species of mouse-tailed bat (Chiroptera: Rhinopomatidae: Rhinopoma) from Yemen. Journal of the National Museum (Prague), Natural History Series, 177: 53-68.

Benda P., ČervvenÝ J., KoneČnÝ A., Reiter A., Ševčík M., Uhrin M. \& Vallo P., 2010a: Some new records of bats from Morocco (Chiroptera). Lynx, n. s., 41: 151-166.

Benda P., Lučan R. K., Obuch J., Reiter A., Andreas M., BačKor P., Bohnenstengel T., Eid E. K., ŠEvČíK M., Vallo P. \& Amr Z. S., 2010b: Bats (Mammalia: Chiroptera) of the Eastern Mediterranean and Middle East. Part 8. Bats of Jordan: fauna, ecology, echolocation, ectoparasites. Acta Societatis Zoologicae Bohemicae, 74: 185-353.

Benda P., Hanák V. \& Č́ervenÝ J., 2011a: Bats (Mammalia: Chiroptera) of the Eastern Mediterranean and the Middle East. Part 9. Bats from Transcaucasia and West Turkestan in collection of the National Museum, Prague. Acta Societatis Zoologicae Bohemicae, 75: 159-222.

Benda P., Vallo P. \& Reiter A., 2011b: Taxonomic revision of the genus Asellia (Chiroptera: Hipposideridae) with a description of a new species from southern Arabia. Acta Chiropterologica, 13: 245-270.

Benda P., Faizolâhi K., Andreas M., Obuch J., Reiter A., Ševčí́ M., Uhrin M., Vallo P. \& Ashrafi S., 2012: Bats (Mammalia: Chiroptera) of the Eastern Mediterranean and Middle East. Part 10. Bat fauna of Iran. Acta Societatis Zoologicae Bohemicae, 76: 163-582.

Benda P., LuČAn R. K., Shohdi W. M., Porteš M. \& HoráčEK I., 2014a: Microbats of the Western Oases of Egypt, Libyan Desert. Vespertilio, 17: 45-58.

Benda P., Spitzenberger F., HanÁk V., Andreas M., Reiter A., Ševčík M., Šmíd J. \& Uhrin M., 2014b: Bats (Mammalia: Chiroptera) of the Eastern Mediterranean and Middle East. Part 11. On the bat fauna of Libya II. Acta Societatis Zoologicae Bohemicae, 78: 1-162.

Benda P., Abi Said M. R., Bou Jaoude I., Karanouh R., Lučan R. K., Sadek R., Ševčík M., Uhrin M. \& HoréČEK I., 2016a: Bats (Mammalia: Chiroptera) of the Eastern Mediterranean and Middle East. Part 13. Review of distribution and ectoparasites of bats in Lebanon. Acta Societatis Zoologicae Bohemicae, 80: 207-316.

Benda P., Kruskop S. V. \& HoráČEK I., 2016b: On the occurrence of Rhinolophus lepidus in West Turkestan: data from the Zoological Museum of the Moscow State University. Vespertilio, 18: 11-21.

Benda P., Nasher A. K., Van Damme K., Vallo P. \& Reiter A., 2017: Bats (Mammalia: Chiroptera) of the Eastern Mediterranean and Middle East. Part 14. Bats of the Socotra Archipelago, Yemen. Acta Societatis Zoologicae Bohemicae, 81: 99-169.

Benda P., Satterfield L., Gücel S., HoráčEK I., LuČan R., Charalambidou I. \& Uhrin M., 2018: Distribution of bats in Northern Cyprus (Chiroptera). Lynx, n. s., 49: 91-138.

Benda P., Kasso M., Nicolas V., Pleurdeau D., Stoetzel E., Workalemahu S., Bekele A. \& Denys C., 2019a: New data on bats from Dire Dawa region, eastern Ethiopia, with the first record of Rhinopoma microphyllum in the country. Journal of Natural History, 53: 2579-2591.

Benda P., Ševčík M., Bego F., Sachanowicz K., Spitzenberger F., Tájek P., Tájková P. \& Uhrin M., 2019b: Bats (Mammalia: Chiroptera) of the Eastern Mediterranean and Middle East. Part 15. The fauna of bats and bat ectoparasites of Albania with a catalogue of bats from the western Balkans in the collection of the National Museum, Prague. Acta Societatis Zoologicae Bohemicae, 83: 1-238.

Boye P., 1983: German Ornithological Research Trip 1983 to the Hashemite Kingdom of Jordan. Unpubl. Report. Bonn.

Bray T. C. \& Benda P., 2016: Distribution of Asellia tridens (Chiroptera: Hipposideridae) lineages including representatives from Saudi Arabia. Zoology in the Middle East, 62: 283-287.

ČERVENÝ J., 1982: Notes on the bat fauna (Chiroptera) of Roumanian Dobrogea. Nyctalus (N. F.), 1(4-5): 349-357.

ČERVENÝ J. \& KryštufeK B., 1988: A contribution to the knowledge of the bats of Central and Southern Dalmatia, Yugoslavia (Chiroptera, Mammalia). Biološki Vestnik, 36: 17-30.

Demos T. C., Webala P. W., Goodman S. M., Kerbis Peterhans J. C., Bartonjo M. \& Patterson B. D., 2019: Molecular phylogenetics of the African horseshoe bats (Chiroptera: Rhinolophidae): expanded geographic and taxonomic sampling of the Afrotropics. BioMedCentral Evolutionary Biology, 19(166): 1-14. 
Disi A. M. \& Hatough-Bouran A., 1999: Biodiversity of the terrestrial vertebrate fauna of Petra (Jordan). Časopis Národního Muzea, Řada Př́rodovédná, 168: 83-98.

Dool S. E., Puechmaille S. J., Dietz C., Juste J., Ibáñez C., Hulva P., Roué S. G., Petit E. J., Jones G., Russo D., Toffoli R., Viglino A., Martinoli A., Rossiter S. J. \& Teeling E. C., 2013: Phylogeography and postglacial recolonization of Europe by Rhinolophus hipposideros: evidence from multiple genetic markers. Molecular Ecology, 22: 4055-4070.

Dool S. E., Puechmaille S. J., Foley N. M., Allegrini B., Bastian A., Mutumi G. L., Maluleke T. G., OdendaAl L. J., Teeling E. C. \& JACOBS D. S., 2016: Nuclear introns outperform mitochondrial DNA in inter-specific phylogenetic reconstruction: Lessons from horseshoe bats (Rhinolophidae: Chiroptera). Molecular Phylogenetics and Evolution, 97: 196-212.

DusbábeK F., 1964: Contribution a la connaisance des acariens (Acarina) parasites des chiroptères de Bulgarie. Acarologia, 6: 5-25.

DusBábeK F., 1970: Mite parasites (Acarina) of bats from Afghanistan. Folia Parasitologica, 17: 61-76.

Felten H., Spitzenberger F. \& Storch G., 1977: Zur Kleinsäugerfauna West-Anatoliens. Teil IIIa. Senckenbergiana Biologica, 58: 1-44.

Flanders J., Jones G., Benda P., Dietz C., Zhang S., Li G., Sharifi M. \& Rossiter S. J., 2009: Phylogeography of the greater horseshoe bat, Rhinolophus ferrumequinum: contrasting results from mitochondrial and microsatellite data. Molecular Ecology, 18: 306-318.

Flanders J., Wei L., Rossiter S. J. \& Zhang S., 2011: Identifying the effects of the Pleistocene on the greater horseshoe bat, Rhinolophus ferrumequinum, in East Asia using ecological niche modelling and phylogenetic analyses. Journal of Biogeography, 38: 439-452.

Frič A., 1864: Cesta do Chorvatska, Dalmacie a na Černou Horu vykonaná na jaře r. 1856 [A trip to Croatia, Dalmatia, and Montenegro made in spring 1856]. Živa, Časopis Př́rodnický, 12: 289-308 (in Czech).

GAISLER J., 1956: Faunistický přehled československých netopýrů (Zpracováno na základě sbírek Národního musea v Praze) [Faunistic review of the Czechoslovakian bats (adapted from collections of the National Museum in Prague]. Ochrana Přirody, 11(6): 161-169 (in Czech, with summaries in Russian and German).

GAISLER J., 1970: The bats (Chiroptera) collected in Afghanistan by the Czechoslovak Expeditions of 19651967. Acta Scientiarum Naturalium Academiae Scientiarum Bohemoslovacae Brno, n. s., 4(6): 1-56.

Gaisler J., HanaK V. \& HoraceK I., 1978: Present status of bat research in Czechoslovakia. Bat Research News, 19(2): 37-46.

Granjon L. \& Birnbaum P., 2010: Forets de faillets et forets galeries au sud du Mali: deux voies pour la perennite des refuges guineens en zone soudanienne. Programme Ecosystèmes Tropicaux. Rapport de fin de contrat. Institut de recherche pour le développement, Ministére de l'Écologie, de l'Énergie, de Dévelopement durable et de la Mer, La recherche agronomique pour la dévelopement, Dakar \& Montpelier, 109 pp.

Groschaft J. \& Tenora F., 1973: Trematodes of the genus Plagiorchis Lühe, 1899 (Plagiorchidae), parasites of bats in Afghanistan. Věstník Československé Společnosti Zoologické, 37: 241-249.

Groschaft J. \& Tenora F., 1974: Some remarks on the morphological variability of the species Plagiorchis vespertilionis (Müller, 1780) and Plagiorchis koreanus Ogata, 1938 (Trematoda, Plagiorchidae) parasitizing bats. Sborník Vysoké Školy Zemédělské v Brně (̌̌ada A), Spisy Fakulty Agronomické, 22: $115-130$.

HaNÁK V., 1964: Zur Kenntnis der Fledermausfauna Albaniens. Věstník Československé Společnosti Zoologické, 28: 68-88.

HaNÁK V., 1969: Zur Kenntnis von Rhinolophus bocharicus Kastchenko et Akimov, 1917 (Mammalia: Chiroptera). Věstnik Československé Společnosti Zoologické, 33: 315-327.

HANÁK V. \& Elgadi A., 1984: On the bat fauna (Chiroptera) of Libya. Věstník Československé Společnosti Zoologické, 48: 165-187.

HANÁK V. \& Josifov M., 1959: Zur Verbreitung der Fledermäuse Bulgariens. Säugetierkundliche Mitteilungen, 7: 145-151. 
Hanak V., Lamani F. \& Muraj X., 1961: Të dhëna nga përhapja e lakuriqëve të natës (Ordo Chiroptera) në Shqipëri [On the distribution of bats (ordo Chiroptera) in Albania]. Buletin i Universitetit Shtetëror të Tiranës, Seria Shkencat Natyrore, 3: 124-158 (in Albanian, with a summary in English).

Hanák V., Benda P., Ruedi M., Horáčex I. \& Sofianidou T. S., 2001: Bats (Mammalia: Chiroptera) of the Eastern Mediterranean. Part 2. New records and review of distribution of bats in Greece. Acta Societatis Zoologicae Bohemicae, 65: 279-346.

HeráŇ I., 1966: Preparáty vzácnějších druhů savců ve výstavních sbírkách Národního muzea v Praze [Preparations of rare species of mammals in the permanent exhibition of the National Museum in Prague]. Lynx, n. s., 7: 20-22 (in Czech, with a summary in German).

HeráŇ I., 1968a: Savci. Katalog k exposici zoologického oddělení Národního muzea v Praze [Mammals. Catalogue of the Permanent Exhibition of the Department of Zoology of the National Museum in Prague]. Národní muzeum, Praha, 56 pp (in Czech, with summaries in English and German).

HeráŇ I., 1968b: Katalog k expozici koster savců [Catalogue of the Permanent Exhibition of the Mammal Skeletons]. Národní muzeum, Praha, 67 pp (in Czech, with summaries in English and German).

HerÁŇ I., 1988: Materiály ze zoologického oddělení Národního muzea v Praze. - IV. Kostry jedinců blízkých horní věkové hranici druhu: Carnivora [Materials of the Department of Zoology of the National Museum in Prague. - IV. Skeletons of individuals close to the upper margin of age of the species: Carnivora]. Lynx, n. s., 24: 87-92 (in Czech, with a summary in English).

HerÁŇ I. \& MAZÁK V., 1976: Materiály z mammalogického referátu zoologického oddělení Národního muzea v Praze. - II. Barevné anomalie [Materials of the mammalogical section of the Department of Zoology of the National Museum in Prague. - II. Colouration anomalies]. Lynx, n. s., 18: 109-112 (in Czech, with a summary in English).

HeráŇ I., Hora J. \& Moravec J., 1992: Materiály obratlovců z pražské zoo, uložené ve sbírkách Národního muzea [Materials of vertebrates from the Prague Zoo deposited in the collection of the National Museum, Prague]. Gazella, 19: 119-130 (in Czech, with a summary in English).

Hermida R. J. Escudero B., García-Mudarra J. L., Juste J. \& Muñoz-Fontela C., 2018: Contribution to the knowledge of Guinean bat fauna. P.: 66. In: ANONyMOUs (ed.): 7th SECEMU Conference. SECEMU Gibraltar 2018. Programme \& Abstracts. Gibraltar National Museum, Gibraltar, 70 pp.

HoRÁČEK I., 1984: Remarks on the causality of population decline in European bats. Myotis, 21-22: $138-147$.

HoRÁČEK I. \& Zima J., 1996: Evolutionary divergence in the lesser horseshoe bat. P.: 26. In: LiNA P. \& SMEEnk C. (eds.): VIIth European Bat Research Symposium. 12-16 August 1996, Veldhoven, The Netherlands. Programme, Abstracts, List of Participants. Bat Research Agency, Veldhoven, [ix]+112 pp.

HoráčeK I., ČervenÝ J., TAUŠL A. \& VÍTeK D., 1971: Prinos kăm izsledvaneto na drebnite bozajnici ot Rodopite [Contribution to the research of small mammals of the Rhodopes Mts.]. Rodopski Pešternjak, 7(54): 40-44 (in Bulgarian).

HoRÁČEK I., ČERVENÝ J., TAUŠL A. \& VíteK D., 1974: Notes on the mammal fauna of Bulgaria (Insectivora, Chiroptera, Rodentia). Věstnik Československé Společnosti Zoologické, 38: 19-31.

Horáček I., Benda P., Sadek R., Karkabi S., Abi-Said M., Lučan R., Hulva P. \& Karanouh R., 2008: Bats of Lebanon. State of knowledge and perspectives. Al-Ouat'Ouate, Revue Libanaise de Speleologie et de Karstologie, n. s., 14: 52-67.

Horáček I., Benda P., SAdek R., Karkabi S., Abi-Said M., LuČan R., Uhrin M., Bou Jaoude I., KaRANOUH R. \& AKIL S., 2009: Bat census in Lebanese caves in 2008 \& 2009. Al-Ouat'Ouate, Revue Libanaise de Speleologie et de Karstologie, n. s., 15: 70-73.

HošEK J., 1985: Př́spěvek k poznání fauny hlístic (Nematoda) netopýrů (Chiroptera) Palearktické a Indomalajské oblasti [Contribution to the knowledge of the fauna of nematodes (Nematoda) in bats (Chiroptera) of the Palaearctic and Indomalyan Regions]. Unpubl. MSc Thesis. Department of Parasitology, Charles University, Praha (in Czech).

HošEK J. \& HorÁČEK I., 1989: Nematodes parasitizing the Palaearctic bats: host-parasite relations. Pp.: 465-473. In: Hanák V., Horáček I. \& Gaisler J. (eds.): European Bat Research 1987. Charles University Press, Praha, $[\mathrm{xx}]+718 \mathrm{pp}$. 
Hron T., Farkašová H., Gifford R. J., Benda P., Hulva P., Görföl T., PaČEs J. \& Elleder D., 2018: Remnants of an ancient Deltaretrovirus in the genomes of horseshoe bats (Rhinolophidae). Viruses [Basel], 10(4): 185; [1-8].

Hulva P., HoráČEK I. \& Benda P., 2007: Molecules, morphometrics and new fossils provide an integrated view of the evolutionary history of Rhinopomatidae (Mammalia: Chiroptera). BioMedCentral Evolutionary Biology, 7(165): 1-15+1-8.

HŮRKA K., 1958: Beitrag zur Nycteribienfauna Bulgariens (Nycteribiidae, Diptera). Zoologické Listy, 7: $231-234$.

HŮRKA K., 1962: Beitrag zur Nycteribien- und Streblidenfauna Albaniens nebst Bemerkungen zur Fauna von Bulgarien, Ungarn und UdSSR. Časopis Československé Společnosti Entomologické, 59: 156-164.

HŮRKA K., 1963a: Ergebnisse der Albanien-Expedition 1961 des Deutschen Entomologischen Institutes. 8. Beitrag. Diptera: Nycteribiidae und Streblidae. Beiträge zur Entomologie, 13: 59-64.

HŮRKA K., 1963b: Bat fleas (Aphaniptera, Ischnopsyliidae) of Czechoslovakia. II. Subgenus Hexactenopsylla Oud., genus Rhinolophopsylla Oud., subgenus Nycteridopsylla Oud., subgenus Dinycteropsylla Ioff. Acta Universitatis Carolinae - Biologica, 1963(1): 1-73.

HŮRKA K., 1969: Basilia (Basilia) rybini sp. n. and notes on the Nycteribiidae of the Caucasus and Central Asia (Diptera, Pupipara). Acta Entomologica Bohemoslovaca, 66: 387-398.

HŮRKA K., 1970: Systematic, faunal and bionomical notes on the European and Asiatic flea species of the family Ischnopsyllidae (Aphaniptera). Acta Universitatis Carolinae - Biologica, 1969: 11-26.

HŮRKA K., 1982: On the insect bat ectoparasites of coastal Libya (Cimicidae, Nycteribiidae, Streblidae, Ischnopsyllidae). Věstník Československé Společnosti Zoologické, 46: 85-91.

HŮRKa K., 1984a: New taxa and new records of Palearctic Nycteribiidae and Streblidae (Diptera, Pupipara). Acta Societatis Zoologicae Bohemoslovacae, 48: 90-101.

HŮRKA K., 1984b: Notes on the taxonomy and distribution of Ischnopsyllidae (Siphonaptera), with description of a new species from Vietnam. Acta Entomologica Bohemoslovaca, 81: 204-211.

HŮRKA K., 1997: New data on taxonomy and distribution of Palaearctic, Oriental and Neotropical Ischnopsyllidae (Siphonaptera), Nycteribiidae and Streblidae (Diptera). Acta Societatis Zoologicae Bohemicae, 61: 23-33.

HŮRKA K. \& PovolnÝ D., 1968: Faunal and ecological study on the families Nycteribidae and Streblidae (Dipt., Pupipara) of the Nangarhar Province (Eastern Afghanistan). Acta Entomologica Bohemoslovaca, 65: $285-298$.

Jiang T., Wang J., Wu H., Csorba G., Puechmaille S. J., Benda P., Boireau J., Toffoli R., Courtois J.-Y., Nyssen P., Colombo R. \& Feng J., 2019: The patterns and possible causes of global geographical variation in the body size of the greater horseshoe bat (Rhinolophus ferrumequinum). Journal of Biogeography, 46: 2363-2377.

JOFFRIN L., 2019: Écologie et évolution de coronavirus dans les populations de chauves-souris des îles de l'ouest de l'Océan Indien. Unpubl. PhD Thesis. Université de La Réunion, [xiv]+203 pp.

JŮN L., 2013: "Nečekaná" setkání. Národní muzeum a Orient ["Unexpected" encounters. The National Museum and the Orient]. Pp.: 85-119. In: JŮnová Macková A., Navrátilová H., JŮn L., HavlŮjová H., Storchová L. \& Oerter W. B. (eds.): Českoslovenští vědci v Orientu. II. díl [Czechoslovakian Scientists in the Orient. Second Volume]. Scriptorium, Praha, 520 pp (in Czech).

Kafaei S., Sharifi M. \& Akmali V., 2020: Population geentic structure and phylogeography of the small mouse-tailed bat, Rhinopoma muscatellum Thomas, 1903 (Chiroptera: Rhinopomatidae) in Iran inferred from mitochondrial DNA. Acta Chiropterologica, 22: 29-40.

Kalúz S. \& ŠEvČík M., 2014: A new species of the genus Grandjeana (Koçak \& Kemal, 2009) (Acari: Trombiculidae) from Mauritanian bat with a key to species of the genus. International Journal of Acarology, 40: 31-36.

KALÚZ S. \& Š́EvČ́́K M., 2015: A new species of Grandjeana (Acari: Trombiculidae) from heart-nosed bat (Chiroptera: Megadermatidae) in Ethiopia (Africa) with notes to biogeography of this genus. Biologia, Bratislava, 70: 380-385. 
Kaňuch P., Aghoví T., Meheretu Yonas, Šumbera R. \& Bryja J., 2015: New discoveries on the ecology and echolocation of the heart-nosed bat Cardioderma cor with a contribution to the phylogeny of Megadermatidae. African Zoology, 50: 53-57.

KARMÁČKOví V., 2017: Morfologické aspekty loveckých strategii netopýrů západního Palearktu [Morphological Aspects of the Foraging Strategies of Bats of the Western Palaearctic]. Unpubl. MSc Thesis. Univerzita Hradec Králové, Hradec Králové, 156 pp (in Czech, with an abstract in English).

Kassahun Aysheshm, Sádlová J., Benda P., KošŤálová T., Warburg A., Hailu Asrat, Baneth G., Volf P. \& VotÝPKa J., 2015: Natural infection of bats with Leishmania in Ethiopia. Acta Tropica, 150: $166-150$.

Koн H. S., Jo J. E., Он J. G., Kweon G. H., Ahn N. H., Sin W. H. \& Sin D. S., 2014: Little genetic divergence of the greater horseshoe bat Rhinolophus ferrumequinum from far-eastern Asia, with a preliminary report on genetic differentiation of $R$. ferrumequinum from Eurasia and northern Africa examined from cytochrome $b$ sequences. Russian Journal of Theriology, 13: 97-103.

Kruskop S. V., Benda P., Vasenkov D. A. \& Lavrenchenko L. A., 2016: First records of bats from the Alatish National Park, north-western Ethiopia (Chiroptera). Lynx, n. s., 47: 51-69.

KRYŠTUFEK B., 1993: Geographic variation in the greater horseshoe bat Rhinolophus ferrumequinum in south-eastern Europe. Acta Theriologica, 38: 67-79.

KryštufeK B. \& Đulć B., 2001: Rhinolophus blasii Peters, 1866 - Blasius' Hufeisennase. Pp.: 75-90. In: Krapp F. (ed.): Handbuch der Säugetiere Europas. Band 4: Fledertiere. Teil I: Chiroptera I. Rhinolophidae, Vespertilionidae 1. Aula-Verlag, Wiebelsheim, xii+604 pp.

Kryštufek B., Vohralík V., Flousek J. \& Petkovski S., 1992: Bats (Mammalia: Chiroptera) of Macedonia, Yugoslavia. Pp.: 93-111. In: Horáček I. \& Vohralík V. (eds.): Prague Studies in Mammalogy. Charles University Press, Praha, 246 pp.

KuČERA J., 1979: Blood parasites of bats from Bulgaria and Czechoslovakia. Věstník Československé Společnosti Zoologické, 43: 112-123.

Kůs P., 2007: Molekulárně genetická studie vrápenců východniho Středomoři (Chiroptera: Rhinolophidae: Rhinolophus) [Molecular Genetic Study of Horseshoe Bats of the Eastern Mediterranean (Chiroptera: Rhinolophidae: Rhinolophus)]. Unpubl. MSc Thesis. Department of Zoology, Charles University, Praha, $81 \mathrm{pp}$.

LANZA B., 1957: Su alcuni chirotteri della penisola balcanica. Monitore Zoologico Italiano, 65: 3-6.

Levin E., Yom-Tov Y., Barnea A. \& Huchon D., 2008: Genetic diversity and phylogeography of the greater mouse-tailed bat Rhinopoma microphyllum (Brünnich, 1782) in the Levant. Acta Chiropterologica, 10: 207-212.

LiANG J., ZhU C. \& ZhANG L., 2021: Cospeciation of coronavirus and paramyxovirus with their bat hosts in the same geographical areas. BioMedCentral Ecology and Evolution, 21(148): 1-11.

Mamba M. L., Dalton D. L., Mahlaba T. A. M., KropfF A. S. \& Monadjem A., 2021: Small mammals of a West African hotspot, the Ziama-Wonegizi-Wologizi transfrontier forest landscape. Mammalia, 85: $127-144$.

MAzÁK V., 1974: Materiály z mammalogického referátu zoologického oddělení Národního muzea v Praze. - I. Felidae (1) [Materials of the mammalogical section of the Department of Zoology of the National Museum in Prague. - I. Felidae (1)]. Lynx, n. s., 15: 77-78 (in Czech, with a summary in English).

MazÁK V., 1976: Kostra velryby v Národním muzeu v Praze a krátký pohled do světa kytovců [Whale Skeleton in the National Museum in Prague, and a Glimpse into the World of Cetaceans]. Národní muzeum, Praha, 64 pp (in Czech).

Mehdizadeh R., Akmali V. \& Sharifi M., 2020: Population genetic structure and phylogeography of the greater horseshoe bat (Rhinolophus ferrumequinum) along Alborz and Zagros Mts. in Iran. Mitochondrial DNA Part A, 31: 87-97.

Mlíkovský J., Benda P., Moravec J., Robovský J., Šanda R. \& Ekrt B., 2011a: Emil Holub's collection of vertebrates in the National Museum in Prague, Czech Republic. Pp.: 113-159. In: JiRoušKové J., Kandert J., MLíkovský J. \& Š́́mal M. (eds.): Emil Holub's Collection in the National Museum. Editio Monographica Musei Nationalis Pragae Num. 13. National Museum, Prague, 204 pp. 
Mlíkovský J., Benda P., Moravec J. \& ŠAnda R., 2011b: Type specimens of recent vertebrates in the collections of the National Museum, Prague, Czech Republic. Journal of the National Museum (Prague), Natural History Series, 180: 133-164.

Monadjem A., Richards L., Taylor P. J., Denys C., Dower A. \& Stoffberg S., 2013: Diveristy of Hipposideridae in the Mount Nimba massif, West Africa, and the taxonomic status of Hipposideros lamottei. Acta Chiropterologica, 15: 341-352.

Najafi N., Sharifi M. \& Akmali V., 2019: First insights into the population genetic structure and the phylogeographic status of the Mehely's horseshoe bat Rhinolophus mehelyi (Chiroptera: Rhinolophidae) in Iran inferred from mitochondrial genes. Mammalian Biology, 99: 97-108.

Neumanoví K., 1997: A list of the scientifically valuable specimens preserved in the collections of the Zoological Department of the National Museum in Prague - the liquid osteological preparations. Casopis Národního Muzea, Řada Př́rodovédná, 166: 127-136.

OрокU A. B., 2016: Morphological and Genetic Variability in Ghanian Populations of Noack's Leaf-Nosed Bat (Hipposideros aff. ruber) Along a Latitudinal Gradient. Unpubl. MSc Thesis. College of Basic and Applied Sciences, University of Ghana, Accra, xiv +100 pp.

Patrick L. E., McCulloch E. S. \& Ruedas L. A., 2013: Systematics and biogeography of the arcuate horseshoe bat species complex (Chiroptera, Rhinolophidae). Zoologica Scripta, 42: 553-590.

Patterson B. D., Webala P. W., Lavery T. H., Agwanda B. R., Goodman S. M., Kerbis Peterhans J. C. \& Demos T. C., 2020: Evolutionary relationships and population genetics of the Afrotropical leaf-nosed bats (Chiroptera, Hipposideridae). ZooKeys, 929: 117-161.

Presetnik P., Paunović M., KarapandŽa B., Đurović M., Ivanović Č., Ždralević M., Benda P. \& BuDINSKI I., 2014: Distribution of bats (Chiroptera) in Montenegro. Vespertilio, 17: 129-156.

RaHMATULINA I. K., 2005: Rukokrylye Azerbajdžana (fauna, èkologiâ, zoogeografiâ) [Bats of Azerbaijan (Fauna, Ecology, Zoogeography)]. Nacional'naâ Akademiâ Nauk Azerbajdžana, Baku, 480 pp (in Russian, with summaries in English and Azeri).

Rahmatulina I. K. \& Gasanov N. A., 2002: Hiropterofauna Abšeron-Gobustana [Bat fauna of AbšeronGobustan]. Plecotus et al. pars specialis: $92-98$ (in Russian, with a summary in English).

Robovský J. \& Benda P., 2006: Catalogue of the cetaceans (Mammalia: Cetacea) in selected collections of the Czech Republic, with special respect to the collection of the National Museum, Praha. Ćasopis Národního Muzea, Řada Př́rodovédná, 175: 127-156.

Robovský J., Gregoroví R., Hotový J. \& Benda P., 2009: Addendum to the revised catalogue of the cetaceans (Cetacea) in collections in the Czech Republic. Lynx, n. s., 40: 141-152.

RoBOvSKÝ J., ANDĚRA M. \& BENDA P., 2010: Revised catalogue of ceratomorph ungulates in the collection of the National Museum Prague and several other collections in the Czech Republic (Perissodactyla: Rhinocerotidae, Tapiridae). Lynx, n. s., 41: 237-294.

Robovský J., Novotná A., Čulík L., Kưs E. \& Benda P., 2014a: Revised catalogue of wild equids in the collection of the National Museum, Prague, and several other collections in the Czech Republic (Perissodactyla: Equidae). Lynx, n. s., 45: 97-138.

RoBovský J., Novotná A., Voldřichová M., Bušta J., Benda P. \& KŮs E., 2014b: Revised catalogue of the Equidae (Mammalia, Perissodactyla) in the collection of the Hippological Museum, Slatiňany and several other collections of domestic equids in the Czech Republic. Gazella, 41: 99-121.

Robovský J., Sleightholme S. R., Vohralík V. \& Benda P., 2015: Specimens of Thylacinus cynocephalus in collections of the Czech Republic (Mammalia: Thylacinidae). Journal of the National Museum (Prague), Natural History Series, 184: 43-50.

Rossiter S., Benda P., Dietz C., Zhang S. \& Jones G., 2007: Rangewide phylogeography in the greater horseshoe bat inferred from microsatellites: implications for population history, taxonomy and conservation. Molecular Ecology, 16: 4699-4714.

Rossoni D. M., Demos T. C., Goodman S. M., Yego R. K., Mohlman J. L., Webala P. W. \& Patterson B. D., 2021: Genetic, morphological and acoustic differentiation of African trident bats (Rhinonycteridae: Triaenops). Zoological Journal of the Linnean Society, 192: 236-257. 
ŠEvČíK M., Benda P. \& LuČAn R., 2013: Diptera Pupipara from bats of two large eastern Mediterranean islands, Crete and Cyprus. Turkish Journal of Zoology, 37: 31-37.

Soisook P., Prajakjitr A., Karapan S., Francis C. M. \& Bates P. J. J., 2015: A new genus and species of false vampire (Chiroptera: Megadermatidae) from peninsular Thailand. Zootaxa, 3931: 528-550.

ŠŤASTNÝ K., BejČEK V. \& PraŽAn B., 2002: Sokotra - Galapágy Indického oceánu [Socotra - The Galapagos of the Indian Ocean]. Živa, 88: 22-30 (in Czech).

VAllo P., 2008: Molecular Genetic Studies in African Leaf-Nosed Bats (Hipposideridae). Unpubl. PhD Thesis. Faculty of Science, Masaryk University, Brno, 130 pp.

Vallo P., Guillén-Servent A., Benda P., Pires D. B. \& Koubek P., 2008: Variation of mitochondrial DNA in the Hipposideros caffer complex (Chiroptera: Hipposideridae) and its taxonomic implications. Acta Chiropterologica, 10: 193-206.

Vallo P., Benda P., Martínková N., Kañuch P., Kalko E. K. V., ČervenÝ J. \& Koubek P., 2011: Morphologically uniform bats Hipposideros aff. ruber (Hipposideridae) exhibit high mitochondrial genetic diversity in southeastern Senegal. Acta Chiropterologica, 13: 79-88.

Volf J., 2010: Osteological material of the Przewalski's horse (Equus przewalskii Poljakov, 1881) in the National Museum in Prague. Equus, 4: 57-63.

Volf J. \& Benda P., 2021: Jedinci koně Převalského (Equus przewalskii) ve sbírce Národního musea v Praze (Perissodactyla: Equidae) [Specimens of the Przewalski's horse (Equus przewalskii) in the collection of the National Museum, Prague, Czech Republic (Perissodactyla: Equidae)]. Lynx, n. s., 52: 153-156 (in Czech, with an abstract in English).

Wu H., Jiang T., Huang X. \& Feng J., 2018: Patterns of sexual size dimorphism in horseshoe bats: Testing Rensch's rule and potential causes. Scientific Reports, 8(2616): 1-13.

YU W., Wu Y. \& YANG G., 2014: Early diversification trend and Asian origin for extant bat lineages. Journal of Evolutionary Biology, 27: 2204-2218.

ŽĎÁRSKÁ L., 2013: Potravni ekologie netopýru východniho Středomoři [Feeding Ecology of Bats in the Eastern Mediterranean]. Unpubl. MSc Thesis. Department of Zoology, Charles University, Praha, $175 \mathrm{pp}$ (in Czech, with an abstract in English).

ZimA J., 2004: Karyotypic variation in mammals of the Balkan Peninsula. Pp.: 109-133. In: GRIFFITHS H. I., KryštufeK B. \& Reed J. M. (eds.): Balkan Biodiversity. Pattern and Process in the European Hotspot. Kluwer Academic Press, Dordrecht, 357 pp.

Zima J., ČervenÝ J., HoráČeK I., Červená A., PrŮCha K., Macholán M. \& Rybin S. N., 1991: Standard karyology of eighteen species of bats (Rhinolophidae, Vespertilionidae, Molossidae) from Eurasia. Myotis, 29: 31-33.

Zima J., Volleth M., Horáček I., Červený J., Červená A., Prưcha K. \& Macholán M., 1992: Comparative karyology of rhinolophid bats (Chiroptera: Rhinolophidae). Pp.: 229-236. In: HoRÁČEK I. \& Vohralík V. (eds.): Prague Studies in Mammalogy. Charles University Press, Praha, 246 pp.

\section{GAZETTEER}

\section{Afghanistan:}

Chak-Naur, caves (Nangarhar Prov.)

$34^{\circ} 15^{\prime} \mathrm{N}, 71^{\circ} 00^{\prime} \mathrm{E}$

\section{Albania:}

Gjirokastër, castle (Gjirokastër Pref.)

Gollomboç, Hermit Cave (Korçë Pref.)

Jermë, bunker (Vlorë Pref.)

Juban, Ali Dedës Cave (Shkodër Pref.)

Krongj, Vris stream (Vlorë Pref.)

Kruje (Durrës Pref.)

Mezhgoran, Mezhgorani Cave (Gjirokastër Pref.)

Ndërlysaj, Thethi River (Shkodër Pref.)

$40^{\circ} 04^{\prime} \mathrm{N}, 20^{\circ} 08^{\prime} \mathrm{E}$

$40^{\circ} 51^{\prime} \mathrm{N}, 20^{\circ} 58^{\prime} \mathrm{E}$

$39^{\circ} 50^{\prime} \mathrm{N}, 20^{\circ} 07^{\prime} \mathrm{E}$

$42^{\circ} 02^{\prime} \mathrm{N}, 19^{\circ} 35^{\prime} \mathrm{E}$

$39^{\circ} 55^{\prime} \mathrm{N}, 20^{\circ} 11^{\prime} \mathrm{E}$

$41^{\circ} 30^{\prime} \mathrm{N}, 19^{\circ} 48^{\prime} \mathrm{E}$

$40^{\circ} 18^{\prime} \mathrm{N}, 20^{\circ} 06^{\prime} \mathrm{E}$

$42^{\circ} 21^{\prime} \mathrm{N}, 19^{\circ} 47^{\prime} \mathrm{E}$ 
Pishkash, Pishkashi Cave (Elbasan Pref.)

Pogradec, Çervenaka Cave (Korçë Pref.)

Prezë, bunker (Tiranë Pref.)

Tren, Treni Cave (Korçë Pref.)

Tren, Treni II Cave (Korçë Pref.)

Vanistër, Vanishta Cave (Gjirokastër Pref.)

Velçë, Velça Cave (Vlorë Pref.)

Vithkuq, chapel crypt (Korçë Pref.)

Zall-Dardhë, Drini i Zi River (Dibër Pref.)

Algeria:

Tébessa (Tébessa Prov.)

Azerbaijan:

Acınohur, steppe (Şəki Dist.)

Mingəçevir, cave (Mingəçevir Dist.)

Ordubad, cave (Ordubad Dist.)

Qobustan, rocky town (Bak1 Dist.)

Şamaxı, canyon (Şamaxı Dist.)

Suçma (Şəki Dist.)

Benin:

Awaya, $10 \mathrm{~km}$ E of Dassa (Collines Dep.)

Tagayé, stream (Atakora Dep.)

Bulgaria:

Âgodina, Dolna Karanska Dupka Cave (Smolân Prov.)

Âgodina, Gorna Karanska Dupka Cave (Smolân Prov.)

Âgodina, Imamova Cave (Smolân Prov.)

Âgodina, Sančeva Dupka Cave (Smolân Prov.)

Bačkovo, Bačkovski Monastery (Plovdiv Prov.)

Bačkovo, cave (Plovdiv Prov.)

Bilka, Golâm Kamăk, cave (Burgas Prov.)

Brestnica, Săeva Dupka Cave (Loveč Prov.)

Čepelare, church (Smolân Prov.)

Devenci, Hajduška Peŝera Cave (Pleven Prov.)

Dobromir, mine (Burgas Prov.)

Gorna Breznica, cottage (Blagoevgrad Prov.)

Gorna Breznica, drainage tube (Blagoevgrad Prov.)

Kamen Brâg, a cave NE of the town (Burgas Prov.)

Karlukovo, Bankovica Cave (Loveč Prov.)

Karlukovo, Bezimenna 22 Cave (Loveč Prov.)

Karlukovo, cave behind monastery (Loveč Prov.)

Karlukovo, Čerdženica Cave (Loveč Prov.)

Karlukovo, Ovnarka Cave (Loveč Prov.)

Karlukovo, rocky amphitheatre (Loveč Prov.)

Karlukovo, Temnata Dupka Cave (Loveč Prov.)

Komunari, rock labyrinth (Varna Prov.)

Kotel, cottage (Sliven Prov.)

Kotel, Nirica Cave (Sliven Prov.)

Lakatnik, Golâmata Vraža Dupka Cave (Sofiâ Prov.)

Lakatnik, Răžiškata (= Suhata) Peŝera Cave (Sofiâ Prov.)

Lakatnik, Svinskata Dupka Cave (Sofiâ Prov.)

Lakatnik, Temnata Dupka Cave (Sofiâ Prov.) $41^{\circ} 05^{\prime} \mathrm{N}, 20^{\circ} 29^{\prime} \mathrm{E}$

$40^{\circ} 55^{\prime} \mathrm{N}, 20^{\circ} 37^{\prime} \mathrm{E}$

$41^{\circ} 26^{\prime} \mathrm{N}, 19^{\circ} 40^{\prime} \mathrm{E}$

$40^{\circ} 40^{\prime} \mathrm{N}, 20^{\circ} 59^{\prime} \mathrm{E}$

$40^{\circ} 40^{\prime} \mathrm{N}, 20^{\circ} 59^{\prime} \mathrm{E}$

$40^{\circ} 01^{\prime} \mathrm{N}, 20^{\circ} 11^{\prime} \mathrm{E}$

$40^{\circ} 20^{\prime} \mathrm{N}, 19^{\circ} 41^{\prime} \mathrm{E}$

$40^{\circ} 32^{\prime} \mathrm{N}, 20^{\circ} 36^{\prime} \mathrm{E}$

$41^{\circ} 48^{\prime} \mathrm{N}, 20^{\circ} 21^{\prime} \mathrm{E}$

$35^{\circ} 24^{\prime} \mathrm{N}, 08^{\circ} 07^{\prime} \mathrm{E}$

$40^{\circ} 58^{\prime} \mathrm{N}, 47^{\circ} 00^{\prime} \mathrm{E}$

$40^{\circ} 46^{\prime} \mathrm{N}, 47^{\circ} 03^{\prime} \mathrm{E}$

$38^{\circ} 54^{\prime} \mathrm{N}, 46^{\circ} 02^{\prime} \mathrm{E}$

$40^{\circ} 07^{\prime} \mathrm{N}, 49^{\circ} 23^{\prime} \mathrm{E}$

$40^{\circ} 38^{\prime} \mathrm{N}, 48^{\circ} 38^{\prime} \mathrm{E}$

$40^{\circ} 57^{\prime} \mathrm{N}, 47^{\circ} 08^{\prime} \mathrm{E}$

$07^{\circ} 47^{\prime} \mathrm{N}, 02^{\circ} 16^{\prime} \mathrm{E}$

$10^{\circ} 15^{\prime} \mathrm{N}, 01^{\circ} 16^{\prime} \mathrm{E}$

$41^{\circ} 38^{\prime} \mathrm{N}, 24^{\circ} 20^{\prime} \mathrm{E}$

$41^{\circ} 38^{\prime} \mathrm{N}, 24^{\circ} 20^{\prime} \mathrm{E}$

$41^{\circ} 38^{\prime} \mathrm{N}, 24^{\circ} 20^{\prime} \mathrm{E}$

$41^{\circ} 38^{\prime} \mathrm{N}, 24^{\circ} 20^{\prime} \mathrm{E}$

$41^{\circ} 56^{\prime} \mathrm{N}, 24^{\circ} 51^{\prime} \mathrm{E}$

$41^{\circ} 57^{\prime} \mathrm{N}, 24^{\circ} 52^{\prime} \mathrm{E}$

$42^{\circ} 55^{\prime} \mathrm{N}, 27^{\circ} 13^{\prime} \mathrm{E}$

$43^{\circ} 04^{\prime} \mathrm{N}, 24^{\circ} 10^{\prime} \mathrm{E}$

$41^{\circ} 43^{\prime} \mathrm{N}, 24^{\circ} 40^{\prime} \mathrm{E}$

$43^{\circ} 19^{\prime} \mathrm{N}, 24^{\circ} 10^{\prime} \mathrm{E}$

$42^{\circ} 57^{\prime} \mathrm{N}, 27^{\circ} 18^{\prime} \mathrm{E}$

$41^{\circ} 45^{\prime} \mathrm{N}, 23^{\circ} 07^{\prime} \mathrm{E}$

$41^{\circ} 45^{\prime} \mathrm{N}, 23^{\circ} 07^{\prime} \mathrm{E}$

$43^{\circ} 27^{\prime} \mathrm{N}, 28^{\circ} 33^{\prime} \mathrm{E}$

$43^{\circ} 10^{\prime} \mathrm{N}, 24^{\circ} 04^{\prime} \mathrm{E}$

$43^{\circ} 10^{\prime} \mathrm{N}, 24^{\circ} 04^{\prime} \mathrm{E}$

$43^{\circ} 11^{\prime} \mathrm{N}, 24^{\circ} 04^{\prime} \mathrm{E}$

$43^{\circ} 10^{\prime} \mathrm{N}, 24^{\circ} 04^{\prime} \mathrm{E}$

$43^{\circ} 10^{\prime} \mathrm{N}, 24^{\circ} 04^{\prime} \mathrm{E}$

$43^{\circ} 10^{\prime} \mathrm{N}, 24^{\circ} 04^{\prime} \mathrm{E}$

$43^{\circ} 10^{\prime} \mathrm{N}, 24^{\circ} 04^{\prime} \mathrm{E}$

$43^{\circ} 01^{\prime} \mathrm{N}, 27^{\circ} 16^{\prime} \mathrm{E}$

$42^{\circ} 56^{\prime} \mathrm{N}, 26^{\circ} 30^{\prime} \mathrm{E}$

$42^{\circ} 56^{\prime} \mathrm{N}, 26^{\circ} 26^{\prime} \mathrm{E}$

$43^{\circ} 05^{\prime} \mathrm{N}, 23^{\circ} 22^{\prime} \mathrm{E}$

$43^{\circ} 05^{\prime} \mathrm{N}, 23^{\circ} 23^{\prime} \mathrm{E}$

$43^{\circ} 05^{\prime} \mathrm{N}, 23^{\circ} 22^{\prime} \mathrm{E}$

$43^{\circ} 05^{\prime} \mathrm{N}, 23^{\circ} 23^{\prime} \mathrm{E}$ 
Lilânovo (Blagoevgrad Prov.)

Lûtibrod, Čerepiški Monastery (Vraca Prov.)

Orehovo, cave (Smolân Prov.)

Peŝera, Novata Peŝera Cave (Pazardžik Prov.)

Peŝera, Snežanka Cave (Pazardžik Prov.)

Ploski, cave (Blagoevgrad Prov.)

Ploski, orchard (Blagoevgrad Prov.)

Primorsko, Arkutino, water station (Burgas Prov.)

Primorsko, Maslen Nos Cape, cave (Burgas Prov.)

Primorsko, Maslen Nos Cape, Karaul Taš (Burgas Prov.)

Razlog, Meča Dupka Cave (Blagoevgrad Prov.)

Ropotamo River Estuary (Burgas Prov.)

Sliven, Zmeevi Dupki Cave (Sliven Prov.)

Spahievo, Aida Hill, mine (Haskovo Prov.)

\section{China:}

Bangfangzi, Chang Pin Valley, stream (Shaanxi Prov.)

Foping, 7 km N, cave (Shaanxi Prov.)

Daguping, cave (Shaanxi Prov.)

Houzhenzi, stream (Shaanxi Prov.)

Taibaishan National Park, Sworded Peak, cave (Shaanxi Prov.)

\section{Croatia:}

Mokošica, cave (Dubrovačko-Neretvanska County)

Pokrovnik, Škarin Samograd Cave (Šibensko-Kninska County)

Selce, sea shore cave (Primorsko-Goranska County)

\section{Cyprus:}

Afendrika, Panagia Hrysiotissa, ruins (İskele Dist.)

Alevkaya, Küpö Cave (Lefkoşa Dist.)

Çınarlı, Inçirli Cave (Gazimağusa Dist.)

Kakopetria, Troodos Forest, mine (Leykōsia Dist.)

Kalkanli, Çoban Cave (Güzelyurt Dist.)

Kalavasos, mine (Larnaka Dist.)

Kumyali, underground quarry (İskele Dist.)

Lapta, water gallery (Girne Dist.)

Neo Horio, Smigies Trail, Magnesia Mine (Pafos Dist.)

Troodos, Troodos Forest, mine (Lemesos Dist.)

\section{Egypt:}

Abu Rawash (El Jizeh Gov.)

Abu Rihal, 90 km E of Idfu (El Bahr El Ahmar Gov.)

Aswan, orchard (Aswan Gov.)

Aswan, tunnel under railway (Aswan Gov.)

Aswan, west bank of the Nile, Tombs of Nobles (Aswan Gov.)

Dakhla Oasis, El Qasr (El Wadi El Jadid Gov.)

Dakhla Oasis, Er Rashda (El Wadi El Jadid Gov.)

El A'aqab (Aswan Gov.)

El Uqsur (Luxor), tombs (El Uqsur Gov.)

Feiran (Janub Sina' Gov.)

Karnak, Eastern Temple of Rameses II (El Uqsur Gov.)

Sheikh Jarad, $25 \mathrm{~km} \mathrm{~N}$ of Aswan (Aswan Gov.)

Siwa Oasis, Old Shaly (Matruh Gov.)

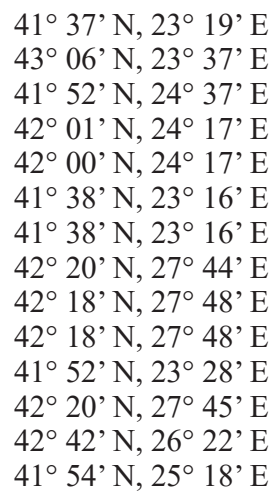

$33^{\circ} 46^{\prime} \mathrm{N}, 107^{\circ} 58^{\prime} \mathrm{E}$ $33^{\circ} 34^{\prime} \mathrm{N}, 107^{\circ} 59^{\prime} \mathrm{E}$ $33^{\circ} 34^{\prime} \mathrm{N}, 107^{\circ} 46^{\prime} \mathrm{E}$ $33^{\circ} 52^{\prime} \mathrm{N}, 107^{\circ} 49^{\prime} \mathrm{E}$ $34^{\circ} 03^{\prime} \mathrm{N}, 107^{\circ} 53^{\prime} \mathrm{E}$

$42^{\circ} 41^{\prime} \mathrm{N}, 18^{\circ} 06^{\prime} \mathrm{E}$ $43^{\circ} 48^{\prime} \mathrm{N}, 16^{\circ} 04^{\prime} \mathrm{E}$ $45^{\circ} 09^{\prime} \mathrm{N}, 14^{\circ} 43^{\prime} \mathrm{E}$

$35^{\circ} 39^{\prime} \mathrm{N}, 34^{\circ} 26^{\prime} \mathrm{E}$ $35^{\circ} 17^{\prime} \mathrm{N}, 33^{\circ} 32^{\prime} \mathrm{E}$ $35^{\circ} 19^{\prime} \mathrm{N}, 33^{\circ} 46^{\prime} \mathrm{E}$ $34^{\circ} 58^{\prime} \mathrm{N}, 32^{\circ} 52^{\prime} \mathrm{E}$ $35^{\circ} 16^{\prime} \mathrm{N}, 33^{\circ} 02^{\prime} \mathrm{E}$ $34^{\circ} 46^{\prime} \mathrm{N}, 33^{\circ} 18^{\prime} \mathrm{E}$ $35^{\circ} 26^{\prime} \mathrm{N}, 34^{\circ} 10^{\prime} \mathrm{E}$ $35^{\circ} 20^{\prime} \mathrm{N}, 33^{\circ} 10^{\prime} \mathrm{E}$ $35^{\circ} 03^{\prime} \mathrm{N}, 32^{\circ} 20^{\prime} \mathrm{E}$ $34^{\circ} 57^{\prime} \mathrm{N}, 32^{\circ} 53^{\prime} \mathrm{E}$

$30^{\circ} 02^{\prime} \mathrm{N}, 31^{\circ} 05^{\prime} \mathrm{E}$ $25^{\circ} 00^{\prime} \mathrm{N}, 33^{\circ} 28^{\prime} \mathrm{E}$ $24^{\circ} 07^{\prime} \mathrm{N}, 32^{\circ} 54^{\prime} \mathrm{E}$ $24^{\circ} 07^{\prime} \mathrm{N}, 32^{\circ} 54^{\prime} \mathrm{E}$ $24^{\circ} 06^{\prime} \mathrm{N}, 32^{\circ} 53^{\prime} \mathrm{E}$ $25^{\circ} 42^{\prime} \mathrm{N}, 28^{\circ} 53^{\prime} \mathrm{E}$ $25^{\circ} 35^{\prime} \mathrm{N}, 28^{\circ} 56^{\prime} \mathrm{E}$ $24^{\circ} 16^{\prime} \mathrm{N}, 32^{\circ} 54^{\prime}$ E $25^{\circ} 43^{\prime} \mathrm{N}, 32^{\circ} 38^{\prime} \mathrm{E}$ $28^{\circ} 42^{\prime} \mathrm{N}, 33^{\circ} 40^{\prime} \mathrm{E}$ $25^{\circ} 43^{\prime} \mathrm{N}, 32^{\circ} 40^{\prime} \mathrm{E}$ $24^{\circ} 19^{\prime} \mathrm{N}, 32^{\circ} 54^{\prime} \mathrm{E}$ $29^{\circ} 12^{\prime} \mathrm{N}, 25^{\circ} 31^{\prime} \mathrm{E}$ 


\section{Ethiopia:}

Abune Aregawi Zeya Cave (Tigray Reg.)

Aksum, King Basen's Tomb (Tigray Reg.)

Alatish National Park, Megbiya Ber Scout Post (Amhara Reg.)

Alatish National Park, Megenagna (Amhara Reg.)

Awash National Park, Gotu Area (Afar Reg.)

Bolo, 18 km NW of Nekemte, Geda Gilinde Cave (Oromiya Reg.)

Bonga, Chara (Southern Nations, Nationalities and Peoples Reg.)

cave $20 \mathrm{~km} \mathrm{NE}$ of Harbona (Oromiya Reg.)

Degum, Yohannis Maikudi Church (Tigray Reg.)

Desea Forest, 2 km E of Atsbi (Tigray Reg.)

Edaga Arbi (Tigray Reg.)

Gondar, Royal Enclosure (Amhara Reg.)

Harbona, cave 20 km NE (Oromiya Reg.)

Kesa, Dangola Washa Caves (Amhara Reg.)

Mago National Park, headquarters

(Southern Nations, Nationalities and Peoples Reg.)

Mai Temen, 47 km SW of Sheraro (Tigray Reg.)

Mille, $10 \mathrm{~km}$ south-west, bridge (Afar Reg.)

Simien National Park, Aman Amba Area (Amhara Reg.)

Sof Omar Caves (Oromiya Reg.)

\section{Georgia:}

Džal, tunnel (Aphazeti Rep.)

$13^{\circ} 34^{\prime} \mathrm{N}, 39^{\circ} 09^{\prime} \mathrm{E}$

$14^{\circ} 08^{\prime} \mathrm{N}, 38^{\circ} 44^{\prime} \mathrm{E}$

$12^{\circ} 16^{\prime} \mathrm{N}, 35^{\circ} 43^{\prime} \mathrm{E}$

$12^{\circ} 12^{\prime} \mathrm{N}, 35^{\circ} 40^{\prime} \mathrm{E}$

$08^{\circ} 51^{\prime} \mathrm{N}, 40^{\circ} 00^{\prime} \mathrm{E}$

$09^{\circ} 12^{\prime} \mathrm{N}, 36^{\circ} 25^{\prime} \mathrm{E}$

$07^{\circ} 18^{\prime} \mathrm{N}, 36^{\circ} 23^{\prime} \mathrm{E}$

$08^{\circ} 49^{\prime} \mathrm{N}, 39^{\circ} 42^{\prime} \mathrm{E}$

$13^{\circ} 51^{\prime} \mathrm{N}, 39^{\circ} 27^{\prime} \mathrm{E}$

$13^{\circ} 53^{\prime} \mathrm{N}, 39^{\circ} 46^{\prime} \mathrm{E}$

$14^{\circ} 13^{\prime} \mathrm{N}, 39^{\circ} 15^{\prime} \mathrm{E}$

$12^{\circ} 36^{\prime} \mathrm{N}, 37^{\circ} 28^{\prime} \mathrm{E}$

$08^{\circ} 49^{\prime} \mathrm{N}, 39^{\circ} 42^{\prime} \mathrm{E}$

$10^{\circ} 52^{\prime} \mathrm{N}, 36^{\circ} 56^{\prime} \mathrm{E}$

$05^{\circ} 40^{\prime} \mathrm{N}, 36^{\circ} 25^{\prime} \mathrm{E}$

$14^{\circ} 06^{\prime} \mathrm{N}, 37^{\circ} 28^{\prime} \mathrm{E}$

$11^{\circ} 21^{\prime} \mathrm{N}, 40^{\circ} 41^{\prime} \mathrm{E}$

$13^{\circ} 13^{\prime} \mathrm{N}, 38^{\circ} 00^{\prime} \mathrm{E}$

$06^{\circ} 54^{\prime} \mathrm{N}, 40^{\circ} 51^{\prime} \mathrm{E}$

Greece (mainland):

Aidonohōri, Āōos River (Īpeiros Reg.)

Delfoi (Sterea Ellada Reg.)

Despotiko, stream (Īpeiros Reg.)

Didymoteiho, cave (Anatolikī Makedonia kai Thrakī Reg.)

Kimmeria, mine (Anatolikī Makedonia kai Thrakī Reg.)

Kompotades, bunker (Sterea Ellada Reg.)

Marōneia, stream (Anatolikī Makedonia kai Thrakī Reg.)

Marōneia, Kyklōpa Cave (Anatolikī Makedonia kai Thrakī Reg.)

Naoysa, cave (Kentrikī Makedonia Reg.)

Petralōna, Petralōna Cave (Kentrikī Makedonia Reg.)

Pylī, Zachariadī Cave (Ditikī Makedonia Reg.)

Stoypa near Kardamylī, cave (Peloponnīsos Reg.)

$42^{\circ} 50^{\prime} \mathrm{N}, 41^{\circ} 31^{\prime} \mathrm{E}$

\section{Greece (Crete):}

Amnisos, Eileithyia Cave (Krīti Reg.)

Avdoy, Agios Fōteinīs Cave (Krīit Reg.)

Gerani, Geranioy Cave (Krīti Reg.)

Katholiko Monastery, Agios Iōannis Cave (Krīti Reg.)

Kolymvari, mine (Krīti Reg.)

Koymares, Arkoydiōtissa Cave (Krīti Reg.)

Kritsa, Gaidoyrotrypa Cave (Krīti Reg.)

Leykogeia, Katō Prevelī Monastery, Venetian bridge (Krīti Reg.)

Milatos, Milatoy Cave (Krīti Reg.)

Omalos, Tzanī Cave (Krīiti Reg.)

Patsos, Agios Antōnios Cave (Krīti Reg.)

Peykoi, Vreiko Cave (Krīti Reg.)

Ploytī, Mikrī Lavyrinthos Cave (Krīti Reg.)

$40^{\circ} 04^{\prime} \mathrm{N}, 20^{\circ} 35^{\prime} \mathrm{E}$

$38^{\circ} 29^{\prime} \mathrm{N}, 22^{\circ} 30^{\prime} \mathrm{E}$

$39^{\circ} 13^{\prime} \mathrm{N}, 20^{\circ} 40^{\prime} \mathrm{E}$

$41^{\circ} 21^{\prime} \mathrm{N}, 26^{\circ} 27^{\prime} \mathrm{E}$

$41^{\circ} 09^{\prime} \mathrm{N}, 24^{\circ} 56^{\prime} \mathrm{E}$

$38^{\circ} 52^{\prime} \mathrm{N}, 22^{\circ} 22^{\prime} \mathrm{E}$

$40^{\circ} 55^{\prime} \mathrm{N}, 25^{\circ} 30^{\prime} \mathrm{E}$

$40^{\circ} 54^{\prime} \mathrm{N}, 25^{\circ} 33^{\prime} \mathrm{E}$

$40^{\circ} 38^{\prime} \mathrm{N}, 22^{\circ} 04^{\prime} \mathrm{E}$

$40^{\circ} 22^{\prime} \mathrm{N}, 23^{\circ} 10^{\prime} \mathrm{E}$

$40^{\circ} 47^{\prime} \mathrm{N}, 21^{\circ} 02^{\prime} \mathrm{E}$

$36^{\circ} 51^{\prime} \mathrm{N}, 22^{\circ} 16^{\prime} \mathrm{E}$

$35^{\circ} 19^{\prime} \mathrm{N}, 25^{\circ} 12^{\prime} \mathrm{E}$

$35^{\circ} 13^{\prime} \mathrm{N}, 25^{\circ} 25^{\prime} \mathrm{E}$

$35^{\circ} 22^{\prime} \mathrm{N}, 24^{\circ} 24^{\prime} \mathrm{E}$

$35^{\circ} 35^{\prime} \mathrm{N}, 24^{\circ} 09^{\prime} \mathrm{E}$

$35^{\circ} 33^{\prime} \mathrm{N}, 23^{\circ} 46^{\prime} \mathrm{E}$

$35^{\circ} 35^{\prime} \mathrm{N}, 24^{\circ} 09^{\prime} \mathrm{E}$

$35^{\circ} 10^{\prime} \mathrm{N}, 25^{\circ} 37^{\prime} \mathrm{E}$

$35^{\circ} 10^{\prime} \mathrm{N}, 24^{\circ} 28^{\prime} \mathrm{E}$

$35^{\circ} 18^{\prime} \mathrm{N}, 25^{\circ} 35^{\prime} \mathrm{E}$

$35^{\circ} 21^{\prime} \mathrm{N}, 23^{\circ} 54^{\prime} \mathrm{E}$

$35^{\circ} 15^{\prime} \mathrm{N}, 24^{\circ} 34^{\prime} \mathrm{E}$

$35^{\circ} 05^{\prime} \mathrm{N}, 25^{\circ} 60^{\prime} \mathrm{E}$

$35^{\circ} 05^{\prime} \mathrm{N}, 24^{\circ} 55^{\prime} \mathrm{E}$ 
Royva Forest, Agios Iōannis Royva (Krīti Reg.)

Sitanos, Exō Latsidi Cave (Krīiti Reg.)

Theriso, Sarakinas Cave (Krïti Reg.)

Greece (islands):

Kalymnos, Skalia Cave (Notio Aigaio Reg.)

Karpathos, Aperi, bridge (Notio Aigaio Reg.)

Petala, cave (Ditikī Ellada Reg.)

Rhodes, Agios Paylos (Notio Aigaio Reg.)

Rhodes, Gadoyra Dam, hut (Notio Aigaio Reg.)

Thassos, Arhaggeloy Monastery, spring (Anatolikī Makedonia kai Thrakī Reg.)

Thassos, Panagia, Drakotrypa Cave (Anatolikī Makedonia kai Thrakī Reg.)

India:

Gola Ka Bas (Rajasthan State)

Iran:

Assalem (Gilan Prov.)

Bandar Siraf, cave (Bushehr Prov.)

Bishapur, cave (Fars Prov.)

Bisotun, cave (Kermanshah Prov.)

Chahak, cave (Bushehr Prov.)

Choqazanbil, ruins (Khuzestan Prov.)

Chuplu, cave (Azarbaijan-e Gharbi Prov.)

Dashkasan, Dashkasan Cave (Ardabil Prov.)

Deh Bakri, small cave (Kerman Prov.)

Dehloran Cave (Ilam Prov.)

Emamzadeh, water gallery (Esfahan Prov.)

Hormoz Island, cave (Hormozgan Prov.)

Hormoz Island, Daneshyu Salt Cave (Hormozgan Prov.)

Jahrom, Sang Eshkan Mine (Fars Prov.)

Jelugir, cave (Lorestan Prov.)

Karaftu Cave (Kordestan Prov.)

Karaj River Valley (Alborz Prov.)

Mach Gur, cave (Sistan va Baluchestan Prov.)

Manian, Manian Cave (Fars Prov.)

Meymand, valley (Kohgiluye va Boyer Ahmad Prov.)

Moghan, Moghan Cave (Khorasan-e Razawi Prov.)

Mormori, cave (Ilam Prov.)

Nosrat Abad, small house (Sistan va Baluchestan Prov.)

Pir Sohrab, cave (Sistan va Baluchestan Prov.)

Pol-e Tang, tomb (Lorestan Prov.)

Sarkan near Izeh, cave (Khuzestan Prov.)

Shanbeh, ruins (Bushehr Prov.)

Tadovan Cave (Fars Prov.)

Tis, cave (Sistan va Baluchestan Prov.)

Italy:

Roma (Lazio Prov.)

Jordan:

Al Batra, cave (Ma'an Prov.)

Al Qurayqira, Wadi Ghuweir, Khirbet Feynan (Aqaba Prov.)

Aqaba, Ottoman fortress (Aqaba Prov.) $35^{\circ} 10^{\prime} \mathrm{N}, 24^{\circ} 55^{\prime} \mathrm{E}$

$35^{\circ} 07^{\prime} \mathrm{N}, 26^{\circ} 09^{\prime} \mathrm{E}$

$35^{\circ} 25^{\prime} \mathrm{N}, 23^{\circ} 59^{\prime} \mathrm{E}$

$37^{\circ} 02^{\prime} \mathrm{N}, 26^{\circ} 57^{\prime} \mathrm{E}$

$35^{\circ} 32^{\prime} \mathrm{N}, 27^{\circ} 11^{\prime} \mathrm{E}$

$38^{\circ} 25^{\prime} \mathrm{N}, 21^{\circ} 06^{\prime} \mathrm{E}$

$35^{\circ} 57^{\prime} \mathrm{N}, 27^{\circ} 50^{\prime} \mathrm{E}$

$36^{\circ} 12^{\prime} \mathrm{N}, 27^{\circ} 59^{\prime} \mathrm{E}$

$40^{\circ} 36^{\prime} \mathrm{N}, 24^{\circ} 44^{\prime} \mathrm{E}$

$40^{\circ} 44^{\prime} \mathrm{N}, 24^{\circ} 44^{\prime} \mathrm{E}$

$27^{\circ} 06^{\prime} \mathrm{N}, 76^{\circ} 17^{\prime} \mathrm{E}$

$37^{\circ} 41^{\prime} \mathrm{N}, 48^{\circ} 51^{\prime} \mathrm{E}$

$27^{\circ} 40^{\prime} \mathrm{N}, 52^{\circ} 20^{\prime} \mathrm{E}$

$29^{\circ} 47^{\prime} \mathrm{N}, 51^{\circ} 35^{\prime} \mathrm{E}$

$34^{\circ} 23^{\prime} \mathrm{N}, 47^{\circ} 26^{\prime} \mathrm{E}$

$29^{\circ} 39^{\prime} \mathrm{N}, 50^{\circ} 27^{\prime} \mathrm{E}$

$32^{\circ} 01^{\prime} \mathrm{N}, 48^{\circ} 32^{\prime} \mathrm{E}$

$36^{\circ} 28^{\prime} \mathrm{N}, 47^{\circ} 02^{\prime} \mathrm{E}$

$38^{\circ} 26^{\prime} \mathrm{N}, 47^{\circ} 52^{\prime} \mathrm{E}$

$29^{\circ} 05^{\prime} \mathrm{N}, 57^{\circ} 56^{\prime} \mathrm{E}$

$32^{\circ} 44^{\prime} \mathrm{N}, 47^{\circ} 18^{\prime} \mathrm{E}$

$33^{\circ} 59^{\prime} \mathrm{N}, 51^{\circ} 17^{\prime} \mathrm{E}$

$27^{\circ} 05^{\prime} \mathrm{N}, 56^{\circ} 27^{\prime} \mathrm{E}$

$27^{\circ} 03^{\prime} \mathrm{N}, 56^{\circ} 26^{\prime} \mathrm{E}$

$28^{\circ} 29^{\prime} \mathrm{N}, 53^{\circ} 35^{\prime} \mathrm{E}$

$33^{\circ} 00^{\prime} \mathrm{N}, 47^{\circ} 48^{\prime} \mathrm{E}$

$36^{\circ} 20^{\prime} \mathrm{N}, 46^{\circ} 53^{\prime} \mathrm{E}$

$35^{\circ} 49^{\prime} \mathrm{N}, 50^{\circ} 59^{\prime} \mathrm{E}$

$26^{\circ} 45^{\prime} \mathrm{N}, 61^{\circ} 05^{\prime} \mathrm{E}$

$28^{\circ} 35^{\prime} \mathrm{N}, 53^{\circ} 14^{\prime} \mathrm{E}$

$31^{\circ} 10^{\prime} \mathrm{N}, 51^{\circ} 16^{\prime} \mathrm{E}$

$36^{\circ} 10^{\prime} \mathrm{N}, 59^{\circ} 18^{\prime} \mathrm{E}$

$32^{\circ} 40^{\prime} \mathrm{N}, 47^{\circ} 34^{\prime} \mathrm{E}$

$29^{\circ} 46^{\prime} \mathrm{N}, 59^{\circ} 52^{\prime} \mathrm{E}$

$25^{\circ} 45^{\prime} \mathrm{N}, 60^{\circ} 50^{\prime} \mathrm{E}$

$32^{\circ} 55^{\prime} \mathrm{N}, 47^{\circ} 55^{\prime} \mathrm{E}$

$31^{\circ} 45^{\prime} \mathrm{N}, 49^{\circ} 48^{\prime} \mathrm{E}$

$28^{\circ} 24^{\prime} \mathrm{N}, 51^{\circ} 46^{\prime} \mathrm{E}$

$28^{\circ} 51^{\prime} \mathrm{N}, 53^{\circ} 20^{\prime} \mathrm{E}$

$25^{\circ} 21^{\prime} \mathrm{N}, 60^{\circ} 37^{\prime} \mathrm{E}$

$41^{\circ} 54^{\prime} \mathrm{N}, 12^{\circ} 29^{\prime} \mathrm{E}$

$30^{\circ} 20^{\prime} \mathrm{N}, 35^{\circ} 27^{\prime} \mathrm{E}$

$30^{\circ} 38^{\prime} \mathrm{N}, 35^{\circ} 29^{\prime} \mathrm{E}$

$29^{\circ} 31^{\prime} \mathrm{N}, 35^{\circ} 00^{\prime} \mathrm{E}$ 
Ar Rajif, Jebel Masuda, Ain Amshit (Ma'an Prov.)

Ash Shawbak, Ash Shawbak Castle (Ma'an Prov.)

Ash Shunah Al Janubiyya, Wadi Shu'ayb, cave ('Amman Prov.)

Bait Idis, Jesus' Cave (Irbid Prov.)

Dhana, Wadi Dhana (Tafila Prov.)

Dibbin, Dibbin Forest, underground corridor (Irbid Prov.)

Ghor As Safi, Lot's Cave (Karak Prov.)

Jabal Al Bayda, cave (Ma'an Prov.)

Khashibah, Al Wardeh Mine (Irbid Prov.)

Kufranja, Iraq Al Wahaj Cave (Irbid Prov.)

Malka, artificial cave (Irbid Prov.)

Petra, cave (Ma'an Prov.)

Tabaqat Fal, Roman Necropolis of Pella (Irbid Prov.)

Wadi As Sir, Iraq Al Amir, cave ('Amman Prov.)

Wadi Dharih, small cave (Tafila Prov.)

Wadi Weida'a, rocky wall (Karak Prov.)

Zubiya, Zubiya Cave (Irbid Prov.)

\section{Kirghizstan:}

Kadamžaj, cave (Batken Reg.)

Kara-Kokty, mine (Oš Reg.)

Kyzyl-Kiâk, cave (Batken Reg.)

Samarkandyk, Kanigut, mine (Batken Reg.)

Toâ-Moûn, Kolodec Fersmana mine (Oš Reg.)

\section{Kosovo:}

Bubël, cave (Gjakovë Dist.)

Mrasor, Mirusha Waterfall, cave (Gjakovë Dist.)

\section{Lebanon:}

Aamchit, Saleh Cave (Jebel Lubnan Gov.)

Aanjar, Aanjar Cave (El Beqaa Gov.)

Afqa, Afqa Cave (Jebel Lubnan Gov.)

Antelias, Kenaan Cave (Jebel Lubnan Gov.)

Bcharre, Qadicha Cave (Lubnan Esh Shamali Gov.)

Dahr El Mghara, Aaonamie Cave (Jebel Lubnan Gov.)

El Aaqoura, Er Rouais Cave (Jebel Lubnan Gov.)

Faraya, El Qana Cave (Jebel Lubnan Gov.)

Faraya, Raymond Cave (Jebel Lubnan Gov.)

Haqel El Azime, Achou Cave (Lubnan Esh Shamali Gov.)

Hrajel, Seraaya Cave (Jebel Lubnan Gov.)

Jezzine, Pont El Khalass (Lubnan El Janubi Gov.)

Kfar Zabad, cave (El Beqaa Gov.)

Khirbet Qanafar, El Jaouz Cave (El Beqaa Gov.)

Marjaba, mine (Jebel Lubnan Gov.)

Nabaa Es Safa, mine (Jebel Lubnan Gov.)

Ouadi Jilo, cave (Lubnan El Janubi Gov.)

Ras Al Assi, cave (Baalbek-El Hermel Gov.)

Ras El Assi, Deir Mar Maroun Monastery (Baalbek-El Hermel Gov.)

Ras Nhach, Musailha Fort, mine (Lubnan Esh Shamali Gov.)

Seraal, Qadicha Valley, cave (Lubnan Esh Shamali Gov.)

Tourzaiya, Mebaaj Cave (Jebel Lubnan Gov.)

Trablous, Mtal El Azraq Cave (Lubnan Esh Shamali Gov.) $30^{\circ} 12^{\prime} \mathrm{N}, 35^{\circ} 23^{\prime} \mathrm{E}$

$30^{\circ} 32^{\prime} \mathrm{N}, 35^{\circ} 34^{\prime} \mathrm{E}$

$31^{\circ} 57^{\prime} \mathrm{N}, 35^{\circ} 41^{\prime} \mathrm{E}$

$32^{\circ} 27^{\prime} \mathrm{N}, 35^{\circ} 41^{\prime} \mathrm{E}$

$30^{\circ} 39^{\prime} \mathrm{N}, 35^{\circ} 32^{\prime} \mathrm{E}$

$32^{\circ} 15^{\prime} \mathrm{N}, 35^{\circ} 50^{\prime} \mathrm{E}$

$31^{\circ} 03^{\prime} \mathrm{N}, 35^{\circ} 30^{\prime} \mathrm{E}$

$30^{\circ} 23^{\prime} \mathrm{N}, 35^{\circ} 27^{\prime} \mathrm{E}$

$32^{\circ} 13^{\prime} \mathrm{N}, 35^{\circ} 43^{\prime} \mathrm{E}$

$32^{\circ} 19^{\prime} \mathrm{N}, 35^{\circ} 43^{\prime} \mathrm{E}$

$32^{\circ} 39^{\prime} \mathrm{N}, 35^{\circ} 45^{\prime} \mathrm{E}$

$30^{\circ} 20^{\prime} \mathrm{N}, 35^{\circ} 27^{\prime} \mathrm{E}$

$32^{\circ} 27^{\prime} \mathrm{N}, 35^{\circ} 37^{\prime} \mathrm{E}$

$31^{\circ} 55^{\prime} \mathrm{N}, 35^{\circ} 45^{\prime} \mathrm{E}$

$30^{\circ} 58^{\prime} \mathrm{N}, 35^{\circ} 42^{\prime} \mathrm{E}$

$31^{\circ} 15^{\prime} \mathrm{N}, 35^{\circ} 35^{\prime} \mathrm{E}$

$32^{\circ} 26^{\prime} \mathrm{N}, 35^{\circ} 45^{\prime} \mathrm{E}$

$40^{\circ} 08^{\prime} \mathrm{N}, 71^{\circ} 41^{\prime} \mathrm{E}$

$40^{\circ} 21^{\prime} \mathrm{N}, 72^{\circ} 37^{\prime} \mathrm{E}$

$39^{\circ} 57^{\prime} \mathrm{N}, 71^{\circ} 05^{\prime} \mathrm{E}$

$40^{\circ} 00^{\prime} \mathrm{N}, 70^{\circ} 27^{\prime} \mathrm{E}$

$40^{\circ} 21^{\prime} \mathrm{N}, 72^{\circ} 37^{\prime} \mathrm{E}$

$42^{\circ} 32^{\prime} \mathrm{N}, 20^{\circ} 39^{\prime} \mathrm{E}$

$42^{\circ} 31^{\prime} \mathrm{N}, 20^{\circ} 35^{\prime} \mathrm{E}$

$34^{\circ} 09^{\prime} \mathrm{N}, 35^{\circ} 40^{\prime} \mathrm{E}$

$33^{\circ} 44^{\prime} \mathrm{N}, 35^{\circ} 57^{\prime} \mathrm{E}$

$34^{\circ} 04^{\prime} \mathrm{N}, 35^{\circ} 54^{\prime} \mathrm{E}$

$33^{\circ} 55^{\prime} \mathrm{N}, 35^{\circ} 36^{\prime} \mathrm{E}$

$34^{\circ} 15^{\prime} \mathrm{N}, 36^{\circ} 02^{\prime} \mathrm{E}$

$33^{\circ} 40^{\prime} \mathrm{N}, 35^{\circ} 37^{\prime} \mathrm{E}$

$34^{\circ} 07^{\prime} \mathrm{N}, 35^{\circ} 55^{\prime} \mathrm{E}$

$34^{\circ} 03^{\prime} \mathrm{N}, 35^{\circ} 49^{\prime} \mathrm{E}$

$33^{\circ} 59^{\prime} \mathrm{N}, 35^{\circ} 49^{\prime} \mathrm{E}$

$34^{\circ} 24^{\prime} \mathrm{N}, 36^{\circ} 01^{\prime} \mathrm{E}$

$34^{\circ} 01^{\prime} \mathrm{N}, 35^{\circ} 48^{\prime} \mathrm{E}$

$33^{\circ} 32^{\prime} \mathrm{N}, 35^{\circ} 35^{\prime} \mathrm{E}$

$33^{\circ} 47^{\prime} \mathrm{N}, 36^{\circ} 01^{\prime} \mathrm{E}$

$33^{\circ} 39^{\prime} \mathrm{N}, 35^{\circ} 43^{\prime} \mathrm{E}$

$33^{\circ} 55^{\prime} \mathrm{N}, 35^{\circ} 45^{\prime} \mathrm{E}$

$33^{\circ} 45^{\prime} \mathrm{N}, 35^{\circ} 41^{\prime} \mathrm{E}$

$33^{\circ} 14^{\prime} \mathrm{N}, 35^{\circ} 19^{\prime} \mathrm{E}$

$34^{\circ} 21^{\prime} \mathrm{N}, 36^{\circ} 22^{\prime} \mathrm{E}$

$34^{\circ} 21^{\prime} \mathrm{N}, 36^{\circ} 22^{\prime} \mathrm{E}$

$34^{\circ} 16^{\prime} \mathrm{N}, 35^{\circ} 41^{\prime} \mathrm{E}$

$34^{\circ} 17^{\prime} \mathrm{N}, 35^{\circ} 56^{\prime} \mathrm{E}$

$34^{\circ} 06^{\prime} \mathrm{N}, 35^{\circ} 46^{\prime} \mathrm{E}$

$34^{\circ} 25^{\prime} \mathrm{N}, 35^{\circ} 50^{\prime} \mathrm{E}$ 


\section{Libya:}

Ain Az Zarqa, oasis (Jabal Al Gharbi Dist.)

Al Bardiyah (Al Butnan Dist.)

$31^{\circ} 55^{\prime} \mathrm{N}, 12^{\circ} 00^{\prime} \mathrm{E}$

Al Jaghbub (Al Butnan Dist.)

Ghat, camp (Ghat Prov.)

Nanatalah, oasis (Jabal Al Gharbi Dist.)

Wadi Al Kuf, cave (Al Jabal Al Akhdar Dist.)

Wadi Darnah, mine (Darnah Dist.)

Wadi Darnah, $10 \mathrm{~km} \mathrm{~S}$ of Darnah, cave (Darnah Dist.)

$31^{\circ} 45^{\prime} \mathrm{N}, 25^{\circ} 05^{\prime} \mathrm{E}$

$29^{\circ} 45^{\prime} \mathrm{N}, 24^{\circ} 31^{\prime} \mathrm{E}$

$24^{\circ} 57^{\prime} \mathrm{N}, 10^{\circ} 11^{\prime} \mathrm{E}$

$31^{\circ} 47^{\prime} \mathrm{N}, 11^{\circ} 47^{\prime} \mathrm{E}$

$32^{\circ} 41^{\prime} \mathrm{N}, 21^{\circ} 33^{\prime} \mathrm{E}$

$32^{\circ} 42^{\prime} \mathrm{N}, 22^{\circ} 37^{\prime} \mathrm{E}$

$32^{\circ} 41^{\prime} \mathrm{N}, 22^{\circ} 36^{\prime} \mathrm{E}$

\section{Mauritania:}

Ouadâne, old town (Adrar Reg.)

Terjit, oasis (Adrar Reg.)

Tin Labbé, Akhnik Akhmoudi Cave (Adrar Reg.)

Tin Labbé, Ghar Alhach Cave (Adrar Reg.)

$20^{\circ} 56^{\prime} \mathrm{N}, 11^{\circ} 37^{\prime} \mathrm{W}$

$20^{\circ} 15^{\prime} \mathrm{N}, 13^{\circ} 05^{\prime} \mathrm{W}$

$20^{\circ} 58^{\prime} \mathrm{N}, 11^{\circ} 40^{\prime} \mathrm{W}$

$20^{\circ} 58^{\prime} \mathrm{N}, 11^{\circ} 40^{\prime} \mathrm{W}$

\section{Montenegro:}

Stari Bar (Bar Dist.)

$42^{\circ} 06^{\prime} \mathrm{N}, 19^{\circ} 08^{\prime} \mathrm{E}$

\section{Morocco:}

Gorges du Dadès, Aït-Ali (Drâa-Tafilalet Reg.)

Massa, rocky overhang (Souss-Massa Reg.)

Sidi Binzarne, canalisation tube (Souss-Massa Reg.)

Takoumit, small cave (Drâa-Tafilalet Reg.)

Talkount, Oued Tessaoud, mine (Béni Mellal-Khénifra Reg.)

Tassetift, palm grove (Drâa-Tafilalet Reg.)

Tazouguerte, Kef Azigza Cave (Drâa-Tafilalet Reg.)

\section{North Macedonia:}

Leskoec, cave (Resen Dist.)

north-eastern bank of the Ohrid Lake (Ohrid Dist.)

Ohrid Lake, north-eastern bank (Ohrid Dist.)

$31^{\circ} 31^{\prime} \mathrm{N}, 05^{\circ} 56^{\prime} \mathrm{W}$

$30^{\circ} 02^{\prime} \mathrm{N}, 09^{\circ} 39^{\prime} \mathrm{W}$

$30^{\circ} 04^{\prime} \mathrm{N}, 09^{\circ} 40^{\prime} \mathrm{W}$

$32^{\circ} 05^{\prime} \mathrm{N}, 03^{\circ} 46^{\prime} \mathrm{W}$

$31^{\circ} 41^{\prime} \mathrm{N}, 07^{\circ} 17^{\prime} \mathrm{W}$

$30^{\circ} 23^{\prime} \mathrm{N}, 06^{\circ} 52^{\prime} \mathrm{W}$

$32^{\circ} 02^{\prime} \mathrm{N}, 03^{\circ} 47^{\prime} \mathrm{W}$

\section{Oman:}

Ain Ayun, cave (Dhofar Prov.)

Ain Hamran Cave (Dhofar Prov.)

Ain Jarziz, cave (Dhofar Prov.)

Ain Tabruq, cave (Dhofar Prov.)

Al Ajal, Wadi Al Ajal, small cave (Al Batinah Al Janub Prov.)

Al Aqar, cave (Al Batinah Al Janub Prov.)

Al Awabi, fortress (Al Batinah Al Janub Prov.)

Al Ghubrah, cave (Al Batinah Al Janub Prov.)

Al Hashah (Wadi Bani Hani), Wadi Hawqain (Al Batinah Al Janub Prov.)

Al Hawqain, fortress (Al Batinah Al Janub Prov.)

Al Hoota Cave (Ad Dakhiliyah Prov.)

Al Iraqi, fortress (Adh Dhahirah Prov.)

Al Karbi Ash Sharqiyah, rocks (Al Buraimi Prov.)

Al Mintirib, fortress (Ash Sharqiyah Ash Shamal Prov.)

Al War, Wadi Khabbah (Ash Sharqiyah Ash Shamal Prov.)

Ar Rawdah, small cave (Musandam Prov.)

Ar Rustaq, fortress (Al Batinah Al Janub Prov.)

At Tabaqah, fortress (Al Batinah Al Janub Prov.)

Az Zihaymi, cave (Al Batinah Ash Shamal Prov.)

Bahla, ruined city (Ad Dakhiliyah Prov.)

$40^{\circ} 57^{\prime} \mathrm{N}, 20^{\circ} 53^{\prime} \mathrm{E}$

$41^{\circ} 10^{\prime} \mathrm{N}, 20^{\circ} 45^{\prime} \mathrm{E}$

$41^{\circ} 10^{\prime} \mathrm{N}, 20^{\circ} 45^{\prime} \mathrm{E}$

$17^{\circ} 15^{\prime} \mathrm{N}, 53^{\circ} 53^{\prime} \mathrm{E}$

$17^{\circ} 06^{\prime} \mathrm{N}, 54^{\circ} 17^{\prime} \mathrm{E}$

$17^{\circ} 06^{\prime} \mathrm{N}, 54^{\circ} 05^{\prime} \mathrm{E}$

$17^{\circ} 06^{\prime} \mathrm{N}, 54^{\circ} 20^{\prime} \mathrm{E}$

$23^{\circ} 31^{\prime} \mathrm{N}, 57^{\circ} 55^{\prime} \mathrm{E}$

$23^{\circ} 09^{\prime} \mathrm{N}, 57^{\circ} 45^{\prime} \mathrm{E}$

$23^{\circ} 18^{\prime} \mathrm{N}, 57^{\circ} 32^{\prime} \mathrm{E}$

$23^{\circ} 19^{\prime} \mathrm{N}, 57^{\circ} 42^{\prime} \mathrm{E}$

$23^{\circ} 26^{\prime} \mathrm{N}, 57^{\circ} 19^{\prime} \mathrm{E}$

$23^{\circ} 33^{\prime} \mathrm{N}, 57^{\circ} 20^{\prime} \mathrm{E}$

$23^{\circ} 06^{\prime} \mathrm{N}, 57^{\circ} 22^{\prime} \mathrm{E}$

$23^{\circ} 17^{\prime} \mathrm{N}, 56^{\circ} 32^{\prime} \mathrm{E}$

$24^{\circ} 43^{\prime} \mathrm{N}, 56^{\circ} 11^{\prime} \mathrm{E}$

$22^{\circ} 26^{\prime} \mathrm{N}, 58^{\circ} 48^{\prime} \mathrm{E}$

$22^{\circ} 56^{\prime} \mathrm{N}, 58^{\circ} 51^{\prime} \mathrm{E}$

$25^{\circ} 51^{\prime} \mathrm{N}, 56^{\circ} 16^{\prime} \mathrm{E}$

$23^{\circ} 24^{\prime} \mathrm{N}, 57^{\circ} 26^{\prime} \mathrm{E}$

$23^{\circ} 23^{\prime} \mathrm{N}, 57^{\circ} 19^{\prime} \mathrm{E}$

$24^{\circ} 27^{\prime} \mathrm{N}, 56^{\circ} 18^{\prime} \mathrm{E}$

$22^{\circ} 58^{\prime} \mathrm{N}, 57^{\circ} 18^{\prime} \mathrm{E}$ 
Bani Habib, house (Ad Dakhiliyah Prov.)

Belt, fortress (Adh Dhahirah Prov.)

Birkat Al Mawz, ruined city (Ad Dakhiliyah Prov.)

Hagarir, haunt (Dhofar Prov.)

Jabrin, fortress (Ad Dakhiliyah Prov.)

Jamma, fortress (Al Batinah Al Janub Prov.)

Khubar, Bait As Saruj Castle (Ad Dakhiliyah Prov.)

Mirbat, house (Dhofar Prov.)

Misfah, village (Ad Dakhiliyah Prov.)

Misfah Al Abriyn, Wadi Misfah, cave (Ad Dakhiliyah Prov.)

Mithqub, Wadi Harabein, Dibab, cave (Masqat Prov.)

Mizbar, cave (Ash Sharqiyah Ash Shamal Prov.)

Mudhai, cave (Dhofar Prov.)

Mudhai, small oasis (Dhofar Prov.)

Muqal, Muqal Cave (Ash Sharqiyah Ash Shamal Prov.)

Qariah (Mansaft), cave (Masqat Prov.)

Rakhyut, wadi (Dhofar Prov.)

Raysut, Wadi Shaith, pools (Dhofar Prov.)

Sadah, cave (Dhofar Prov.)

Sal Alah, Birkat Khaldiyah, cistern (Musandam Prov.)

Samail, castle (Ad Dakhiliyah Prov.)

Sawt (Al Ghayyan), cave (Ash Sharqiyah Ash Shamal Prov.)

Shisr, Wubar, cave (Dhofar Prov.)

Taiq Cave (Dhofar Prov.)

Tanuf, Ain Ghubrat Cave (Ad Dakhiliyah Prov.)

Wadi Banah, cave (Musandam Prov.)

Wadi Hannah, pool (Dhofar Prov.)

Yanqul, Bait Al Marah Castle (Adh Dhahirah Prov.)

Romania:

Limanu, Peştera de la Limanu Cave (Constanţa County)

Russia:

Staraâ Macesta (Krasnodarskij Prov.)

Serbia:

Petnica (Kolubarski Dist.)

South Africa:

Cradock, cave (Eastern Cape Prov.)

Ka-Sunduza, house (Limpopo Prov.)

Musina, Limpopo Safaris Farm, pool (Limpopo Prov.)

Sudan:

Bayudah Desert (Wadi Barkol), 8 km W of Masoud (Nahr En Nil State)

Dungulah El Ajuz (Old Dongola), tombs (Esh Shimaliya State)

Jebel El Azraq, cave (Khartoum State)

Karima, Jebel Barkal (Esh Shimaliya State)

Kuikkah, tomb (Esh Shimaliya State)

Syria:

As Salihiyyah, Dura Europos (Dayr Az Zawr Gov.)

Bosra, citadelle (Daraa Gov.)

Halabiyyeh, ruins (Dayr Az Zawr Gov.)

Qala'at Al Hosn, 5 km west (Homs Gov.) $23^{\circ} 04^{\prime} \mathrm{N}, 57^{\circ} 36^{\prime} \mathrm{E}$

$23^{\circ} 56^{\prime} \mathrm{N}, 56^{\circ} 14^{\prime} \mathrm{E}$

$22^{\circ} 56^{\prime} \mathrm{N}, 57^{\circ} 40^{\prime} \mathrm{E}$

$16^{\circ} 42^{\prime} \mathrm{N}, 53^{\circ} 09^{\prime} \mathrm{E}$

$22^{\circ} 55^{\prime} \mathrm{N}, 57^{\circ} 15^{\prime} \mathrm{E}$

$23^{\circ} 34^{\prime} \mathrm{N}, 57^{\circ} 33^{\prime} \mathrm{E}$

$23^{\circ} 19^{\prime} \mathrm{N}, 58^{\circ} 02^{\prime} \mathrm{E}$

$16^{\circ} 59^{\prime} \mathrm{N}, 54^{\circ} 41^{\prime} \mathrm{E}$

$23^{\circ} 14^{\prime} \mathrm{N}, 57^{\circ} 08^{\prime} \mathrm{E}$

$23^{\circ} 09^{\prime} \mathrm{N}, 57^{\circ} 19^{\prime} \mathrm{E}$

$23^{\circ} 04^{\prime} \mathrm{N}, 59^{\circ} 00^{\prime} \mathrm{E}$

$23^{\circ} 08^{\prime} \mathrm{N}, 58^{\circ} 26^{\prime} \mathrm{E}$

$17^{\circ} 29^{\prime} \mathrm{N}, 53^{\circ} 21^{\prime} \mathrm{E}$

$17^{\circ} 28^{\prime} \mathrm{N}, 53^{\circ} 20^{\prime} \mathrm{E}$

$22^{\circ} 37^{\prime} \mathrm{N}, 59^{\circ} 06^{\prime} \mathrm{E}$

$23^{\circ} 04^{\prime} \mathrm{N}, 58^{\circ} 52^{\prime} \mathrm{E}$

$16^{\circ} 45^{\prime} \mathrm{N}, 53^{\circ} 24^{\prime} \mathrm{E}$

$17^{\circ} 00^{\prime} \mathrm{N}, 53^{\circ} 51^{\prime} \mathrm{E}$

$17^{\circ} 04^{\prime} \mathrm{N}, 55^{\circ} 05^{\prime} \mathrm{E}$

$26^{\circ} 02^{\prime} \mathrm{N}, 56^{\circ} 22^{\prime} \mathrm{E}$

$23^{\circ} 19^{\prime} \mathrm{N}, 58^{\circ} 00^{\prime} \mathrm{E}$

$23^{\circ} 03^{\prime} \mathrm{N}, 58^{\circ} 41^{\prime} \mathrm{E}$

$18^{\circ} 15^{\prime} \mathrm{N}, 53^{\circ} 39^{\prime} \mathrm{E}$

$17^{\circ} 09^{\prime} \mathrm{N}, 54^{\circ} 37^{\prime} \mathrm{E}$

$23^{\circ} 04^{\prime} \mathrm{N}, 57^{\circ} 22^{\prime} \mathrm{E}$

$25^{\circ} 55^{\prime} \mathrm{N}, 56^{\circ} 17^{\prime} \mathrm{E}$

$17^{\circ} 03^{\prime} \mathrm{N}, 54^{\circ} 37^{\prime} \mathrm{E}$

$23^{\circ} 35^{\prime} \mathrm{N}, 56^{\circ} 32^{\prime} \mathrm{E}$

$43^{\circ} 48^{\prime} \mathrm{N}, 28^{\circ} 31^{\prime} \mathrm{E}$

$43^{\circ} 34^{\prime} \mathrm{N}, 39^{\circ} 48^{\prime} \mathrm{E}$

$44^{\circ} 15^{\prime} \mathrm{N}, 19^{\circ} 56^{\prime} \mathrm{E}$

$32^{\circ} 10^{\prime} \mathrm{S}, 25^{\circ} 37^{\prime} \mathrm{E}$

$22^{\circ} 42^{\prime} \mathrm{S}, 31^{\circ} 01^{\prime} \mathrm{E}$

$22^{\circ} 19^{\prime} \mathrm{S}, 29^{\circ} 52^{\prime} \mathrm{E}$

$17^{\circ} 49^{\prime} \mathrm{N}, 33^{\circ} 03^{\prime} \mathrm{E}$

$18^{\circ} 13^{\prime} \mathrm{N}, 30^{\circ} 45^{\prime} \mathrm{E}$

$15^{\circ} 47^{\prime} \mathrm{N}, 32^{\circ} 28^{\prime} \mathrm{E}$

$18^{\circ} 32^{\prime} \mathrm{N}, 31^{\circ} 50^{\prime} \mathrm{E}$

$20^{\circ} 40^{\prime} \mathrm{N}, 30^{\circ} 20^{\prime} \mathrm{E}$

$34^{\circ} 45^{\prime} \mathrm{N}, 40^{\circ} 44^{\prime} \mathrm{E}$

$32^{\circ} 32^{\prime} \mathrm{N}, 36^{\circ} 29^{\prime} \mathrm{E}$

$35^{\circ} 41^{\prime} \mathrm{N}, 39^{\circ} 50^{\prime} \mathrm{E}$

$34^{\circ} 46^{\prime} \mathrm{N}, 36^{\circ} 12^{\prime} \mathrm{E}$ 
Qala'at Ar Rahba (Dayr Az Zawr Gov.)

Qala'at Najm, cellar (Halab Gov.)

Qala'at Nimrud, ruins (Al Qunaytrah Gov.)

Qala'at Salah Ad Din, ruins (Al Ladhiqiyah Gov.)

Qala'at Samaan, cellar (Halab Gov.)

Qala'at Sheisar, ruins (Hama Gov.)

Qanawat, house (As Suwayda' Gov.)

Qatura, ruins (Halab Gov.)

Tadmor, Afqa Cave (Homs Gov.)

Tadmor, desert (Homs Gov.)

Tadmor, ruins (Homs Gov.)

Zalabiyyeh, ruins (Dayr Az Zawr Gov.)

Tajikistan:

Čorku, mine (Sugid Reg.)

Hoça Šaqiqi Balhi, Danġara Tunnel (Hatlon Reg.)

Levap, old farm (Hatlon Reg.)

Magov, mine (Dušanbe Reg.)

Qaraġoč, loess cave (Hatlon Reg.)

Širg, mine (Muhtori Kūhistoni Badahšon Reg.)

Zingroğ, small cave (Muhtori Kūhistoni Badahšon Reg.)

Turkey:

Çevlik, tomb (Hatay Prov.)

Konacik (Hatay Prov.)

Muradiye (Van Prov.)

Narlıkuyu, Cehennem Cave (Mersin Prov.)

Posyagbasan (Adana Prov.)

Sergen, Safe Suyu Spring Cave (Kirklareli Prov.)

Turkmenistan:

Bäherden, Bäherden Cave (Ahal Reg.)

Uzbekistan:

Aman-Kutan, mine (Samarqand Reg.)

Samarqand, cave (Samarqand Reg.)

Toshkent, cave (Toshkent Reg.)

Yemen:

$25 \mathrm{~km}$ WSW of Sayhut, well (Al Mahra Gov.)

Al Mahabishah (Hajjah Gov.)

Al Mawqir, Wadi Zabid, stream (Al Hudaydah Prov.)

Ash Sheher, house (Hadramawt Gov.)

Damqawt, cave (Al Mahra Gov.)

Hawf, border check-point, pool (Al Mahra Gov.)

Hawf, gardens, pool (Al Mahra Gov.)

Kadamat Al 'Abdali, Wadi Tuban (Lahj Gov.)

Qaryat Al Hasib, Wadi Zabid, channel (Al Hudaydah Gov.)

Riqab, Jebel Bura Mts., pool (Al Hudaydah Gov.)

Socotra Island, Desmoiten, house (Suqutra Gov.)

Socotra Island, Diksam Plateau, Hofur Cave (Suqutra Gov.)

Socotra Island, Diksam Plateau, Marshim Cave (Suqutra Gov.)

Socotra Island, Kam (Suqutra Gov.)

Socotra Island, Keisu (Suqutra Gov.)

Socotra Island, Mazaaba, Wadi Darho (Suqutra Gov.) $35^{\circ} 00^{\prime} \mathrm{N}, 40^{\circ} 25^{\prime} \mathrm{E}$

$36^{\circ} 33^{\prime} \mathrm{N}, 38^{\circ} 16^{\prime} \mathrm{E}$

$33^{\circ} 15^{\prime} \mathrm{N}, 35^{\circ} 43^{\prime} \mathrm{E}$

$35^{\circ} 36^{\prime} \mathrm{N}, 36^{\circ} 03^{\prime} \mathrm{E}$

$36^{\circ} 20^{\prime} \mathrm{N}, 36^{\circ} 51^{\prime} \mathrm{E}$

$35^{\circ} 17^{\prime} \mathrm{N}, 36^{\circ} 34^{\prime} \mathrm{E}$

$32^{\circ} 46^{\prime} \mathrm{N}, 36^{\circ} 37^{\prime} \mathrm{E}$

$36^{\circ} 19^{\prime} \mathrm{N}, 36^{\circ} 50^{\prime} \mathrm{E}$

$34^{\circ} 33^{\prime} \mathrm{N}, 38^{\circ} 16^{\prime} \mathrm{E}$

$34^{\circ} 34^{\prime} \mathrm{N}, 38^{\circ} 13^{\prime}$ E

$34^{\circ} 33^{\prime} \mathrm{N}, 38^{\circ} 17^{\prime} \mathrm{E}$

$35^{\circ} 40^{\prime} \mathrm{N}, 39^{\circ} 51^{\prime} \mathrm{E}$

$39^{\circ} 58^{\prime} \mathrm{N}, 70^{\circ} 34^{\prime} \mathrm{E}$

$38^{\circ} 17^{\prime} \mathrm{N}, 69^{\circ} 18^{\prime} \mathrm{E}$

$37^{\circ} 26^{\prime} \mathrm{N}, 68^{\circ} 30^{\prime} \mathrm{E}$

$38^{\circ} 41^{\prime} \mathrm{N}, 69^{\circ} 06^{\prime} \mathrm{E}$

$37^{\circ} 44^{\prime} \mathrm{N}, 69^{\circ} 40^{\prime} \mathrm{E}$

$38^{\circ} 29^{\prime} \mathrm{N}, 70^{\circ} 48^{\prime} \mathrm{E}$

$38^{\circ} 27^{\prime} \mathrm{N}, 70^{\circ} 49^{\prime} \mathrm{E}$

$36^{\circ} 07^{\prime} \mathrm{N}, 35^{\circ} 56^{\prime} \mathrm{E}$

$36^{\circ} 21^{\prime} \mathrm{N}, 35^{\circ} 50^{\prime} \mathrm{E}$

$39^{\circ} 03^{\prime} \mathrm{N}, 43^{\circ} 45^{\prime} \mathrm{E}$

$36^{\circ} 27^{\prime} \mathrm{N}, 34^{\circ} 06^{\prime} \mathrm{E}$

$37^{\circ} 30^{\prime} \mathrm{N}, 35^{\circ} 15^{\prime} \mathrm{E}$

$41^{\circ} 45^{\prime} \mathrm{N}, 27^{\circ} 40^{\prime} \mathrm{E}$

$38^{\circ} 21^{\prime} \mathrm{N}, 57^{\circ} 23^{\prime} \mathrm{E}$

$39^{\circ} 19^{\prime} \mathrm{N}, 66^{\circ} 56^{\prime} \mathrm{E}$

$39^{\circ} 39^{\prime} \mathrm{N}, 66^{\circ} 58^{\prime} \mathrm{E}$

$41^{\circ} 19^{\prime} \mathrm{N}, 69^{\circ} 15^{\prime} \mathrm{E}$

$15^{\circ} 10^{\prime} \mathrm{N}, 51^{\circ} 02^{\prime} \mathrm{E}$

$15^{\circ} 57^{\prime} \mathrm{N}, 43^{\circ} 26^{\prime} \mathrm{E}$

$14^{\circ} 10^{\prime} \mathrm{N}, 43^{\circ} 30^{\prime} \mathrm{E}$

$14^{\circ} 46^{\prime} \mathrm{N}, 49^{\circ} 36^{\prime} \mathrm{E}$

$16^{\circ} 35^{\prime} \mathrm{N}, 52^{\circ} 50^{\prime} \mathrm{E}$

$16^{\circ} 40^{\prime} \mathrm{N}, 53^{\circ} 05^{\prime} \mathrm{E}$

$16^{\circ} 39^{\prime} \mathrm{N}, 53^{\circ} 03^{\prime} \mathrm{E}$

$13^{\circ} 08^{\prime} \mathrm{N}, 44^{\circ} 51^{\prime} \mathrm{E}$

$14^{\circ} 09^{\prime} \mathrm{N}, 43^{\circ} 31^{\prime} \mathrm{E}$

$14^{\circ} 52^{\prime} \mathrm{N}, 43^{\circ} 25^{\prime} \mathrm{E}$

$12^{\circ} 30^{\prime} \mathrm{N}, 54^{\circ} 02^{\prime} \mathrm{E}$

$12^{\circ} 30^{\prime} \mathrm{N}, 53^{\circ} 57^{\prime} \mathrm{E}$

$12^{\circ} 31^{\prime} \mathrm{N}, 53^{\circ} 56^{\prime} \mathrm{E}$

$12^{\circ} 40^{\prime} \mathrm{N}, 54^{\circ} 07^{\prime} \mathrm{E}$

$12^{\circ} 40^{\prime} \mathrm{N}, 53^{\circ} 28^{\prime} \mathrm{E}$

$12^{\circ} 29^{\prime} \mathrm{N}, 54^{\circ} 02^{\prime} \mathrm{E}$ 
Socotra Island, Suq (Suqutra Gov.)

Socotra Island, Timre (Suqutra Gov.)

Socotra Island, Wadi Zerig (Suqutra Gov.)

Sayhut, well 25 km WSW (Al Mahra Gov.) $12^{\circ} 40^{\prime} \mathrm{N}, 54^{\circ} 04^{\prime} \mathrm{E}$

$12^{\circ} 37^{\prime} \mathrm{N}, 54^{\circ} 18^{\prime} \mathrm{E}$

$12^{\circ} 29^{\prime} \mathrm{N}, 53^{\circ} 59^{\prime} \mathrm{E}$

$15^{\circ} 10^{\prime} \mathrm{N}, 51^{\circ} 02^{\prime} \mathrm{E}$ 